\title{
Chapter 5 \\ Response to Tides, Barometric Pressure and Seismic Waves
}

\author{
On the shores of the Bætis (now the Guadalquivir River, Spain), \\ there is a town where the wells become lower when the tide \\ rises, and fill again when it ebbs; while at other times they \\ remain stationary. The same thing occurs in one well in the town \\ of Hispalis (now Seville, Spain), while there is nothing peculiar \\ in the other wells. \\ Pliny the Elder, Natural History, Chapter 100, translation of \\ Bostock 1855).
}

\begin{abstract}
Groundwater responses to Earth tides and barometric pressure have long been reported and increasingly used in hydrogeology to advance our understanding of groundwater systems. The response of groundwater to seismic waves has also been used in recent years to study the interaction between earthquakes and fluids in the crust. These methods have gained popularity for monitoring groundwater systems because they are both effective and economical. This chapter reviews the response of groundwater system to Earth tides, barometric pressure, and seismic waves as a continuum of poroelastic responses to oscillatory forcing across a broad range of frequency.
\end{abstract}

\subsection{Introduction}

Pliny the Elder (AD 23-79) may be the first to report that the water level in a coastal well responds to the rise and fall of ocean tides. The basic principle of tidal and barometric effects on groundwater may be illustrated by using Fig. 5.1. Barometric pressure, ocean tides and the Earth's solid tides cause poroelastic deformation of the aquifer, inducing changes of pore pressure and groundwater flow between aquifers and wells. Such changes of water level in wells may be measured, analyzed and interpreted to reveal the hidden information on the hydraulic properties of the aquifer and their changes.

In the past few decades a great amount of work has been done to use the tidal response of aquifers to estimate the hydraulic properties of groundwater systems 


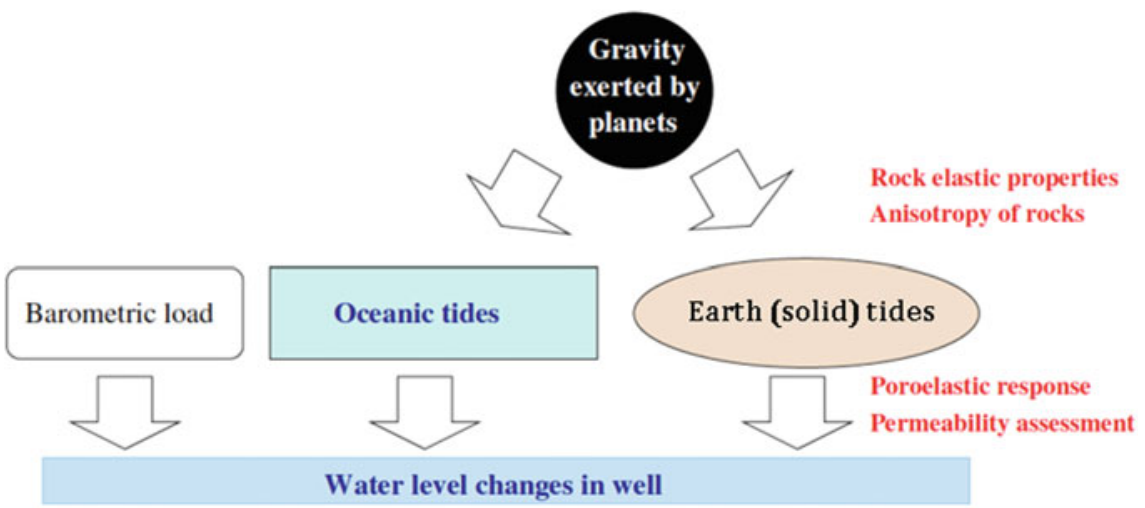

Fig. 5.1 Poroelastic response of solid Earth to tidal, barometric and other types of disturbances and water level changes in wells (modified from Doan et al. 2006)

(e.g., Hsieh et al., 1987; Roeloffs, 1996) and to compare these properties before and after earthquakes in order to quantify earthquake effects (e.g., Elkhoury et al. 2006; Xue et al. 2013; Yan et al. 2014). In addition, the tidal response of aquifers was also found to be particularly sensitive to subsurface disturbances such as mining (Shi et al. 2020). The ocean tides, though much bigger in amplitude than the solid tides (Earth tides) along the coast, are complicated because they depend sensitvely on the local bathymetry and the configuration of the coast. The Earth tides, on the other hand, are much better characterized and are therefore more useful in the study of the groundwater system. In the following three sections we introduce the principles of tides, the tide-induced deformation of the solid Earth, i.e., the Earth tides, the response of groundwater to the Earth tides, and the models that are used to interpret the tidal responses of water level.

Groundwater level also responds to changes of the barometric pressure, and the study of this response can provide important insight to the hydraulic properties of both the aquifer and the aquitard (e.g., Jacob 1940; Rojstaczer 1988; Olding et al. 2015). A welcoming development is a joint analysis of the tidal and the barometric responses in some recent studies to evaluate earthquake effects on groundwater systems (Barbour et al. 2019; Zhang-Shi et al. 2019; Zhang-Wang et al. 2019). We review in a separate section the principles of the barometric response of the water level in wells and the existing applications to earthquake hydrology.

At the high-frequency end of the continuum is the response of groundwater to seismic waves. It has been known for a long time that groundwater responds to seismic waves (e.g., Byerly and Blanchard 1935). Some recent efforts have made use of this response to estimate aquifer properties (Barbour et al. 2019; Shih 2009; Sun et al. 2019, 2020), based on a model developed by Cooper et al. (1965). Such efforts may provide useful understanding on the dependence of aquifer properties on the frequency of the forcing mechanisms. We review in another separate section 
the principles of water-level response to seismic waves and the model used in its interpretation and application to earthquake hydrology.

Finally, fractures in the shallow crust may significantly affect the response of water level to tides, barometric pressure, and seismic waves. This aspect has not received adequate attention.

\subsection{Tidal Potential}

The tidal acceleration due to the gravitational attraction of a planet with center $P$ and mass $M$, at a point $N$ on the surface of the Earth with center at $O$, is

$$
g=G M\left(\frac{\overrightarrow{P N}}{P N^{3}}-\frac{\overrightarrow{P N}}{P O^{3}}\right) .
$$

Given the notations in Fig. 5.2, we may express the tidal potential $W$ at a point $N$ on Earth's surface due to the planet $P$ with mass $M$ as

$$
W=\frac{G M}{s},
$$

where $M$ is the mass of the planet. Expressing $1 / s$ in terms of $a, R$ and $\alpha$, we have

$$
\begin{aligned}
\frac{1}{s} & =\frac{1}{\left(a^{2}+R^{2}-2 a R \cos \alpha\right)^{1 / 2}}=\frac{1}{R}\left[1-2 \frac{a}{R} \cos \alpha+\left(\frac{a}{R}\right)^{2}\right]^{-1 / 2} \\
& =\frac{1}{R}\left[1+\left(\frac{a}{R}\right) \cos \alpha+\left(\frac{a}{R}\right)^{2} \frac{3 \cos ^{2} \alpha-1}{2}+\left(\frac{a}{R}\right)^{3} \frac{5 \cos ^{3} \alpha-3 \cos \alpha}{2}+\ldots\right]
\end{aligned}
$$

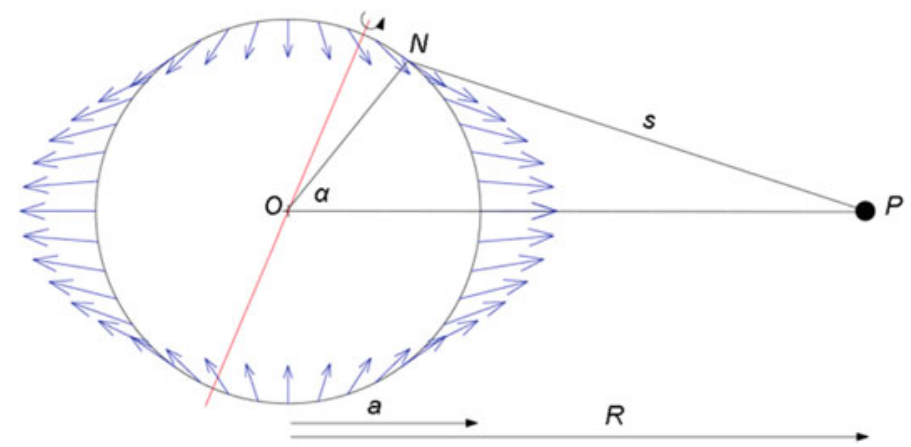

Fig. 5.2 Tidal displacement (exaggerated) of the equipotential surface on Earth's surface due to planet $\mathrm{P}$ 


$$
=\frac{1}{R}\left[1+\sum_{1}^{\infty}\left(\frac{a}{R}\right)^{n} P_{n}(\cos \alpha)\right],
$$

where $P_{n}(\cos \alpha)$ are the Legendre polynomials of order $n$.

Hence the gravitational potential $W$ may be expressed as

$$
W=\frac{G M}{R}\left[1+\sum_{1}^{\infty}\left(\frac{a}{R}\right)^{n} P_{n}(\cos \alpha)\right] .
$$

The first term is a constant and does not give rise to a force. The second term gives rise to the attraction at the centers, i.e., $G M\left(\frac{\overrightarrow{P O}}{P O^{3}}\right)$. Thus, the tidal potential consists of the remaining terms. Furthermore, since the ratio $a / R$ is small, $(a / R)^{n}$ decreases rapidly with $n$, only the term with $n=2$ is usually considered in the studies of Earth tides, and we may express the tidal potential approximately as

$$
W_{2}=\frac{G M}{R}\left(\frac{a}{R}\right)^{2} \frac{3 \cos ^{2} \alpha-1}{2} \text {. }
$$

Finally, expressing $\cos \alpha$ in terms of the latitudes and longitudes of the observation point $\left(\lambda_{N}, \phi_{N}\right)$ and of the planet $\left(\lambda_{P}, \phi_{P}\right)$ and $\omega t$, where $\omega$ is the angular frequency of Earth's rotation, we have (e.g., Doan et al. 2006)

$$
W_{2}=\frac{G M a^{2}}{R^{3}}\left\{\begin{array}{c}
\frac{1}{32}\left[\cos ^{2} \lambda_{N} \cos ^{2} \lambda_{P} \cos \left(2 \omega t-2 \phi_{P}\right)\right] \\
+\frac{3}{8}\left[\sin \left(2 \lambda_{N}\right) \sin \left(2 \lambda_{P}\right) \cos \left(\omega t-\phi_{P}\right)\right] \\
+\frac{1}{32}\left[3 \cos \left(2 \lambda_{N}-1\right)\right]\left[3 \cos \left(2 \lambda_{P}-1\right)\right]
\end{array}\right\} .
$$

The first term inside the parenthesis is the semi-diurnal tide that produces the two symmetrical bulges in Fig. 5.2; the second term is the diurnal tide due to the inclination of the orbit of the planet (Moon) to the equator; the third term is independent of the rotation of the Earth and is thus a constant.

In reality, the potential is more complicated due to the facts that the Earth's orbit about the Sun and the Moon's orbit about the Earth are both elliptical rather than circular, the Moon's orbital plane does not align with Earth's equator and the Earth's rotation is not aligned with the ecliptic. There are thus numerous tides (see Fig. 5.3), but most of these tides are too small to be clearly recorded in water level data and thus are not used in groundwater studies. The solar tides are affected by thermally induced changes in the atmospheric pressure, which are difficult to correct. As a consequence, the most often used tides for hydrological studies are the semi-diurnal lunar tide $\mathrm{M}_{2}$ and the diurnal lunar tide $\mathrm{O}_{1}$. 
Tidal potential: amplitude spectra
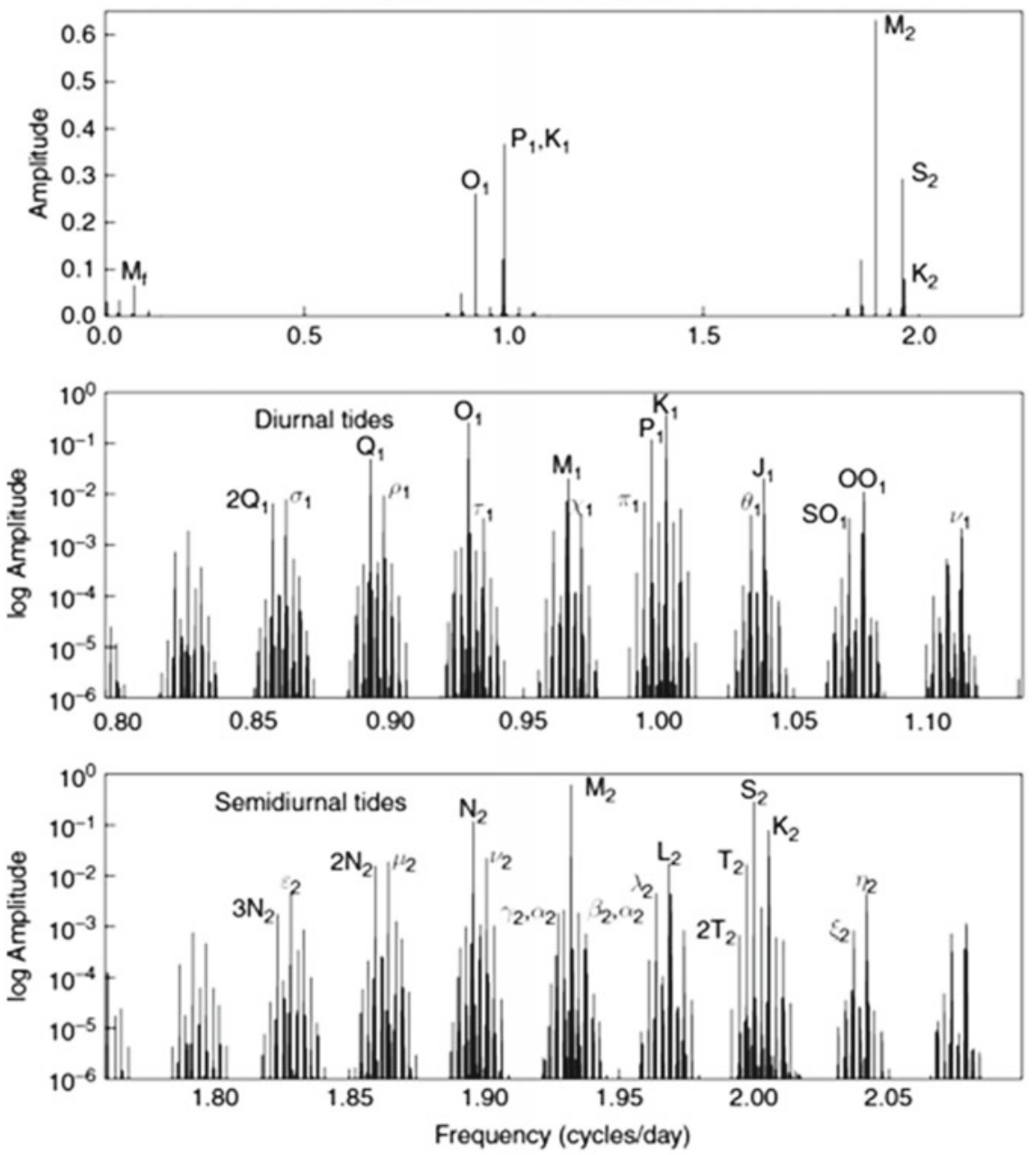

Fig. 5.3 Spectrum of the tidal potential on Earth's surface shown as the amplitudes of the tidal harmonics (from Agnew 2007). The larger harmonics are shown in the top diagram and the diurnal and the semi-diurnal harmonics in the lower two diagrams

\subsection{Earth Tides}

Figure 5.4 shows an example of the Earth tides in Oklahoma recorded by a threecomponent, broadband seismometer. Because of the long periods of the Earth tides, the tidal deformations occur at mechanical equilibrium, i.e., there is no acceleration. The ground velocity in the records (Fig. 5.4) may be integrated with time to yield the surface displacements that, in turn, may be used to calculate the tidal strain at 

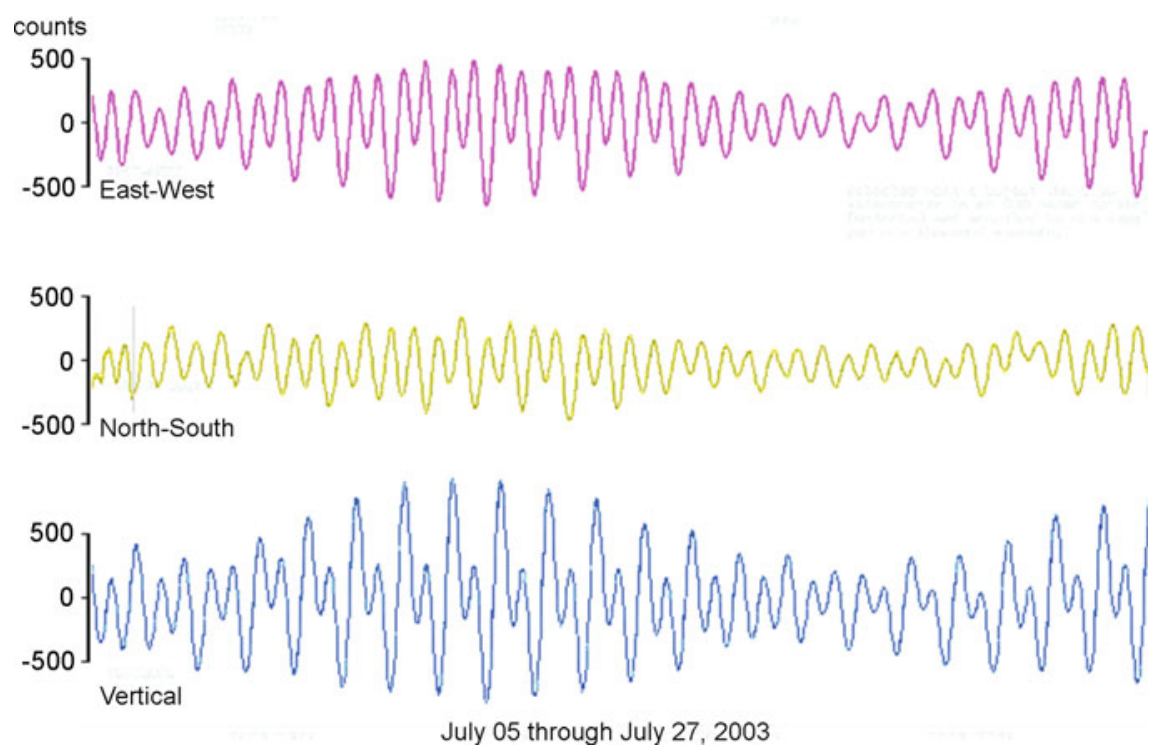

Fig. 5.4 Earth tides recorded by a three-component, broadband seismometer in a $840 \mathrm{~m}$ deep well in Leonard, Oklahoma (Oklahoma Geological Survey Observatory)

this location (Eqs. 5.8 and 5.9). GPS measurements have also been used to measure tidal displacements at many stations.

Love (1911) associated the tidal displacement to the tidal potential by the following relations:

$$
\begin{gathered}
u_{r}=\sum_{n} \frac{h_{n}}{g} W_{n} \\
u_{\theta}=\sum_{n} \frac{l_{n}}{g} \frac{\partial W_{n}}{\partial \theta} \\
u_{\phi}=\sum_{n} \frac{l_{n}}{g} \frac{1}{\sin \theta} \frac{\partial W_{n}}{\partial \phi}
\end{gathered}
$$

where $h_{n}$ is the Love number, $l_{n}$ is the Shida number, and $(r, \theta, \phi)$ are the spherical coordinates of the point of interest.

From the tidal displacements, the tidal strains may be evaluated from the tidal potential:

$$
\epsilon_{r r}=\frac{\partial u_{r}}{\partial r}=\sum_{n} \frac{h_{n}}{g a} \frac{\partial W_{n}}{\partial r}
$$


Table 5.1 Love numbers calculated from several Earth models (from Doan et al. 2006)

\begin{tabular}{l|l|l|l}
\hline Software & $h_{2}$ & $l_{2}$ & $k_{2}$ \\
\hline Wilhelm et al. (1997, p. 46) & 0.6033 & 0.0838 & 0.2980 \\
\hline PREM & 0.6032 & 0.0839 & 0.2990 \\
\hline Gutenberg-Bullen & 0.6114 & 0.0832 & 0.3040 \\
\hline MT80W (MOLODENSKY model) & 0.6206 & 0.0904 & \\
\hline ETGTAB/ETERNA & 0.6165 & 0.0840 & 0.3068 \\
\hline PIASD & 0.6114 & 0.0832 & 0.304 \\
\hline BAYTAP & 0.606 & 0.0840 & 0.299 \\
\hline
\end{tabular}

$$
\begin{aligned}
\epsilon_{\theta \theta} & =\frac{u_{r}}{r}+\frac{1}{r} \frac{\partial u_{\theta}}{\partial \theta}=\sum_{n} \frac{1}{g a}\left(h_{n} W_{n}+l_{n} \frac{\partial^{2} W_{n}}{\partial \theta^{2}}\right) \\
\epsilon_{\phi \phi} & =\frac{u_{r}}{r}+\frac{u_{\theta} \cot \theta}{r}+\frac{1}{r} \frac{\partial u_{\phi}}{\partial \phi} \\
& =\sum_{n} \frac{1}{g a}\left(h_{n} W_{n}+l_{n} \cot \theta \frac{\partial W_{n}}{\partial \theta}+\frac{l_{n}}{\sin \theta} \frac{\partial^{2} W_{n}}{\partial \phi^{2}}\right)
\end{aligned}
$$

The areal tidal strain $\left(\epsilon_{a}\right)$ and the volumetric tidal strain $\left(\epsilon_{v}\right)$ may then be calculated

$$
\begin{gathered}
\epsilon_{a}=\epsilon_{\theta \theta}+\epsilon_{\phi \phi}=\sum_{n} \frac{2 h_{n}-n(n+1) l_{n}}{g} \frac{W_{n}}{a} \\
\epsilon_{v} \cong \frac{1-2 v}{1-v} \epsilon_{a}=\frac{1-2 v}{1-v} \sum_{n} \frac{2 h_{n}-n(n+1) l_{n}}{g} \frac{W_{n}}{a} .
\end{gathered}
$$

The approximation in Eq. (5.9b) is valid near the Earth's surface. The Love numbers may be calculated from Earth models. Table 5.1 shows the Love numbers $(n=2)$ calculated from different Earth models.

The tidal strains may be measured with strain gauges. They may also be calculated theoretically from Earth models, as shown in Fig. 5.5. In practice, strain measurements are often unavailable near the well site and theoretical tides are calculated and used as the reference for the tidal response.

\subsection{Groundwater Response to Earth Tides}

Wells (or boreholes) are hydrogeologists' 'telescopes' to study the properties of groundwater systems. Thus the analysis of the response of groundwater level in wells to various kinds of forcing has been a time-honored topic of groundwater research and is an important and effective tool for the study of the hydraulic properties of aquifers. 


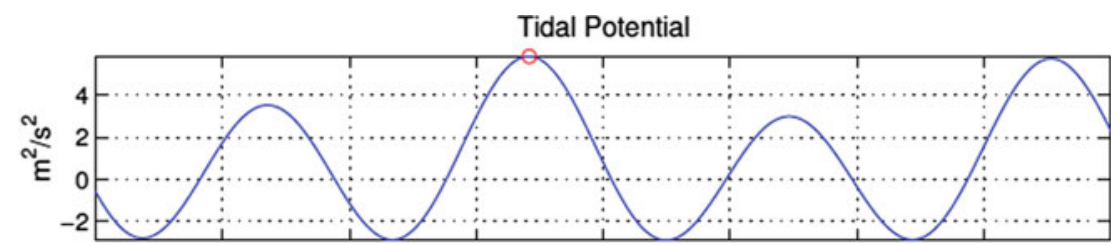

Vertical Tidal Gravity (Positive down)
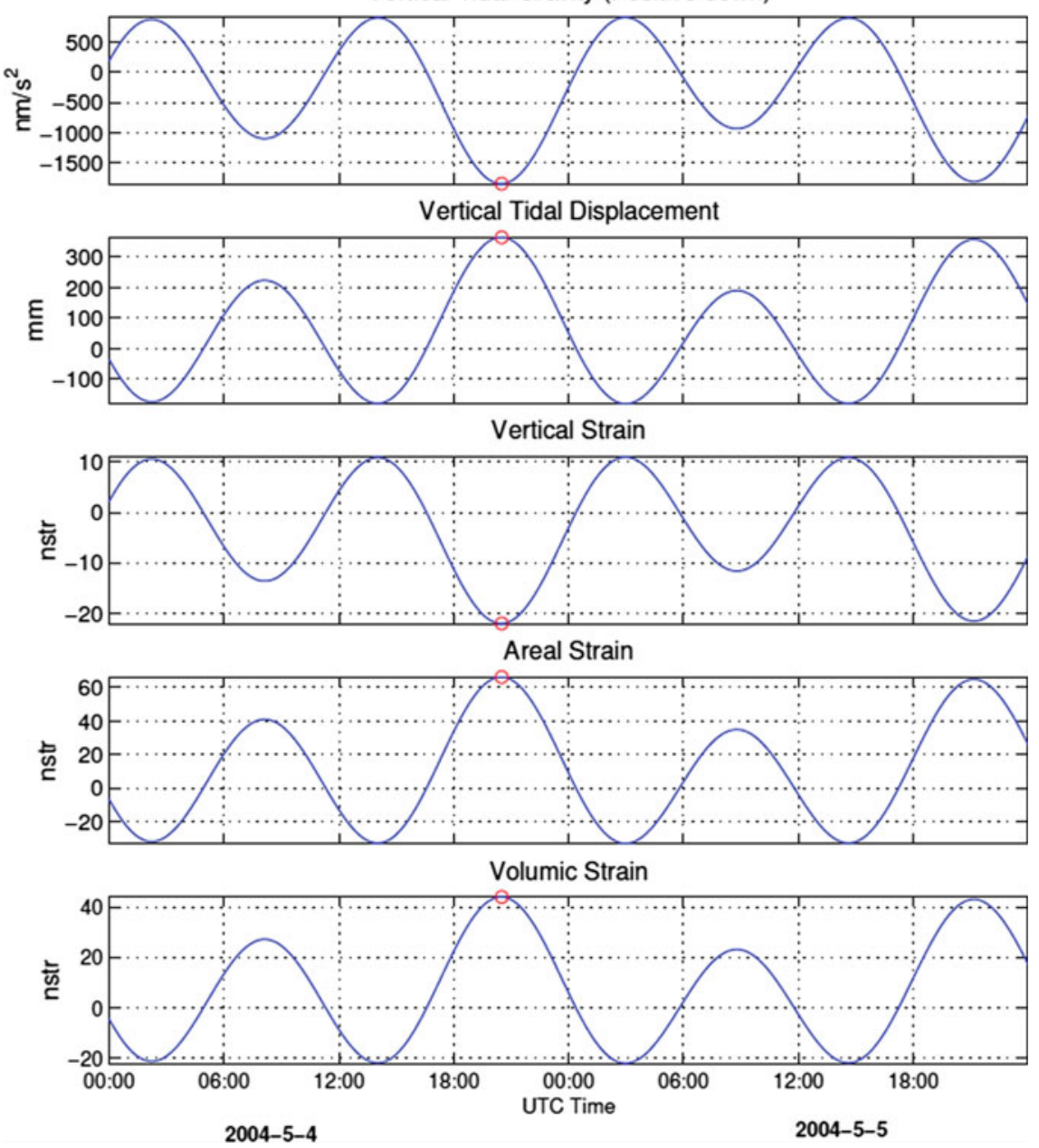

Fig. 5.5 Theoretical Earth tides predicted by ETGTAB software for the lunar eclipse of May 4, 2004, 20:30 UT, northeast of Madagascar (from Doan et al. 2006) 
The most often used technique is the so-called 'well test' where the water level in a well is artificially changed and the subsequent time-dependent recovery of water level measured in the well or in nearby wells is interpreted to estimate the hydraulic properties of the affeted aquifer. For the study of the interactions between earthquakes and groundwater, however, one often needs to compare the responses before and after the earthquake, and well tests become impractical because continuous well tests are too laborious and expensive. In comparison, the analyses of the response of groundwater level to natural forcing, such as tides and barometric pressure, are much more economical for continuously monitoring the hydraulic properties of aquifers and have gained increasing attention in hydrogeologic studies, particularly in the study of groundwater response to large earthquakes (e.g., Ingebritsen and Manga 2019).

The volumetric tidal strain causes oscillations of pore pressure in aquifers and water level in wells (e.g., Fig. 5.6). The tidal signals are often small in comparison with water-level changes due to seasonal recharge, ocean tides and groundwater extraction and need to be isolated from the water level time series by applying some standard technique such as Fourier analysis. The flow of groundwater between the aquifer and a well or a boundary causes a difference between the phase of the water level and that of the tidal strain, referred to as the phase shift and in the amplitude of the water level compared to that of the equivalent pore pressure produced by the Earth tide; the ratio between the two amplitudes is referred to as the amplitude ratio. Since direct measurement of the tidal strains near the studied well is often not available, the theoretical tidal strain at the well location is often used as the reference in calculating the phase shift and amplitude ratio of the tidal response. However, tidal strains are known to be significantly affected by local geologic hetrrogeneity, topographic irregularity and underground cavities (Beaumont and Berger, 1975; Harrison, 1974); hence this assumption constitutes an uncertainty in most studies, especially when some small differences in phase shift are of concern, as discussed later in this chapter.

Interpretation of the tidal oscillations in water levels requires an understanding of the flow of groundwater from aquifers to wells. Traditional interpretations treated aquifers either as perfectly confined (Hsieh et al., 1987) or perfectly unconfined (Roeloffs 1996; Wang 2000; Doan et al. 2006). Most aquifers, however, are neither perfectly confined nor perfectly unconfined,but are between these two end members. A leaky aquifer model (Wang et al. 2018; Zhu and Wang 2020) is therfore more appropriate for such interpretation. In addition, the water table of an unconfined aquifer is usually overlain by an unsaturated zone. The interfacial tension between air, water and solid grains in the unsaturated zone may cause groundwater to rise and form a layer of negative pore pressure, i.e., a capillary zone, above the water table, which may significantly affect the tidal response of some unconfined aquifers (Wang et al. 2019). These different models are discussed in the following sub-sections in the sequence of their historical development. 
(a) है

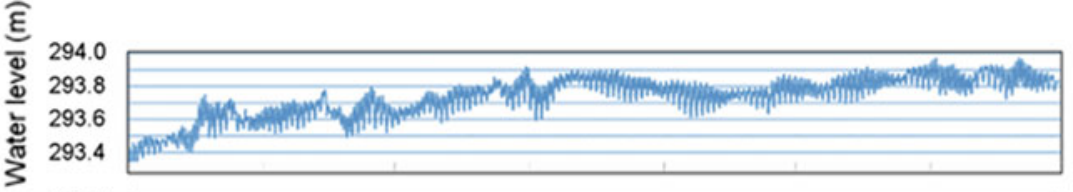

(b)

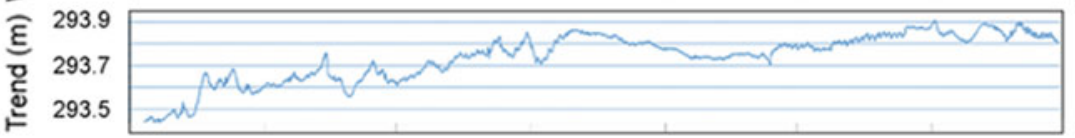

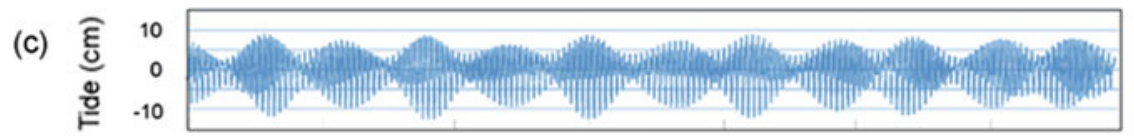

(d)

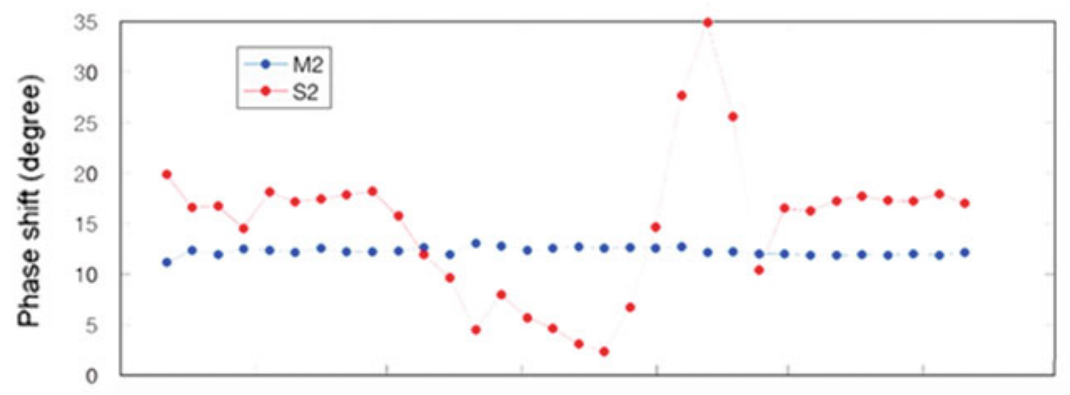

(e)

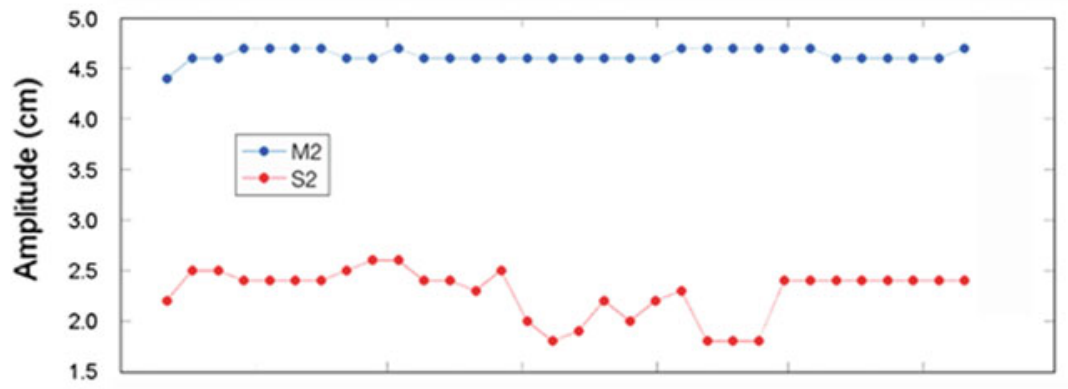

(f)

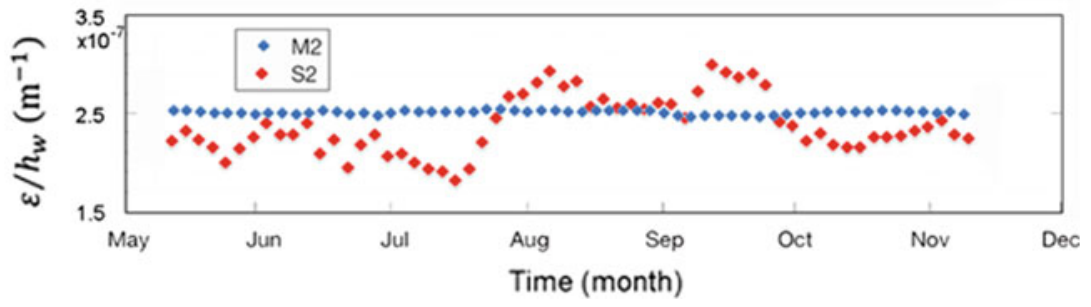

Fig. 5.6 Time series of a raw data for water level above the mean sea level in the USGS Oklahoma deep monitoring well, $\mathbf{b}$ drift that was removed, $\mathbf{c}$ remaining tides in water level used in the analysis, d phase shift of water level response to the $\mathrm{M}_{2}$ and $\mathrm{S}_{2}$ tides referenced to the local tidal volumetric strain, e amplitude of water level response to the $\mathrm{M}_{2}$ and $\mathrm{S}_{2}$ tides, and $\mathbf{f}$ response of $\varepsilon_{o} / h_{w, o}$ to the $\mathrm{M}_{2}$ and $\mathrm{S}_{2}$ tides, where $\varepsilon_{o}$ is the amplitude of the volumetric strain converted from surface strain computed in Baytap08, and $h_{w, o}$ is the amplitude of water level changes (modified from Wang et al. 2018) 


\subsubsection{Tidal Response of a Confined Aquifer}

The following discussion parallels that in Hsieh et al. (1987) but with fewer special functions to simplify the expressions. Consider a horizontal, laterally extensive aquifer of thickness $b$, confined at its top and base, and open to a vertical well. The differential equation of groundwater flow in the aquifer may be expressed in cylindrical coordinates

$$
T\left[\frac{\partial^{2} h}{\partial r^{2}}+\frac{1}{r} \frac{\partial h}{\partial r}\right]=S \frac{\partial h}{\partial t}+Q b,
$$

where $h$ is the hydraulic head in the aquifer above a common reference (Fig. 5.7), $r$ is the radial distance from the axis of the well, $T=K b$ and $S=S_{S} b$ are the transmissivity and storativity of the aquifer, respectively, and $Q$ is the source of groundwater per unit volume (Eq. 2.12c). The aquitard is assumed to be perfectly impervious, i.e., $K^{\prime}$ $=0$.

Roeloffs (1996) pointed out that differential Eq. (5.10) does not consider aquifer deformation, even though deformation may occur in response to pore pressure changes. The equation, however, is valid under conditions of constant vertical stress and zero strain in the two orthogonal directions (Sect. 3.2.6), which are approximately met for areally extensive aquifers near the Earth's surface under tidal loading.

The solid tides cause volumetric strains in the aquifer, which change the hydraulic head and induce cyclic flows of groundwater between the aquifer and well. Representing the tidal-induced head as a source term and taking compression to be positive,

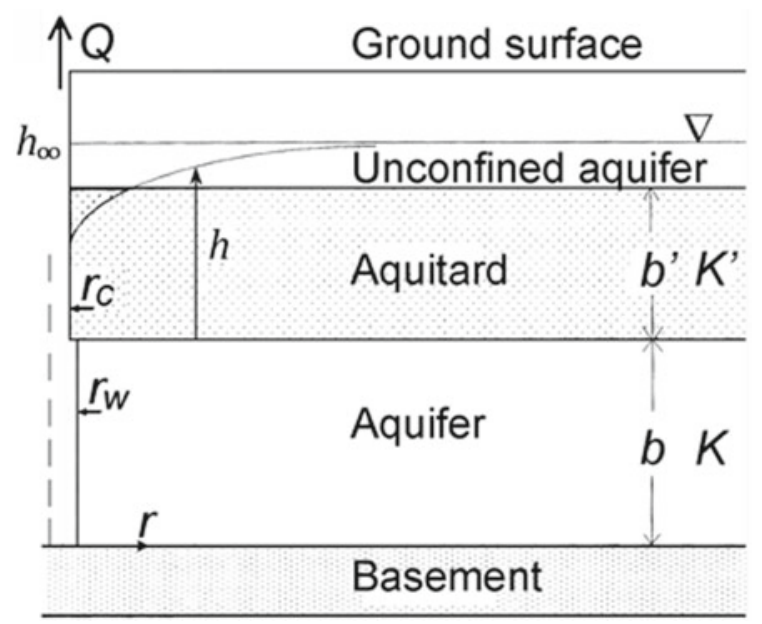

Fig. 5.7 Idealized open well drilled into a confined aquifer. If $K^{\prime}=0$, the aquifer is perfectly confined, as assumed in Hsieh et al. (1989). If $K^{\prime}>0$, groundwater may leak in and out of the aquifer through the aquitard, as assumed in Wang et al. (2018) 
i.e., $Q=-S_{s} \frac{B K_{u}}{\rho g} \frac{\partial \epsilon}{\partial t}$, the flow equation becomes

$$
T\left[\frac{\partial^{2} h}{\partial r^{2}}+\frac{1}{r} \frac{\partial h}{\partial r}\right]=S\left(\frac{\partial h}{\partial t}-\frac{B K_{u}}{\rho g} \frac{\partial \epsilon}{\partial t}\right) .
$$

The symbol $\epsilon$ in the last term of Eq. (5.11) is the tidal volumetric strain of the aquifer, $B$ is the Skempton's coefficient, $B=(\partial P / \partial \sigma)_{f}$, and $K_{u}$ is the undrained bulk modulus of the aquifer, defined as

$$
K_{u}=(\partial \sigma / \partial \epsilon)_{f}
$$

where $P$ is pore pressure, $\sigma$ the mean stress, and the subscript $f$ denotes constant fluid content, i.e., an undrained condition. Considering only the tidal driven water-level oscillations, $h$ in Eq. (5.11) represents the change of hydraulic head due to the tidal strain.

The boundary conditions for the problem are

$$
\begin{gathered}
h(r, t)=h_{\infty}(t) \text { at } r=\infty, \\
h(r, t)=h_{w}(t)=r_{w} \text { and }, \\
2 \pi r_{w} T(\partial h / \partial r)_{r=r_{w}}=\pi r_{c}^{2}\left(\partial h_{w} / \partial t\right),
\end{gathered}
$$

where $h_{w}=h_{w, o} e^{i \omega t}$ is the periodically changing water level in the well, with complex amplitude $h_{w, o}, h_{\infty}(t)$ is the pressure-equivalent water level in the aquifer at $r=\infty$, $\omega\left[\mathrm{s}^{-1}\right]=2 \pi / \tau$ is the angular frequency, $\tau$ is the period of the tidal oscillation, $r_{w}$ is the radius of the screened portion of the well, and $r_{c}[\mathrm{~m}]$ is the inner radius of well casing in which water level fluctuates with tides.

The solution to the boundary value problem is derived in Appendix 5.1 (see also Hsieh et al. 1987) and may be expressed in terms of a well factor $\xi$, i.e.,

$$
h_{w, o}=\frac{1}{\xi}\left(\frac{B K_{u} \epsilon_{o}}{\rho g}\right)=\frac{1}{\xi} h_{\infty, o}
$$

where

$$
\xi=1+\left(\frac{r_{c}}{r_{w}}\right)^{2} \frac{i \omega r_{w}}{2 T \beta} \frac{K_{o}\left(\beta r_{w}\right)}{K_{1}\left(\beta r_{w}\right)}
$$

$h_{\infty, o}$ is the amplitude of $h_{\infty}, K_{0}$ and $K_{1}$ are modified Bessel functions of the second kind of zeroth and first order, respectively, and 


$$
\beta=\left(\frac{i \omega S}{T}\right)^{1 / 2}
$$

The tidal response of a confined aquifer thus depends on the aquifer's poroelastic properties, $B$ and $K_{u}$, its hydraulic properties, $T$ and $S$, the tidal frequency $\omega$, and the well geometry, $r_{w}$ and $r_{c}$. From (5.16) we may calculate the amplitude ratio $A$ and the phase shift $\eta$ of the tidal response as

$$
A=\left|h_{w, o} / h_{\infty, o}\right|=\left|\frac{1}{\xi}\right|,
$$

and

$$
\eta=\arg \left[h_{w, o} / h_{\infty, o}\right]=\arg \left[\frac{1}{\xi}\right]
$$

where $\arg (z)$ is the argument of the complex number $z$.

The well-bore storage produces a slight delay in the water-level response, thus a negative phase shift, as shown in Fig. 5.8. Given the measured phase shift and amplitude ratio of the tidal response of the water level, we may estimate $T$ and $S$ of the aquifer.

Figure 5.8a shows that the phase shift of a confined aquifer is largely negative due to the finite well bore storage. At large transmissivity, however, the phase shift approaches zero and the amplitude ratio approaches one. Thus, at sufficiently large transmissivity, the tidal response in the well perfectly matches that in the aquifer and is no longer sensitive to transmissivity. Given a typical well radius of a few $\mathrm{cm}$ and the period of the $\mathrm{M}_{2}$ tide, this occurs at $T \geq 10^{-4} \mathrm{~m}^{2} / \mathrm{s}$.

\subsubsection{Tidal Response of an Unconfined Aquifer with Flow to the Water Table}

The tidal response of unconfined aquifers is traditionally treated with the boundary condition of free flow to the water table (Fig. 5.9). In Sect. 5.4.4 we will discuss the effect of capillary tension above the water table on the tidal response of unconfined aquifers.

The traditional governing differential equation for groundwater flow in an unconfined aquifer is

$$
K \frac{\partial^{2} h}{\partial z^{2}}=S_{s}\left(\frac{\partial h}{\partial t}-\frac{B K_{u}}{\rho g} \frac{\partial \epsilon}{\partial t}\right)
$$

where the parameters are the same as defined in the last section. Introducing the hydraulic diffusivity $D=K / S_{s}$, Eq. (5.20a) is simplified as 

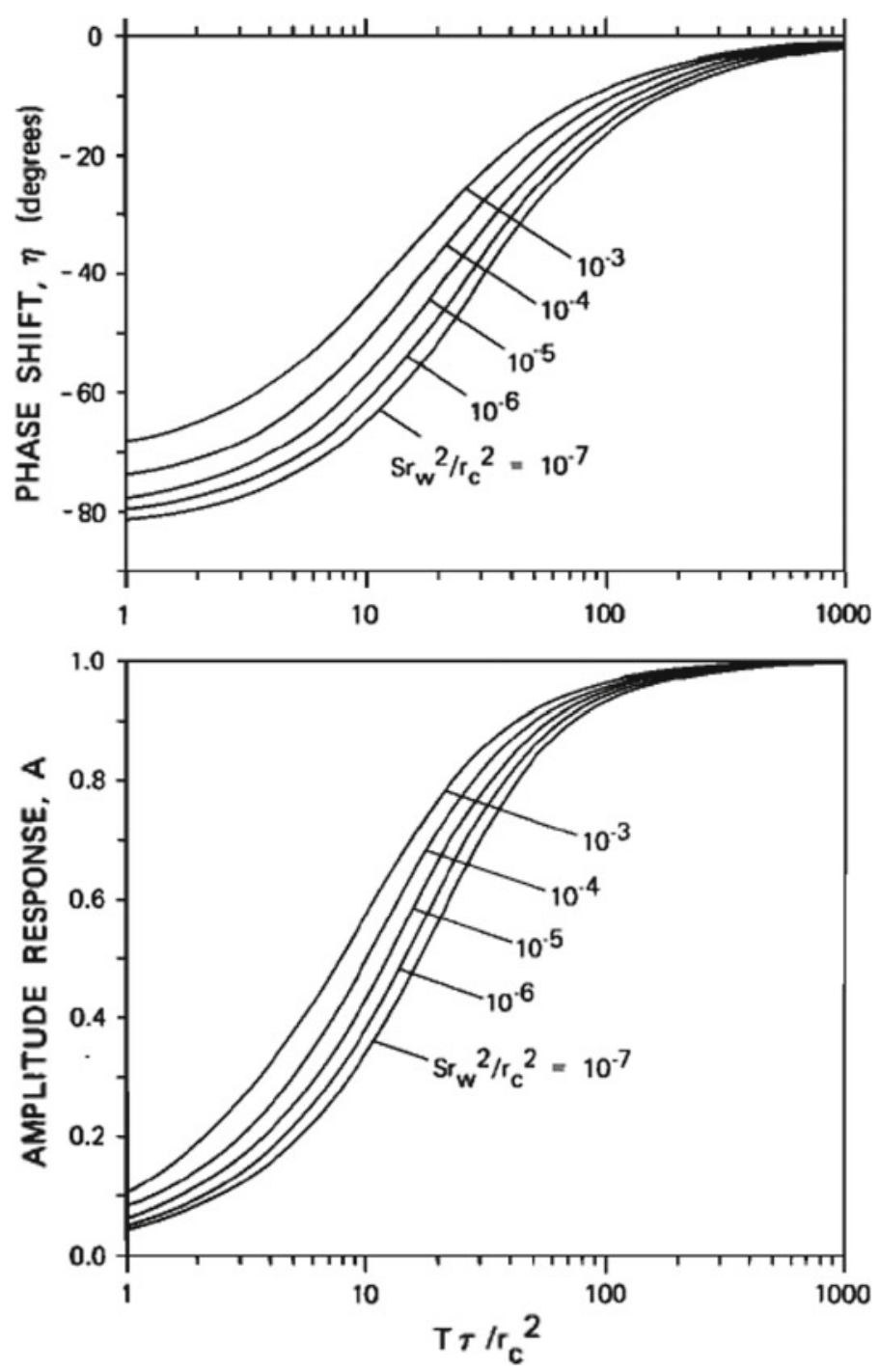

Fig. 5.8 Predicted phase shift and amplitude ratio of the tidal response of a confined aquifer (from Hsieh et al. 1987)

$$
D \frac{\partial^{2} h}{\partial z^{2}}=\frac{\partial h}{\partial t}-\frac{B K_{u}}{\rho g} \frac{\partial \epsilon}{\partial t} .
$$

If the water table is at the surface, the boundary condition at the surface is

$$
h(z=0)=0 .
$$


Fig. 5.9 Well in an unconfined aquifer with free flow to the water table at the surface (from Doan et al. 2006)

Often the unconfined aquifer is approximated by a half space and the boundary condition at the base is

$$
h(z \rightarrow \infty)=\frac{B K_{u}}{\rho g} \epsilon
$$

The general solution is

$$
h_{o}=\frac{B K_{u}}{\rho g} \epsilon_{o}\left(1+D_{1} e^{(1+i) z / \delta}+D_{2} e^{-(1+i) z / \delta}\right),
$$

where $\delta \equiv \sqrt{2 D / \omega}$. The boundary conditions (5.22) and (5.23) assert that $D_{1}=0$ and $D_{2}=-1$. The solution is thus

$$
h_{o}=\frac{B K_{u}}{\rho g} \epsilon_{o}\left(1-e^{-(1+i) z / \delta}\right) .
$$

When the finite thickness of the aquifer is considered, a no-flow boundary condition is assigned at the base $(z=L)$,

$$
\left.\frac{\partial h}{\partial z}\right|_{z=L}=0
$$

The solution becomes (Detournay and Cheng 1993)

$$
h_{o}=\frac{B K_{u}}{\rho g} \epsilon_{o}[1+\tanh \lambda \sinh (\lambda z / L)-\cosh (\lambda z / L)] \text {, }
$$

where $\lambda \equiv L \sqrt{i \omega / D}$.

Figure 5.10 compares the solutions for the tidal response of an unconfined aquifer with the half-space approximation and that with an assumed thickness of 
Fig. 5.10 Comparison between the half-space model for an unconfined aquifer and the finite layer model with an assumed thickness of $L=\sqrt{D / 2 \omega}$ (author's figure)
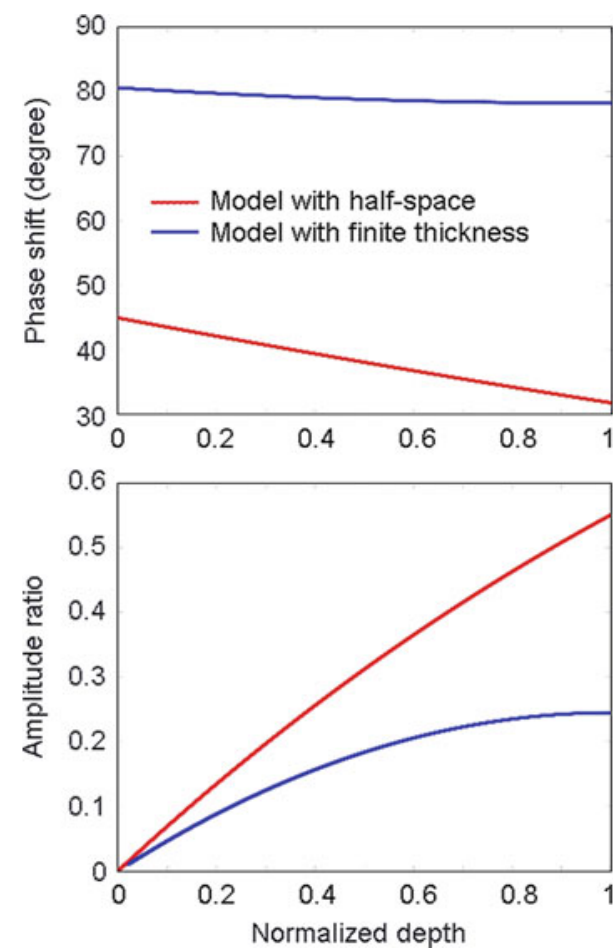

$L=\sqrt{D / 2 \omega}$. For $z / L$ between 0 and 1 , the phase shift for a half-space model declines from 45 to $\sim 30^{\circ}$, while that for a finite layer model declines gently from slightly above 80 degrees to slightly below $80^{\circ}$.

The phase shift for the unconfined aquifer model is positive, in contrast to that for the confined aquifer model. The explanation for the positive phase shift of an unconfined aquifer has been a point of debate. Allègre et al. (2016) explained: "The apparent phase leads are due to the constant pressure boundary condition at the water table that makes the driving force effective the tidal strain rate, which is phase shifted from the dilatational strain." However, under identical boundary conditions to those in the confined aquifer model (Eqs. 5.14-5.16), the leaky aquifer model also predicts positive phase shift at significant leakage (Fig. 5.13; Wang et al. 2018). We examine this point further at the end of Sect. 5.4.4.

\subsubsection{An Example of Seasonal Change of Tidal Response}

Most existing studies of the tidal response of an unconfined aquifer use the traditional unconfined aquifer model (without considering the capillary effect) to interpret the observed positive phase shift. An unusual case occurs in SW China where the positive 
(a)

elevation $(\mathrm{m})$

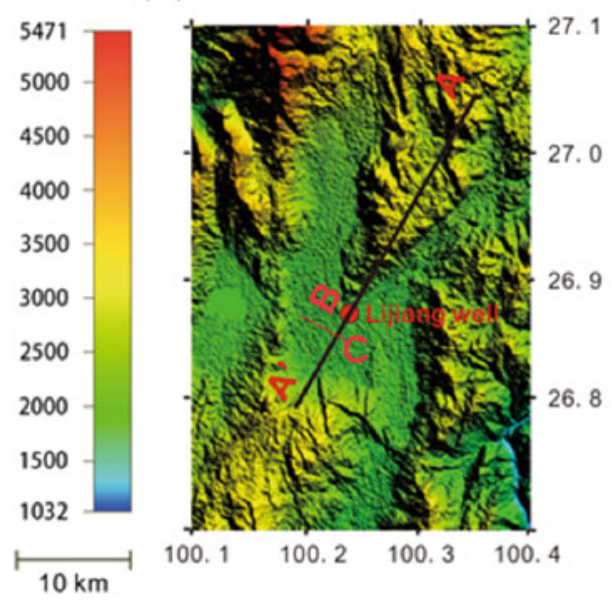

(b)

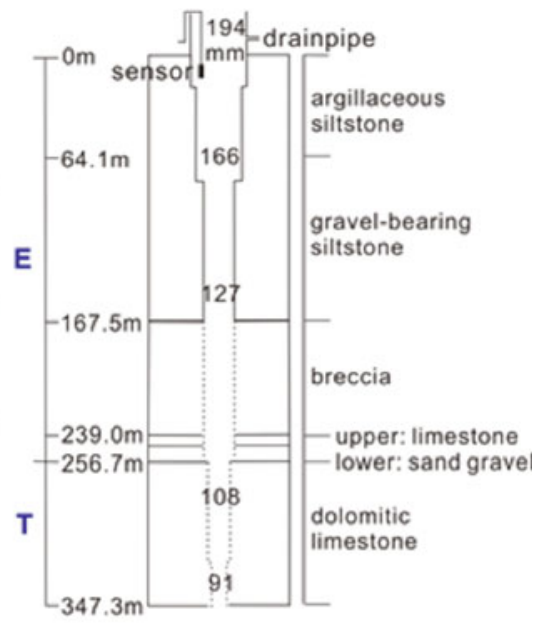

(c)

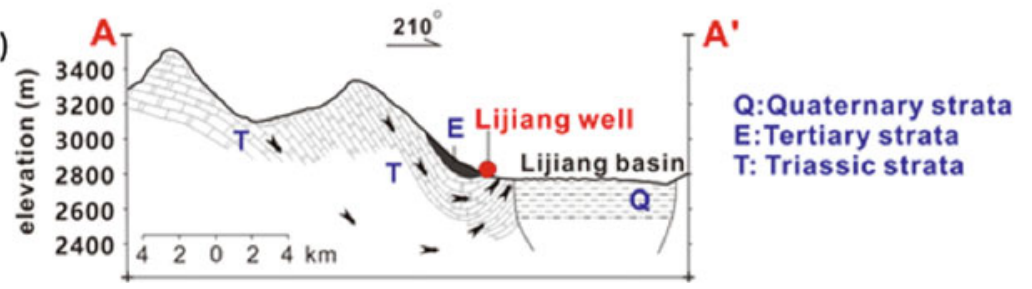

Fig. 5.11 a The hydrogeology and the location of the observation well (Lijiang well). b Simplified diagram of the Lijiang well. Numbers in the well show the inner diameters of the well in mm; numbers on the side show depth beneath the surface. Dashed lines show the open section of the well. c Sketch of the hydrogeologic cross-section of the groundwater recharge and discharge of the aquifer open to the Lijiang well (from Liao and Wang 2018)

phase shift of the tidal response of water level in a well changes with season (Fig. 5.11) and was interpreted with the traditional model (Liao and Wang 2018) and also with the capillary model (Wang et al. 2019). We use this case as an example to first illustrate the interpretation with the traditional model and then compare this interpretation with that with a different model that includes the capillary effect in Sect. 5.4.5.

Figure 5.12a shows a 10 year record of the water level response to the $\mathrm{M}_{2}$ tide in the Lijiang well. The record shows large swings of the tidal responses with season, with large increases of the phase shift and corresponding decreases of the amplitude during the local rainy season (June-October). Figure 5.12b shows a 10-year composite plot of the phase shift and amplitude versus water level. It shows that the upward swing of the phase shift and the downward swing of the amplitude occur at the time when the groundwater level rises to the surface. The data points with water level above the surface correspond to overflow of the well and are not included in the analysis. Liao and Wang (2018) interpreted the seasonal variation of the tidal response with 

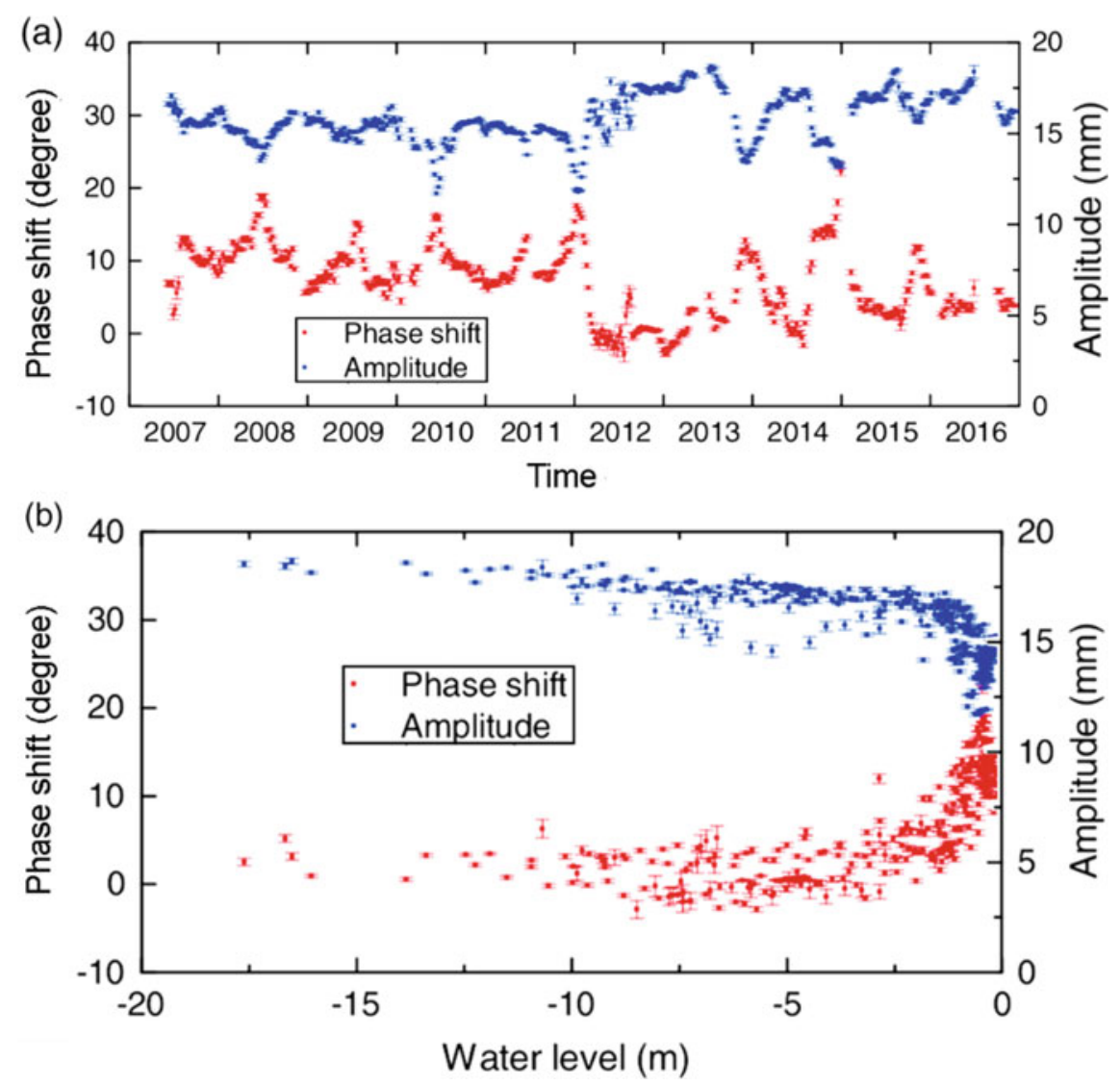

Fig. 5.12 a Time series of the amplitude and phase shift of the tidal response of water level in the Lijiang well to the local $\mathrm{M}_{2}$ (theoretical) tide, plotted with error bars. The root-mean-square errors, on average, are $\sim 0.3^{\circ}$ for phase shift and $\sim 0.2 \mathrm{~mm}$ for amplitude. $\mathbf{b}$ Composite of 10 years of amplitude and phase shift of the water level response to the $\mathrm{M}_{2}$ tide plotted as functions of water level. Water level was referenced to the drainage pipe (Fig. 5.11b) $0.4 \mathrm{~m}$ above ground. Each point in the plot represents an averaged value over a 30 -day period. Positive phase shift indicates local phase advance (from Liao and Wang 2018)

Eq. (5.24)—-the unconfined aquifer model—suggesting a seasonal six-fold increase of permeability during the rainy season. The data may also be interpreted with the capillary model, as discussed in Sect. 5.4.5.

\subsubsection{Tidal Response of a Leaky Aquifer}

As noted earlier, most aquifers are neither completely confined nor completely unconfined, but somewhere between the two end conditions. The vertical impedance to flow 
across a confining layer (aquitard) is not infinite but depends on the thickness of the layer and the time scale of the applied load. At low frequencies, a confining layer may exchange flow across its boundaries; but at high frequencies, it may exhibit confining behavior. Thus it may be more appropriate to treat groundwater systems as a leaky system with a broad spectrum of different degrees of aquifer leakage.

In addition, earthquakes may breach the confinement of aquifers and cause leakage from an initially confined aquifer, as discussed in Sect. 6.8. The analysis of the tidal response of leaky aquifers may thus be useful for quantitative assessment of the effect of an earthquake on the confinement of a groundwater system.

In this section we discuss the analytical solution for the tidal response of a simplified leaky aquifer. Hantush and Jacob (1955) provided the first differential equation for a horizontal and laterally extensive aquifer confined by a semi-confining aquitard, assuming that the flow through it is vertical. With these simplifications they derived the flow equation for a leaky aquifer (Hantush and Jacob 1955):

$$
T\left[\frac{\partial^{2} h}{\partial r^{2}}+\frac{1}{r} \frac{\partial h}{\partial r}\right]-\frac{K^{\prime}}{b^{\prime}} h=S \frac{\partial h}{\partial t},
$$

where $h$ is the hydraulic head in the aquifer above a common reference (Fig. 5.7), $r$ is the radial distance from the studied well, $T$ and $S$, respectively, are the transmissivity and storativity of the aquifer, $K^{\prime}$ is the vertical hydraulic conductivity of the aquitard and $b^{\prime}$ is its thickness (Fig. 5.7). Here the aquifer leakage per unit area $q_{1}$ is approximated by a sink proportional to the product of the average hydraulic gradient and the conductivity across the aquitard, i.e.,

$$
q_{1}=-K^{\prime} \frac{h}{b^{\prime}} .
$$

and the ratio $K^{\prime} / b^{\prime}$ is referred as the leakage factor. The model by Hantush and Jacob has been extensively used and extended in well tests. Here we discuss the tidal response of groundwater in a leaky aquifer. Adding a source term in Eq. (5.27) to represent the driving tidal strain we have (Wang et al. 2018):

$$
T\left[\frac{\partial^{2} h}{\partial r^{2}}+\frac{1}{r} \frac{\partial h}{\partial r}\right]-\frac{K^{\prime}}{b^{\prime}} h=S\left(\frac{\partial h}{\partial t}-\frac{B K_{u}}{\rho g} \frac{\partial \epsilon}{\partial t}\right) .
$$

where $\epsilon$ is the oscillating tidal volumetric strain of the aquifer (compression is taken to be positive), and $B$ and $K_{u}$, respectively, are the Skempton's coefficient and the undrained bulk modulus of the aquifer.

The boundary conditions for the horizontal flow of groundwater between the aquifer and the well are identical to those for a confined aquifer, i.e.,

$$
h(r, t)=h_{\infty}(t) \text { at } r=\infty
$$




$$
\begin{gathered}
h(r, t)=h_{w}(t) \text { at } r=r_{w}, \text { and } \\
2 \pi r_{w} T(\partial h / \partial r)_{r=r_{w}}=\pi r_{c}^{2}\left(\partial h_{w} / \partial t\right)
\end{gathered}
$$

where $r_{w}$ is the radius of the screened portion of the well, $r_{c}$ is the inner radius of well casing in which water level fluctuates with tides, $h_{w}=h_{w, o}^{\prime} e^{i \omega t}$ is the periodic water level in the well, with complex amplitude $h_{w, o}^{\prime}, \omega=2 \pi / \tau$ is the angular frequency, and $\tau$ is the period of tidal oscillation.

The solution for the boundary value problem, (5.29)-(5.32), is obtained by first deriving the response away from the well, $h_{\infty}$, and then considering the effect of the well on aquifer response by using a flux condition at the well that accounts for wellbore storage.

The hydraulic head away from the well may be evaluated by replacing $h$ by $h_{\infty}$ in (5.29)

$$
-\frac{K^{\prime}}{b^{\prime}} h_{\infty}=S \frac{\partial h_{\infty}}{\partial t}-\frac{S B K_{u}}{\rho g} \frac{\partial \epsilon}{\partial t} .
$$

Since $h_{\infty}$ and $\epsilon$ are both periodic with the same frequency $\omega$ we have the relation between their complex amplitudes $h_{\infty, o}^{\prime}$ and $\epsilon_{o}$

$$
h_{\infty, o}^{\prime}=\frac{i \omega S}{i \omega S+K^{\prime} / b^{\prime}}\left(\frac{B K_{u} \epsilon_{o}}{\rho g}\right) .
$$

It is notable that leakage causes both the amplitude and the phase shift of $h_{\infty, o}^{\prime}$ to deviate from that of a perfectly confined aquifer and that $h_{\infty, o}^{\prime}$ becomes identical to that of a perfectly confined aquifer when $K^{\prime}=0$.

The rest of the derivation of the solution is given in Appendix 5.2 (see also Wang et al. 2018); the solution may be expressed in terms of a modified well factor $\xi^{\prime}$, i.e.,

$$
h_{w, o}=\frac{i \omega S}{\left(i \omega S+K^{\prime} / b^{\prime}\right) \xi^{\prime}}\left(\frac{B K_{u} \epsilon_{o}}{\rho g}\right)=\frac{1}{\xi^{\prime}} h_{\infty, o}^{\prime},
$$

where

$$
\xi^{\prime}=1+\left(\frac{r_{c}}{r_{w}}\right)^{2} \frac{i \omega r_{w}}{2 T \beta^{\prime}} \frac{K_{o}\left(\beta^{\prime} r_{w}\right)}{K_{1}\left(\beta^{\prime} r_{w}\right)}
$$

and

$$
\beta^{\prime}=\left(\frac{K^{\prime}}{T b^{\prime}}+\frac{i \omega S}{T}\right)^{1 / 2}
$$


Here the primed parameters $h_{\infty, o}^{\prime}, \xi^{\prime}$ and $\beta^{\prime}$ are used to distinguish them from those parameters for the perfectly confined aquifer in Eqs. (5.16)-(5.18).

The amplitude ratio and the phase shift of the tidal response are, respectively,

$$
\begin{gathered}
A=\left|h_{w, o} /\left(\frac{B K_{u} \epsilon_{o}}{\rho g}\right)\right|, \\
\eta=\arg \left[h_{w, o} /\left(\frac{B K_{u} \epsilon_{o}}{\rho g}\right)\right] .
\end{gathered}
$$

The difference between these expressions (5.38) and those for a confined aquifer (5.19) reflects the fact that, for a leaky aquifer, the tidal response away from the well may no longer be useful as a reference because this response now depends on the unknown aquifer storativity $(S)$ and the aquitard leakage $\left(K^{\prime}\right)(5.34)$. The solution (5.35) has three independent parameters, $T$ and $S$ for the aquifer and $K^{\prime} / b^{\prime}$ for the aquitard. The material property $B K_{u}$ is an additional unknown but is eliminated in the expressions for $A$ and $\eta$. The parameters $T, S$ and $K^{\prime} / b$ ' may be estimated from the measured phase shifts and amplitude ratios of the diurnal tide and the semidiurnal tide. In the case where $T$ and $S$ of the aquifer are known from independent measurements, the model may be used to estimate the leakage of the aquitard.

Figure 5.13 plots the phase shift and the amplitude ratio of the tidal response against $K^{\prime} / b^{\prime}$ for assumed values of $T$ and $S$. At $T>10^{-4} \mathrm{~m}^{2} / \mathrm{s}$ and given $S$, the curves for different $T$ collapse onto a single curve (red markers in Fig. 5.13); in other words, at such high $T$ the tidal response is no longer sensitive to the changes of $T$. On the other hand, the phase shift for a given pair of $T$ and $S$ may change with $K^{\prime} / b^{\prime}$ from a confined response at low leakage over a transition to an unconfined response at high leakage. At relatively small leakage the phase shift may be negative but becomes positive at increasing $K^{\prime} / b^{\prime}$. Thus the traditional criterion that a positive phase shift signifies an unconfined aquifer and a negative phase shift identifies an confined aquifer (e.g., Hsieh et al. 1987; Doan et al. 2006) may fail where the aquitard has finite conductivity.

We end this sub-section with a brief comment on the difference between the tidal response of a leaky aquifer and that of a confined aquifer. Since the two models have identical boundary conditions, the difference between the predicted tidal responses must originate from the difference between the two controlling equations, i.e., the introduction of $K^{\prime} / b^{\prime}$ in Eq. 5.29. For the convenience of discussion, we re-express the solution for phase shift (5.38b), together with (5.35), as $\eta=\arg \left\{i \omega S /\left(i \omega S+K^{\prime} / b^{\prime}\right)\right\} / \xi^{\prime}$, $=\arg \left\{i /\left(i+\left[K^{\prime} / b^{\prime}\right] / \omega S\right)\right\} / \xi^{\prime}$. Since the argument of a product is the sum of the arguments of its factors, the phase shift of the tidal response of a leaky aquifer is the sum of the phase shifts of $i /\left(i+\left[K^{\prime} / b^{\prime}\right] / \omega S\right)$ and that of $1 / \xi^{\prime}$. Plotting the former as a function of $\left[K^{\prime} / b^{\prime}\right] / \omega S$ in Fig. 5.14, we see that the phase shift of $i /\left(i+\left[K^{\prime} / b^{\prime}\right] / \omega S\right)$ is nearly zero when $\left[K^{\prime} / b^{\prime}\right] / \omega S \ll 1$ (i.e., small leakage) but increases to $+\pi / 2$ when $\left[K^{\prime} / b^{\prime}\right] / \omega S \gg 1$ (i.e., large leakage). In other words, when $K^{\prime} / b^{\prime} \ll \omega S$, the phase shift of a leaky aquifer is primarily controlled by borehole storage, similar to that for a confined aquifer, and the flow may be predominantly horizontal; on the other hand, 

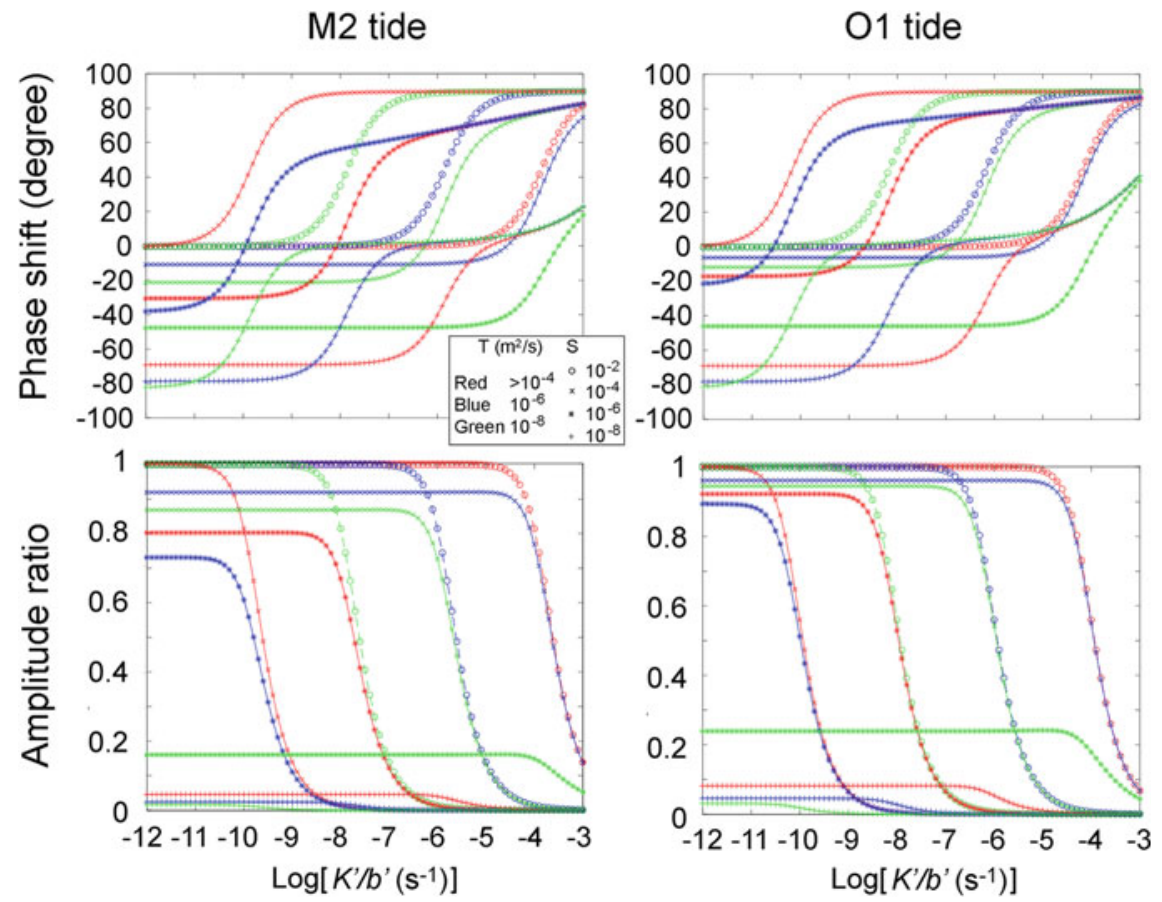

Fig. 5.13 a Phase shift of water level response to the $\mathrm{M}_{2}$ tidal strain predicted by the leaky aquifer model, plotted against the logarithm of the specific leakage $K^{\prime} / b^{\prime}$ for assigned values of $T$ and $S$ and $r_{\mathrm{c}}=r_{\mathrm{w}}=10 \mathrm{~cm}$. b Amplitude ratio of water level response to that converted from the $\mathrm{M}_{2}$ tidal volumetric strain, plotted against the logarithm of $K^{\prime} / b^{\prime}$ for assigned values of $T$ and $S$. $\mathbf{c}$ Phase shift of water level response to the $\mathrm{O}_{1}$ tidal strain, plotted against the logarithm of the specific leakage $K^{\prime} / b^{\prime}$ for assigned values of $T$ and $S$ and $r_{\mathrm{c}}=r_{\mathrm{w}}=10 \mathrm{~cm}$. d Logarithm of the amplitude ratio of water level response to that converted from the $\mathrm{O}_{1}$ tidal volumetric strain, plotted against the logarithm of $K^{\prime} / b^{\prime}$ for assigned values of $T$ and $S$

when $K^{\prime} / b^{\prime} \gg \omega S$, the phase shift of a leaky aquifer is primarily controlled by the free surface, similar to that for an unconfined aquifer, and the flow may be predominantly vertical. In the transition between these two end conditions where $K^{\prime} / b^{\prime}$ is of the same magnitude as $\omega S$, the flow may be neither predominantly horizontal nor predominantly vertical.

\subsubsection{Numerical Simulation for the Tidal Response of a Leaky Aquifer}

The above analytical model made several approximations to simplify the analysis. First, the leakage is treated as a volumetric sink in the aquifer. In reality, the aquifer is part of a system with multiple layers and the leakage occurs across the boundary 


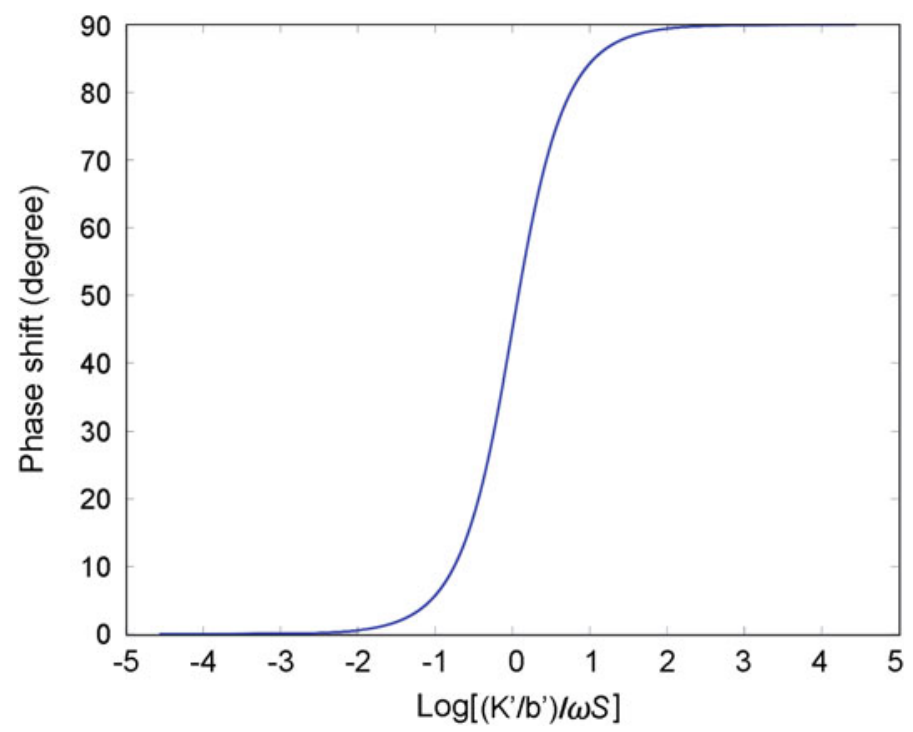

Fig. 5.14 Phase shift of $i /\left(i+\left[K^{\prime} / b^{\prime}\right] / \omega S\right)$ plotted against $\left[K^{\prime} / b^{\prime}\right] / \omega S$

between the aquifer and the aquitard. Thus, the approximation is acceptable only if the aquifer is relatively thin. Second, the analytical model neglects the storage and assumes a linear head profile in the aquitard, implying that the hydraulic head in the aquitard is always in a steady state, which may fail for aquitards with relatively low conductivity and large thickness with time-dependent boundary conditions (Neuman and Witherspoon 1969; Witherspoon and Freeze 1972; Feng and Zhan 2015). Third, it assumes that the flow in the aquitard is always vertical, which occurs only if the vertical hydraulic conductivity of the aquifer is large compared with that of the aquitard. Last, the analytical model assumes that the basement leakage is negligible. Most large induced earthquakes, however, occur in the basement (e.g., Schoenball and Ellsworth 2017), suggesting that some of the injected fluids must have entered the basement (e.g., Barbour et al. 2017). It is thus desirable to understand how basement leakage may affect the tidal response of an aquifer. In order to remove these simplifications and to quantify their influence on the predictions of the tidal response, Zhu and Wang (2020) revisited the tidal response of a leaky aquifer with 2D finiteelement numerical simulations. Below we briefly describe the numerical approach and show how it may be used to simulate the tidal response of a multi-layered, leaky groundwater system.

The numerical model consists of a horizontal aquifer on top of a potentially leaky basement. The aquifer is overlain by a semi-confining aquitard that in turn is overlain by an unconfined aquifer (Fig. 5.15). In this model, the aquifer and the aquitard can both accommodate groundwater flow in the horizontal and the vertical directions. Also, the aquitard and the basement are assumed to have finite transmissivity and 


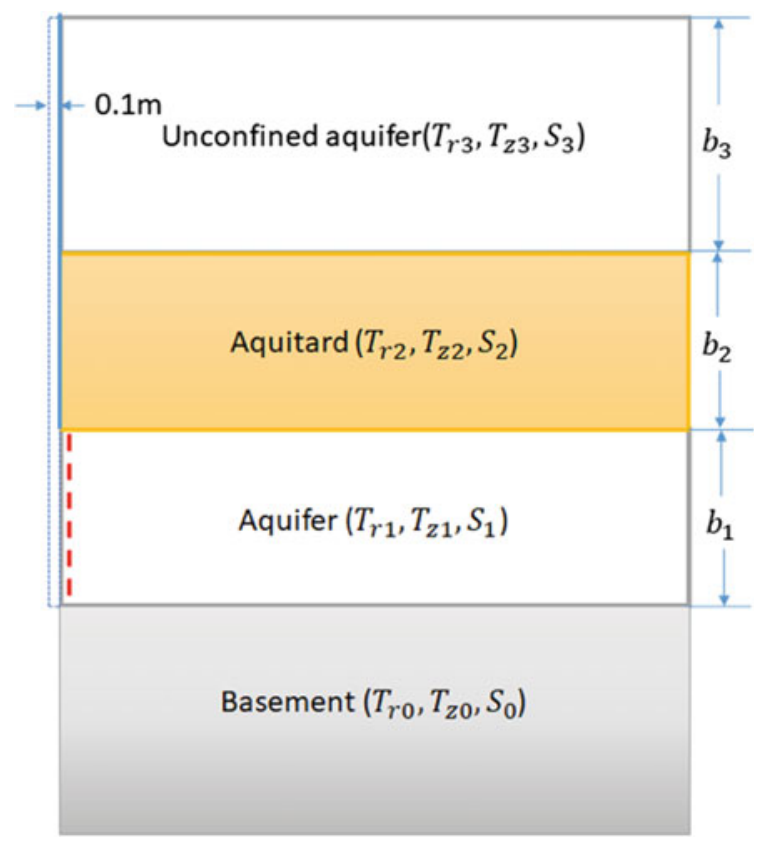

Fig. 5.15 Schematic drawing of a multi-layered groundwater system used in the numerical simulation. The vertical dashed line on the left is the position of the well axis and the radius of the well is $0.1 \mathrm{~m}$; the thicknesses of the aquifer, the aquitard and the topmost unconfined aquifer are, $b_{1}, b_{2}$, and $b_{3}$, respectively. The transmissivity and storativity of the layers are denoted by, respectively, $\left(T_{1}, S_{1}\right),\left(T_{2}, S_{2}\right)$ and $\left(T_{3}, S_{3}\right)$ where $T_{\mathrm{i}}=b_{\mathrm{i}} K_{\mathrm{ri}}$ and $S_{\mathrm{i}}=b_{\mathrm{i}} S_{\mathrm{si}}$. The transmissivity and storativity of the basement $\left(T_{0}, S_{0}\right)$ are assumed to be zero except where the effect of basement leakage is specifically discussed (from Zhu and Wang 2020)

storativity. The topmost unconfined aquifer is assumed to have high vertical hydraulic conductivity and is thus characterized by a hydrostatic head.

Groundwater flow in such a multi-layered system driven by the Earth tides may be simulated by solving the following differential equation:

$$
K_{r i}\left[\frac{\partial^{2} h_{i}}{\partial r^{2}}+\frac{1}{r} \frac{\partial h_{i}}{\partial r}\right]+K_{z i} \frac{\partial^{2} h_{i}}{\partial z^{2}}=S_{s i}\left(\frac{\partial h_{i}}{\partial t}-\frac{B_{i} K_{u i}}{\rho g} \frac{\partial \epsilon}{\partial t}\right),
$$

under the boundary conditions

$$
2 \pi r_{b} T_{1} \frac{\partial h_{1}(r, t)}{\partial r}-\pi r_{c}^{2} \frac{\partial h_{1}(r, t)}{\partial t}=0
$$

where $h_{i}[\mathrm{~m}]$ is the hydraulic head in the $i$ th layer, $r[\mathrm{~m}]$ the radial distance from the axis of the well, $K_{r i}$ and $K_{z i}$, respectively, the hydraulic conductivities in the radial and vertical directions of the $i$ th layer, $S_{s i}$ the specific storage of the $i$ th layer, with the subscript 1 denotes the aquifer layer, $\epsilon$ is the tidal volumetric strain, $B_{i}$ and 
$K_{u i}$, respectively, are the Skempton's coefficient and the undrained bulk modulus of the $i$ th layer, and $\rho$ and $g$, respectively, the density of water and the gravitational acceleration. $K_{r i}$ and $K_{z i}$, respectively, are related to the horizontal and vertical permeabilities $k_{r i}$ and $k_{z i}$ of the $i$ th layer by $K_{r i}=k_{r i} \rho g / \mu$ and $K_{z i}=k_{z i} \rho g / \mu$, respectively, $\mu$ the viscosity of water, $b_{i}$ the thickness of the $i$ th layer, $r_{b}$ is the radius of the opened section of the well and $r_{c}$ is the radius of the cased section of the well. Finally, a boundary condition of $p=0(1 \mathrm{~atm})$ is assigned on the surface $(z=0)$ and a no-flow conditions on the cased section of the well, on the right boundary $(r \rightarrow \infty)$ of the model, and at the base $(z \rightarrow \infty)$ of the model.

It is noticeable that leakage of groundwater across the boundary between the aquifer and the aquitard is permitted in this model, eliminating the use of a source in Eq. (5.39) to represent the leakage of the aquifer. For the lack of experimental data, $B_{i}$ and $K_{u i}$ are assumed uniform in all layers. The basement beneath the aquifer is assumed to be impervious in most simulations, except where the effect of basement leakage is specifically examined.

Zhu and Wang (2020) used a commercially available finite element code, COMSOL, to investigate the questions stated at the beginning of this sub-section.

The simulation with different aquifer thickness and hydraulic conductivity show good agreement between the analytical model and the numerical solution when the parameter $\alpha=\left(K_{z 1} / b_{1}\right) /\left(K_{z 2} / b_{2}\right)$ is greater or equal to 5 for the ranges of studied aquitard leakage factor $K_{z 2} / b_{2}, K_{r 1}$ and $S_{1}$ (Fig. 5.16), where the subscript 1 denotes the parameters of the aquifer and the subscript 2 denotes the parameters of the aquitard. At $\alpha<5$, however, the simulated results depart progressively from the analytic solutions and lie further to the right (greater $K_{z 2} / b_{2}$ ) of the analytical model for given values of $T_{r 1}$ and $S_{1}$.

Another assumption in the analytical leaky aquifer model (Hantush and Jacob 1955; Wang et al. 2018) is that the semi-confining aquitard has negligible storativity. As noted earlier, this assumption is equivalent to assuming that the aquitard goes immediately into a steady state, which is valid only if the time constant for the hydraulic equilibrium across the aquitard is short in comparison with the period of the tidal forcing. The occurrence of aquitard storage significantly increases the time constant for the hydraulic equilibrium across the aquitard and renders the assumption invalid if the aquitard has relatively low conductivity and large thickness (Neuman and Witherspoon 1969; Witherspoon and Freeze 1972; Feng and Zhan 2015). Figure 5.17 compares results simulated with $S_{2} / S_{1}=0,1,10$ and 100 , respectively, for $K_{r 1}=10^{-5} \mathrm{~m} / \mathrm{s}$ and $\alpha=10$. Good agreement between the simulated results and the analytical solution occurs when $S_{2} / S_{1}=0$. But when $S_{2} / S_{1}$ is significantly greater than 0 , the departure of the simulated results from the analytical solution increases with increasing aquitard storativity at a given aquitard leakage $K_{z 2} / b_{2}$. Another interesting feature is that the simulated peak amplitude ratio may exceed 1 and the magnitude of this excess becomes greater with increasing aquitard storativity. Similar increases of the amplitude ratio were reported before and interpreted to be due to the poroelastic coupling between pore pressure and deformation (Detournay and Cheng 1993; Hsieh and Cooley 1995; Wang 2000). 

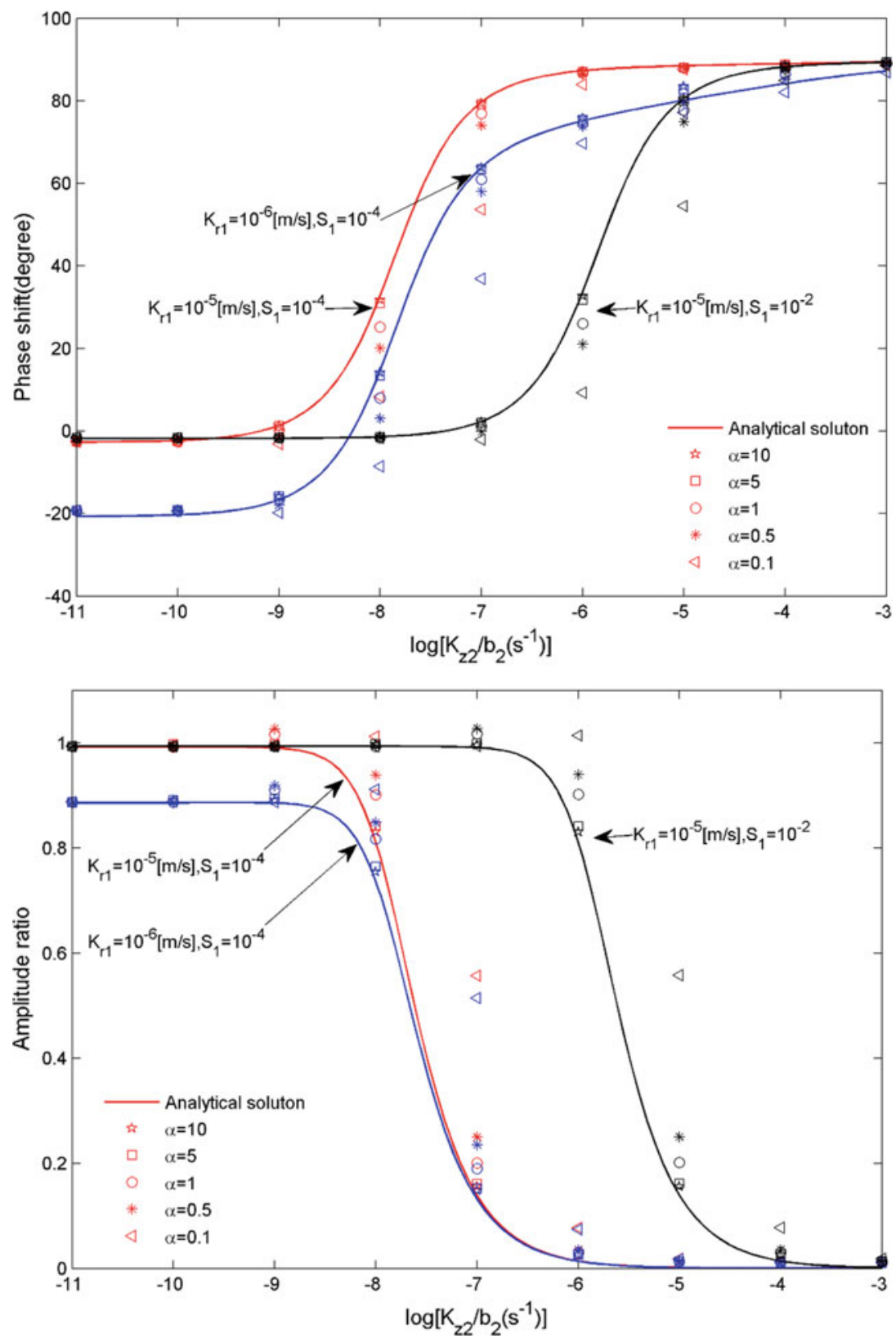

Fig. 5.16 Comparison between the numerically simulated water level response to the $\mathrm{M}_{2}$ tide at different values of $\alpha$ and specific aquifer transmissivity $\left(T_{1}\right)$ and storativity $\left(S_{1}\right)$ (symbols) and the analytical solutions (curves; Wang et al. 2018). a Phase shift and $\mathbf{b}$ amplitude ratio plotted against aquitard leakage factor $\mathrm{K}_{\mathrm{z} 2} / \mathrm{b}_{2}$ (from Zhu and Wang 2020) 

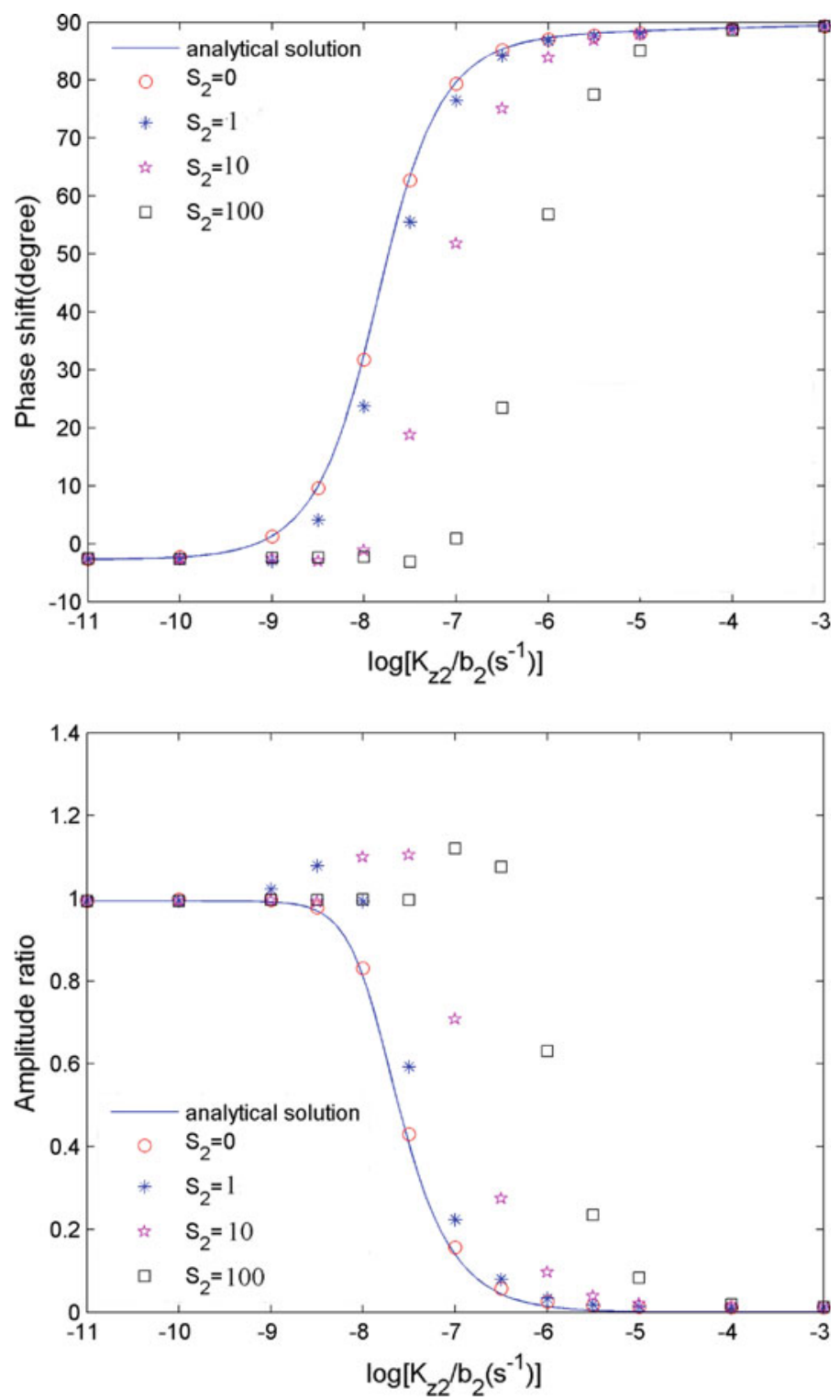

Fig. 5.17 Comparison between the numerically simulated water level response to the $\mathrm{M}_{2}$ tide at different aquitard storativity $\left(S_{2}\right)$ (symbols) and the analytical solutions (curves; Wang et al. 2018). a Phase shift and $\mathbf{b}$ amplitude ratio plotted against aquitard leakage factor $K_{z 2} / b_{2}$ (from Zhu and Wang 2020) 
Zhu and Wang (2020) also examined the effect of basement leakage. Previous studies suggested that the basement diffusivity may be as high as $1 \mathrm{~m}^{2} / \mathrm{s}$ in order to explain the induced seismicity (Barbour et al. 2017), but the effect of basement leakage on the response to Earth tides has not been investigated. Figure 5.18 shows that the effect of basement leakage on tidal response may be neglected only if the basement conductivity is below $10^{-7} \mathrm{~m} / \mathrm{s}$. At greater basement conductivity, basement leakage may cause significant decrease in phase shift and increase in amplitude ratio. Thus the omission of basement leakage from the interpretation of tidal response of water level in wells may also lead to significant underestimates of the aquifer leakage.

Finally, Zhu and Wang (2020) used their numerical procedure to simulate the tidal response in a U.S. Geological Survey monitoring well in Oklahoma (Fig. 5.19), which opens at a depth of $900 \mathrm{~m}$ to the carbonate Arbuckle aquifer that has been used for the injection of wastewaters co-produced from hydrocarbon exploration. Figure 5.20 shows the well construction and the lithology of the wall rocks of the well. The aquifer lies on the top of a crystalline basement and is overlain by an
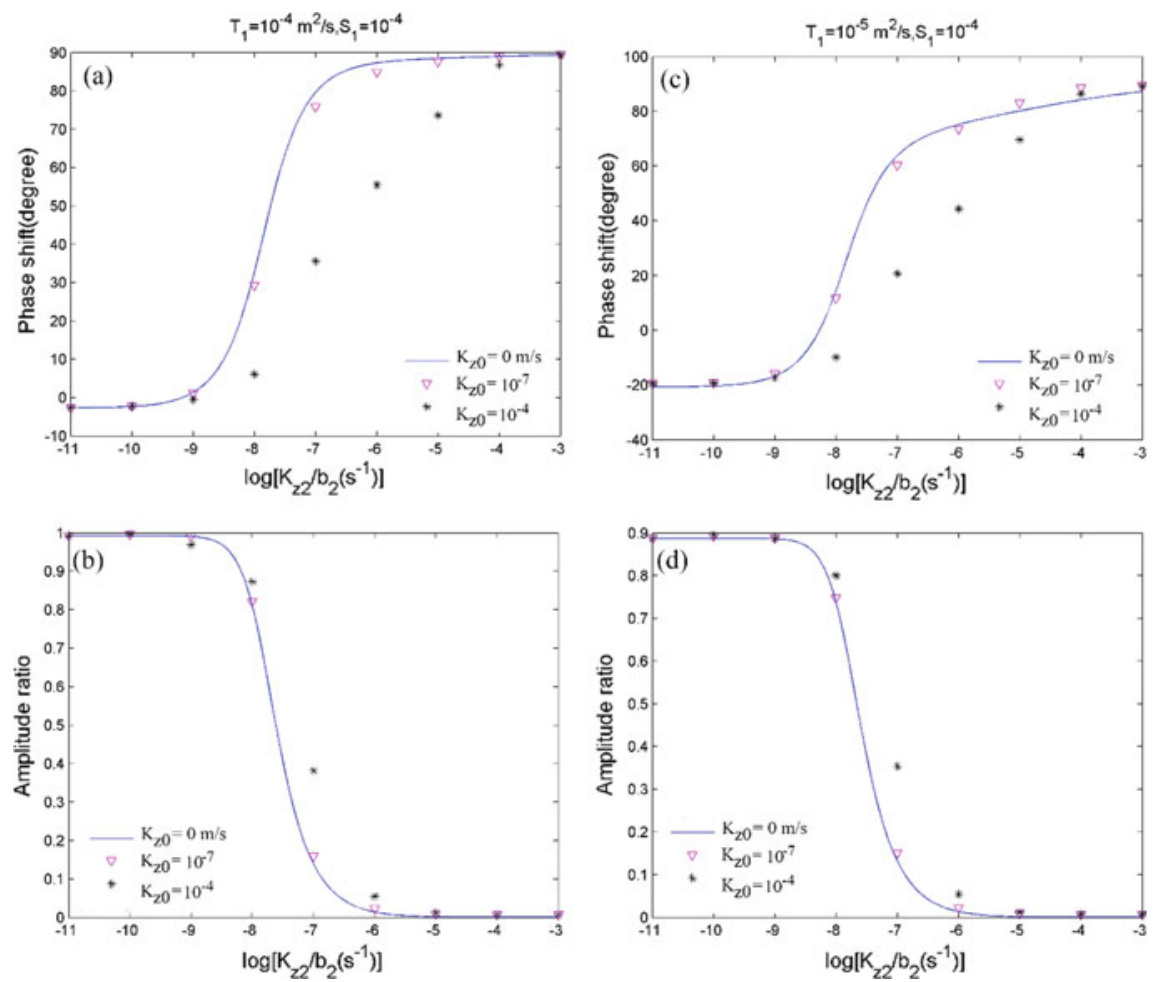

Fig. 5.18 Comparison between the numerically simulated (symbols) water level response to the $\mathrm{M}_{2}$ tide at different basement leakage $\left(K_{z 0}\right)$ and aquifer transmissivity $\left(\mathrm{T}_{1}\right)$ and the analytical solutions (curves; Wang et al. 2018). a, c Phase shift and b, $\mathbf{d}$ amplitude ratio, plotted against aquitard leakage factor $K_{z 2} / b_{2}$ (from Zhu and Wang 2020) 


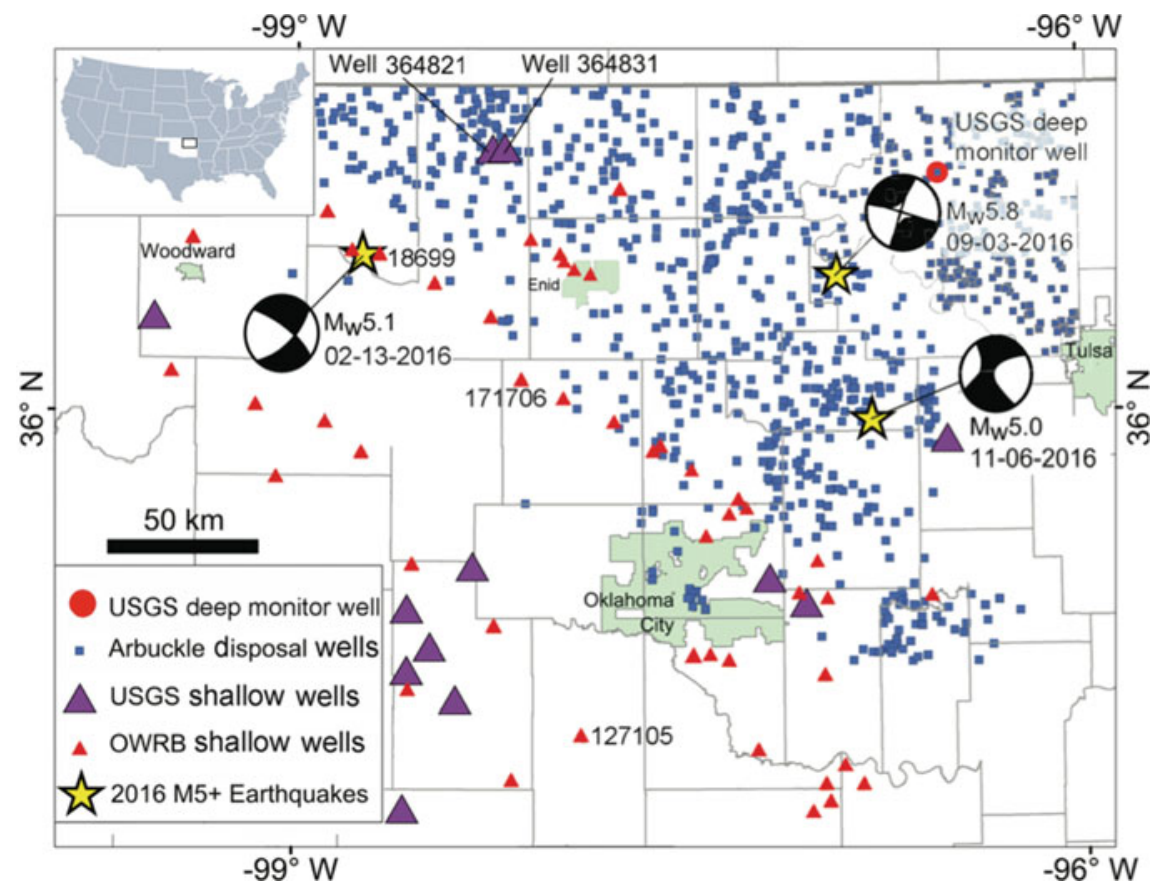

Fig. 5.19 The location of the USGS Oklahoma Deep Well (red circle in the upper right corner of figure). The epicenters of three $2016 \mathrm{M} \geq 5$ earthquakes are shown as yellow stars. The locations of water wells and injection wells, respectively, are shown by triangles and blue dots (from Wang et al. 2018)

aquitard consisting of a sequence of layered rocks with a basal shale; the aquitard in turn is overlain by a layer of unconsolidated sediments.

Figure 5.21 shows the time series of water level in the USGS Oklahoma Deep Well in 2017, the tides in water level and the phase shift, and amplitude of water level response to the $\mathrm{M}_{2}$ and $\mathrm{S}_{2}$ tides referenced to the local theoretical tidal volumetric strain. The response shows a positive phase shift of $\sim 12.5^{\circ}$ to the $\mathrm{M}_{2}$ tide (Wang et al. 2018). Barbour et al. (2019) also studied the tidal response of water level in the same well (Fig. 5.21); their analysis shows a similar positive phase shift of the response to the $\mathrm{M}_{2}$ tide. Hence both studies suggest that the Arbuckle aquifer may be leaking.

Table 5.2 lists the hydraulic properties of the Arbuckle aquifer and the geometry of the USGS Oklahoma Deep Well. Figure 5.22 shows the simulated phase shift for the $\mathrm{M}_{2}$ tide plotted against $\log \left(K_{z 2} / b_{2}\right)$ with the ratio of aquitard storativity specified as $S_{2} / S_{1}=0,1$ and 10 , respectively. The horizontal line, showing the phase shift of $12.5^{\circ}$ for the tidal response of the Arbuckle aquifer to the $\mathrm{M}_{2}$ tide in the USGS well (Wang et al. 2018; Barbour et al. 2019), intersects the model curves at $K_{z 2} / b_{2}=\sim 10^{-8.1}, \sim 10^{-7.5}$ and $\sim 10^{-6.6}\left[\mathrm{~s}^{-1}\right]$, respectively. Given the thickness of the aquitard of $277 \mathrm{~m}$, the corresponding average vertical conductivity of the aquitard 


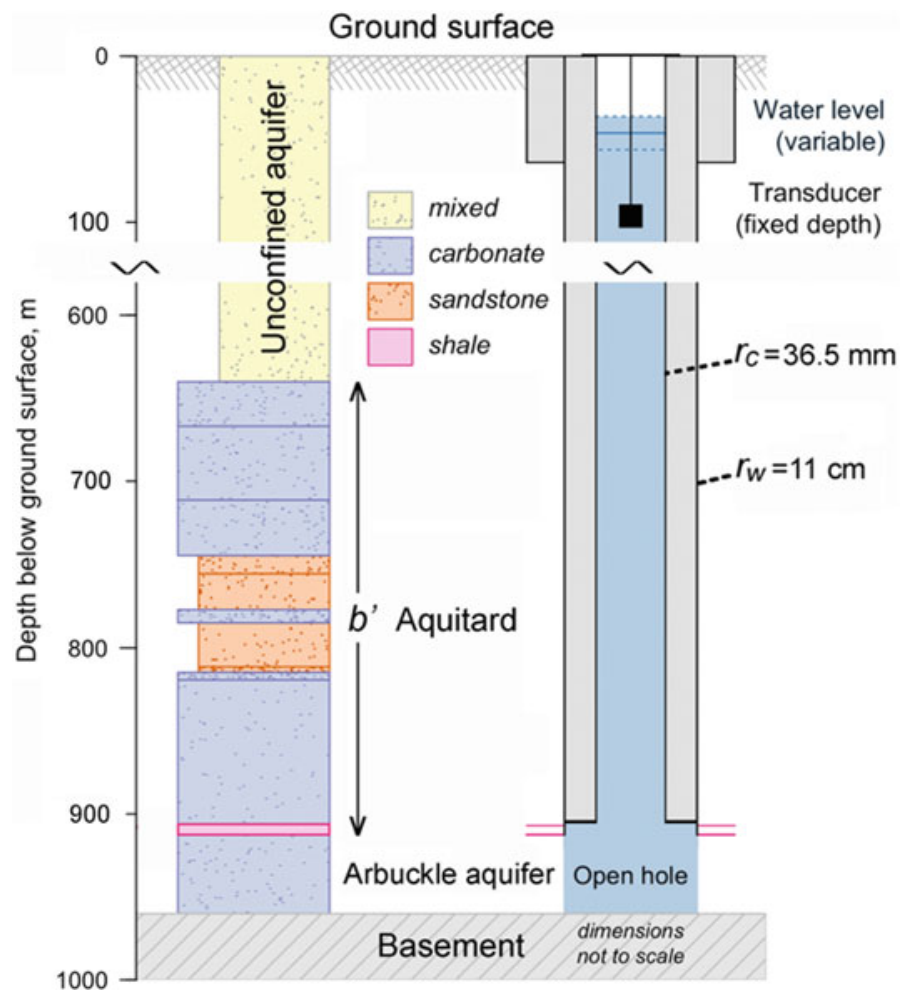

Fig. 5.20 Well construction of, and the lithology in, the USGS Oklahoma Deep Well (from Wang et al. 2018)

are, respectively, $K_{z 2}=2 \times 10^{-6}, 9 \times 10^{-6}$ and $7 \times 10^{-5} \mathrm{~m} / \mathrm{s}$, similar to that for aquifers.

No direct measurement is available for the basement conductivity in Oklahoma. Simulating induced seismicity in Oklahoma, Langenbruch et al. (2018) estimate a basement permeability of $2 \times 10^{-15} \mathrm{~m}^{2}$ and Barbour et al. (2017) suggest a basement diffusivity that decreases from $1 \mathrm{~m}^{2} / \mathrm{s}$ at the top of the basement to $0.002 \mathrm{~m}^{2} / \mathrm{s}$ at a depth of $8 \mathrm{~km}$. Here we assume two uniform basement conductivities of $10^{-8}$ and $10^{-4} \mathrm{~m} / \mathrm{s}$ between the top of the basement and a depth of $8 \mathrm{~km}$. The simulated results, plotted against the aquitard leakage factor $K_{z 2} / b_{2}$ in Fig. 5.7b, intersect the horizontal black line of $12.5^{\circ}$ phase shift at $K_{z 2} / b_{2}=10^{-8.1}$ to $10^{-7.75} \mathrm{~s}^{-1}$. Given the thickness of the aquitard of $277 \mathrm{~m}$, the corresponding average vertical conductivity of the aquitard is $K_{z 2}=2 \times 10^{-6}$ and $5.4 \times 10^{-6} \mathrm{~m} / \mathrm{s}$, respectively, as high as those of the aquifer.

In order to understand the origin of the leakage, we note that the aquitard above the Arbuckle aquifer at this location consists of a sequence of horizontally layered rocks with a total thickness of $277 \mathrm{~m}$. The average vertical hydraulic conductivity of 


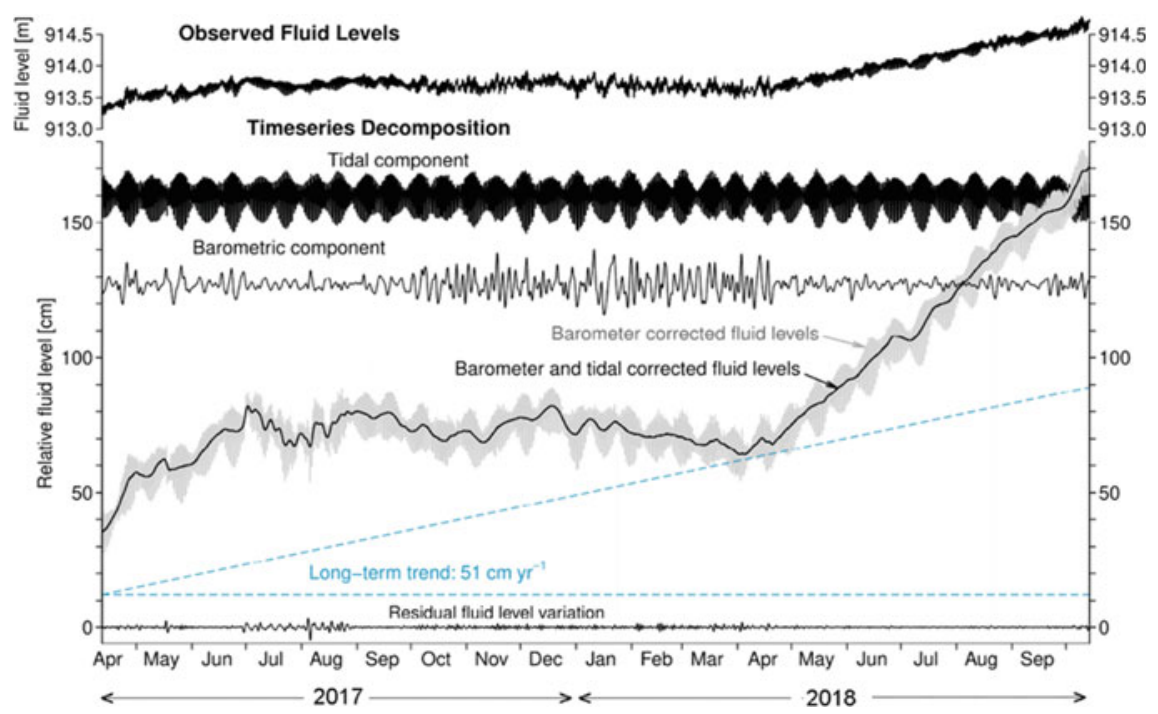

Fig. 5.21 Observed fluid level (top) from 2017 to 2018, and its decomposition into a tidal response, a barometric response, and a long-term trend (dashed line). Notice the rapid increase of water level in the well. Positive change indicates pressure increase in the Arbuckle (modified from Barbour et al. 2019)

the aquitard is therefore $b_{1} / \sum_{i}\left(b_{i} / K_{i}\right)$ (Chap. 2), where the subscript $i$ denotes the $i$ th layer in the sequence and $b_{1}$ denotes the total thickness of the layers. This relation suggests that the average vertical conductivity of the aquitard is controlled by the layer with the lowest conductivity. Table 5.3 lists the thickness of each individual layer in the aquitard and its representative hydraulic conductivity assigned according to the lithology of the layer. The calculated average vertical hydraulic conductivity of the hypothetical aquitard is $\sim 5 \times 10^{-12} \mathrm{~m} / \mathrm{s}$ that is many orders of magnitude lower than that estimated from tidal analysis $\left(10^{-8}-10^{-7} \mathrm{~m} / \mathrm{s}\right)$. This average vertical conductivity is controlled by the 6-m-thick intact shale at the base of the aquitard and, in order to raise the estimation to the same order as that from tidal analysis, this basal 'shale' needs to have a vertical conductivity many orders of magnitude greater than that of intact shale. Wang et al (2018) thus concluded that the basal shale above the Arbuckle aquifer near the USGS Oklahoma Deep Well (Fig. 5.20) was fractured and is leaking. In other words, the 'aquitard' may not be confining at all at this location. On the other hand, the tidal response does not provide information on the earthquake effects on the aquifer leakage because the USGS well was installed after the occurrence of the four large ( $\mathrm{Mw} f \geq 5$ ) earthquakes in 2016. Given the fast rise of fluid level in this well (Fig. 5.21) and in many Arbuckle wells (Ansari et al. 2019), the Arbuckle may need to be carefully monitored in order to safeguard the overlying freshwater reservoirs and the surface environment from the hundreds of millions of barrels of wastewater injected into this aquifer. 
Table 5.2 Parameters of the USGS Oklahoma deep well and the hydrogeological parameters used in the numerical simulation

\begin{tabular}{|c|c|c|c|}
\hline Parameters & Symbol & Values & References \\
\hline Well location and elevation & & $\begin{array}{l}36.7269 \mathrm{~N}, 96.5317 \mathrm{~W} \\
340.16 \mathrm{~m} \text { above sea level }\end{array}$ & USGS website $^{\mathrm{a}}$ \\
\hline Well depth & & $960 \mathrm{~m}$ beneath surface & Wang et al. (2018) \\
\hline Well radius & $r_{\mathrm{w}}$ & $11 \mathrm{~cm}$ & Wang et al. (2018) \\
\hline Casing radius & $r_{\mathrm{c}}$ & $3.65 \mathrm{~cm}$ & Wang et al. (2018) \\
\hline Thickness of aquitard & $b^{\prime}$ & $277 \mathrm{~m}$ & Wang et al. (2018) \\
\hline Thickness of aquifer & $b$ & $48 \mathrm{~m}$ & Wang et al. (2018) \\
\hline Permeability & $k$ & $\begin{array}{l}2 \times 10^{-14} \text { to } 3 \times 10^{-12} \\
\mathrm{~m}^{2}\end{array}$ & Morgan and Murray (2015) \\
\hline Transmissivity $^{\mathrm{b}}$ & $T$ & $\begin{array}{l}9.6 \times 10^{-6} \text { to } 1.4 \times 10^{-3} \\
\mathrm{~m}^{2} / \mathrm{s}\end{array}$ & Calculated from $k$ \\
\hline Hydraulic conductivity & $K$ & $\begin{array}{l}1.9 \times 10^{-7} \text { to } 2.8 \times 10^{-5} \\
\mathrm{~m} / \mathrm{s}\end{array}$ & Calculated from $T$ \\
\hline Specific storage ${ }^{\mathrm{c}}$ & $S_{s}$ & $\begin{array}{l}5.4 \times 10^{-6} \text { to } 5.6 \times 10^{-5} \\
\mathrm{~m}^{-1}\end{array}$ & Rahi and Halihan, (2009) \\
\hline Storativity ${ }^{\mathrm{d}}$ & $S$ & $2.6 \times 10^{-4}$ to $2.7 \times 10^{-3}$ & Calculated from $S_{S}$ \\
\hline
\end{tabular}

Modified from Wang et al. (2018)

${ }^{a}$ https://waterdata.usgs.gov/nwis/uv/?site_no=364337096315401

${ }^{\mathrm{b}}$ Transmissivity is calculated from permeability using the relationship $T=b(\rho g k / \mu)$, where $\rho$ and $\mu$ are, respectively, the density and viscosity of pore fluid in the Arbuckle aquifer. As explained in the text, groundwater in the Arbuckle aquifer near the USGS well is similar to freshwater; thus we take $\rho=1000 \mathrm{~kg} / \mathrm{m}^{3}$ and $\mu=0.001 \mathrm{~Pa}$ s in the calculation of $T$ from $k$

${ }^{\mathrm{c}}$ The difference between the values listed here and those in Wang et al. (2018) is due to an error in this reference in converting the unit from $\mathrm{cm}^{-1}$ to $\mathrm{m}^{-1}$

${ }^{\mathrm{d}}$ Storativity $S$ is calculated from specific storage $S_{S}$ (Rahi and Halihan 2009) using the relationship $S=b S$

\subsubsection{Tidal Response of an Unconfined Aquifer with the Capillary Effect}

As noted earlier, the traditional unconfined aquifer model discussed in Sect. 5.4.2 has been used for more than thirty years to interpret the positive phase shift of the groundwater response to Earth tides (e.g., Roeloffs 1996; Allègre et al. 2016; Liao and Wang 2018). But, if the water table is below the ground surface as in most cases, there is an unsaturated zone above the water table and the capillary tension between water and the solid surfaces of sediment grains may pull the pore water up against gravity to create a zone of negative (capillary) pressure. Several studies have documented that the capillary zone may have significant effects on the water table behavior. Meyboom (1967) observed that the rise in the water table during precipitation is frequently much greater in magnitude than would be predicted from the amount of precipitation and the specific yield of the aquifer. Gillham (1984) showed that the 

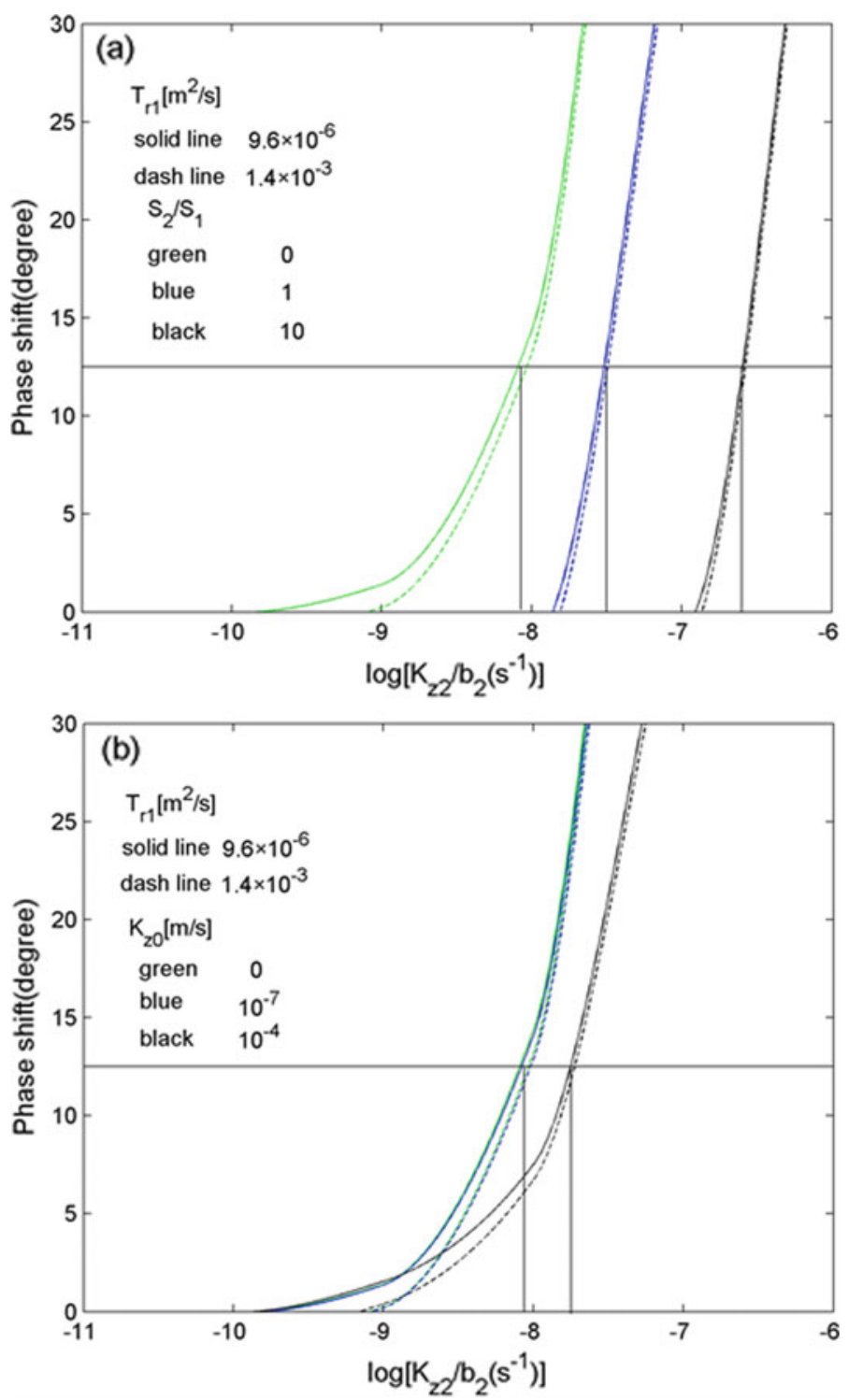

Fig. 5.22 Simulated phase shift against aquitard leakage factor $K_{z 2} / b_{2}$. a Without considering the basement leakage, the Arbuckle aquifer at three specified aquitard storativities of $S_{2} / S_{1}=0$ (red), 1 (blue) and 10 (black) and two different aquifer radial transmissivity $\left(T_{r 1}\right)$. b Effect of the basement leakage simulated with $S_{2} / S_{1}=0$ and two different aquifer transmissivities $\left(T_{r 1}\right)$. Horizontal black line shows phase shift of $12.5^{\circ}$ of the response to the $\mathrm{M}_{2}$ tide of the water level in the USGS Deep Well, Oklahoma (from Zhu and Wang 2020) 
Table 5.3 Thickness and assumed permeability of rocks in calculating the harmonic mean of vertical permeability of a hypothetical, hydraulically intact aquitard

\begin{tabular}{l|l|l|l}
\hline Rock layer & Thickness $(\mathrm{m})$ & $\begin{array}{l}\text { Vertical hydraulic conductivity } \\
(\mathrm{m} / \mathrm{s})\end{array}$ & References \\
\hline Carbonate & 106 & $10^{-6}$ & Morgan and Murray (2015) \\
\hline Sandstone & 31 & $10^{-8}$ & Wang (2000) \\
\hline Carbonate & 9 & $10^{-6}$ & Morgan and Murray (2015) \\
\hline Sandstone & 28 & $10^{-8}$ & Wang (2000) \\
\hline Carbonate & 92 & $10^{-6}$ & Morgan and Murray (2015) \\
\hline Shale & 6 & $10^{-13}$ & Wang (2000) (Piere shale) \\
\hline
\end{tabular}

addition of a small amount of water can lead to an immediate and large rise in the water table if the saturated zone of the capillary zone extends to ground surface. Turner and Nielsen (1997) measured pore pressure beneath ocean beaches in the surf zone and found that pore pressure oscillates at amplitudes much greater than that due directly to the change of surface pressure during the swash; they attributed this fluctuation of pressure to the appearance and disappearance of meniscuses at the sand surface during the swash. For the response to oscillatory forces, Barry et al. (1996) suggested a criterion that the capillary fringe may significantly affect the water table oscillations if the ratio $K /(\omega b) \ll 1$, where $K$ is the hydraulic conductivity, $b$ the effective thickness of the capillary fringe, and $\omega$ the angular frequency of the waterlevel oscillation. Applying this criterion to the present study, with $K \sim 10^{-6} \mathrm{~m} / \mathrm{s}$ and $b \sim 1.6 \mathrm{~m}$ for a silt aquifer (Fetter 1999), $K /(\omega b) \sim 0.006$ for the angular frequency of the $\mathrm{M}_{2}$ tide $\left(\omega \sim 1.4 \times 10^{-4} \mathrm{~s}^{-1}\right)$. Thus, the criterion by Barry et al. (1996) suggests that the capillary fringe in a silt aquifer would significantly affect the water table response to the $\mathrm{M}_{2}$ tide. For a sand aquifer, on the other hand, with $b \sim 0.17 \mathrm{~m}$ (Fetter $1999)$ and $K \sim 10^{-4} \mathrm{~m} / \mathrm{s}$, we have $K /(\omega b) \sim 6$; thus the same criterion suggests that the capillary effect in a sand aquifer may be marginal on the water table response to Earth tides. Wang et al. (2019) showed numerically that the capillary tension may have a significant influence on the tidal response of fine grained unconfined aquifers. Here we review capillary effects and discuss their potential impact.

The basic equations for continuity of pore water in the unsaturated zone was derived in Sect. 2.6 but is relisted below for completeness,

$$
\frac{\partial \theta}{\partial t}=-\nabla \cdot \boldsymbol{q}
$$

where $\theta$ is the water content in a unit volume of variably saturated media and $\boldsymbol{q}$ the vector of specific discharge. For flow in the vertical direction we have

$$
q_{z}=-K(\theta)\left(\frac{\partial h_{p}}{\partial z}+1\right)
$$


where $K(\theta)=k_{r} K_{s}$ is the unsaturated vertical hydraulic conductivity, $k_{r}$ is the relative conductivity and $K_{s}$ the saturated vertical hydraulic conductivity, $h_{p}$ is the pressure head that equals to $p / \rho g, \rho$ the density of groundwater, $g$ the gravitational acceleration, and $z$ the elevation above a vertical reference.

In the absence of fluid sources, the water content $\theta$ in an isotropic, partially saturated poroelastic medium is a function of the volumetric stress $\sigma$ and pore pressure $p$; the change of water content may thus be expressed as

$$
\mathrm{d} \theta=S_{\sigma}(\theta)[-B(\theta) \mathrm{d} \sigma+\mathrm{d} p]
$$

where $S_{\sigma}(\theta) \equiv(\partial \theta / \partial p)_{\sigma}$ is the 'unconstrained' storage, $B(\theta)$ is the Skempton's coefficient, and compression is considered positive to be consistent with the sign convention in the previous sections. In view that the differences among the storages defined under different boundary conditions (discussed in Chap. 3) are small, we follow Bear (1972) to express the storage as $\left(C(\theta)+S_{e} S_{s}\right) / \rho g$ to include both the saturated and unsaturated media, where $C(\theta)=\partial \theta / \partial h_{p}$ is the specific moisture capacity, $S_{s}$ is the specific storage for saturated media, $S_{e}$ is the effective saturation defined as

$$
S_{e}=\left(\theta-\theta_{r}\right) /\left(\theta_{s}-\theta_{r}\right),
$$

where $\theta_{r}$ and $\theta_{s}$ are, respectively, the residual and the saturated water content. Thus (5.43) may be rewritten as

$$
\mathrm{d} \theta=\left(C(\theta)+S_{e} S_{s}\right)(-B(\theta) \mathrm{d} \sigma+\mathrm{d} p) / \rho g
$$

Combining Eqs. (5.41), (5.42) and (5.45), we obtain

$$
\frac{\partial}{\partial z}\left[K(\theta)\left(\frac{\partial h_{p}}{\partial z}+1\right)\right]=\left(C(\theta)+S_{e} S_{s}\right)\left(-\frac{B(\theta)}{\rho g} \frac{\partial \sigma}{\partial t}+\frac{\partial h_{p}}{\partial t}\right) .
$$

Finally, given $\sigma=K_{u} \epsilon$, Eq. (5.38) may be expressed as

$$
\frac{\partial}{\partial z}\left[K(\theta)\left(\frac{\partial h_{p}}{\partial z}+1\right)\right]=\left(C(\theta)+S_{e} S_{s}\right)\left(-\frac{B(\theta) K_{u}}{\rho g} \frac{\partial \epsilon}{\partial t}+\frac{\partial h_{p}}{\partial t}\right) .
$$

Under saturated conditions, $C(\theta)=0, S_{e}=1, B(\theta)=B$, and $K(\theta)=K_{s}$, and Eq. (5.47) reduces to the traditional equation for the tidal effect on saturated flow in unconfined aquifers (5.20a).

For simulation, Wang et al. (2019) assumed a column of uniform sediment extending from the ground surface to infinite depth (Fig. 5.23), where an unsaturated zone lies above a water table at a depth $b$. For boundary conditions, Wang et al. (2019) assigned a no-flow boundary condition at infinite depth, i.e.,

$$
q=0 \text { at } z=\infty
$$




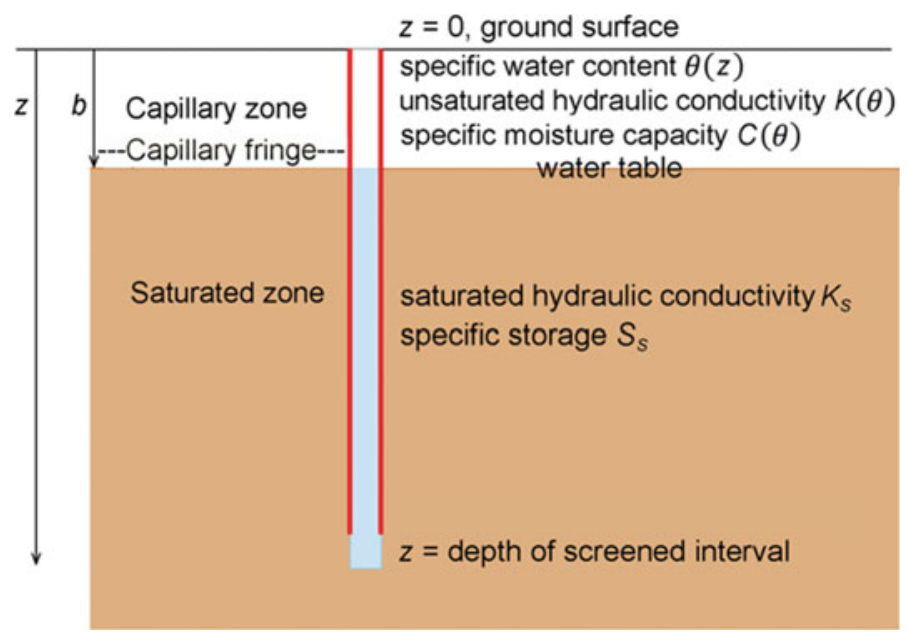

Fig. 5.23 Well in an unconfined aquifer with the water table below the surface (from Wang et al. 2019)

and a mixed boundary condition is assigned at the ground surface, i.e.,

$$
q=-k_{r} K_{s} h_{p} / b \text { at } z=0
$$

which is a type of boundary condition used in numerical simulation of problems where the boundary condition depends on the solution, such as seepage-face formation, evapotranspiration and rainfall infiltration. It has the advantage that it adjusts to the dynamic changes of boundary conditions automatically without additional checks. For the present case, the water table oscillates due to seasonal and tidal forcing. When the depth of the water table is greater than the thickness of the capillary fringe, $S_{e}(z=0) \rightarrow 0$ and $k_{r}(z=0) \rightarrow 0$, and (5.49) is a no-flow condition. On the other hand, when the water table reaches the ground surface, i.e., $b=0$, $k_{r} K_{s} / b=K_{s} / b \rightarrow \infty$, and (5.49) becomes a free-flow condition.

A large amount of experimental measurements has been accumulated for the hydraulic properties of unsaturated sediments and several empirical relations have been developed to fit the experimental data, including the van Genuchten-Mualem relation between the effective saturation $S_{e}(\theta)$ and the capillary pressure head $h$ (van Genuchten 1980)

$$
S_{e}(\theta)=\left[1+(\alpha h)^{n}\right]^{-m}
$$

the van Genuchten-Mualem relation for the relative conductivity $k_{r}(\theta)$ (Mualem 1976)

$$
k_{r}(\theta)=S_{e}^{l}\left[1-\left(1-S_{e}^{\frac{1}{m}}\right)^{m}\right]^{2},
$$


and the van Genuchten relation for the specific moisture capacity $C(\theta)$ (van Genuchten 1980)

$$
C(\theta)=\frac{\alpha m}{1-m}\left(\theta_{s}-\theta_{r}\right) S_{e}^{\frac{1}{m}}\left(1-S_{e}^{\frac{1}{m}}\right)^{m},
$$

where $\alpha, l, m$ and $n$ are fitting parameters in the empirical relations for fitting experimental data for unsaturated sediments.

Wang et al. (2019) assumed a constant Skempton coefficient in the unsaturated zone because there is no experimental data for the dependence of $B$ on $\theta$. Furthermore, the change of pore pressure occurs mostly in the saturated zone that is also volumetrically larger than the unsaturated zone; thus, the change of $B$ with $\theta$ in the unsaturated zone should have a minimal effect on the tidal response of the water level. Because the system of equations is nonlinear and difficult to solve with analytical methods, a finite element numerical procedure is used. Figure 5.24 shows the simulated hydraulic head at different depths in response to the $\mathrm{M}_{2}$ tide, with an average water table depth at $0.5 \mathrm{~m}$.

Figure 5.25 shows the amplitude ratio and phase shift to the $\mathrm{M}_{2}$ tide for (a) a silt aquifer and (b) a sand aquifer, with the average water table set at different depths, plotted against the dimensionless depth $z / \delta$, where $\delta=\sqrt{2 D / \omega}, D$ is the hydraulic diffusivity and $\omega$ is the angular frequency of the $\mathbf{M}_{2}$ tide. The difference in the tidal

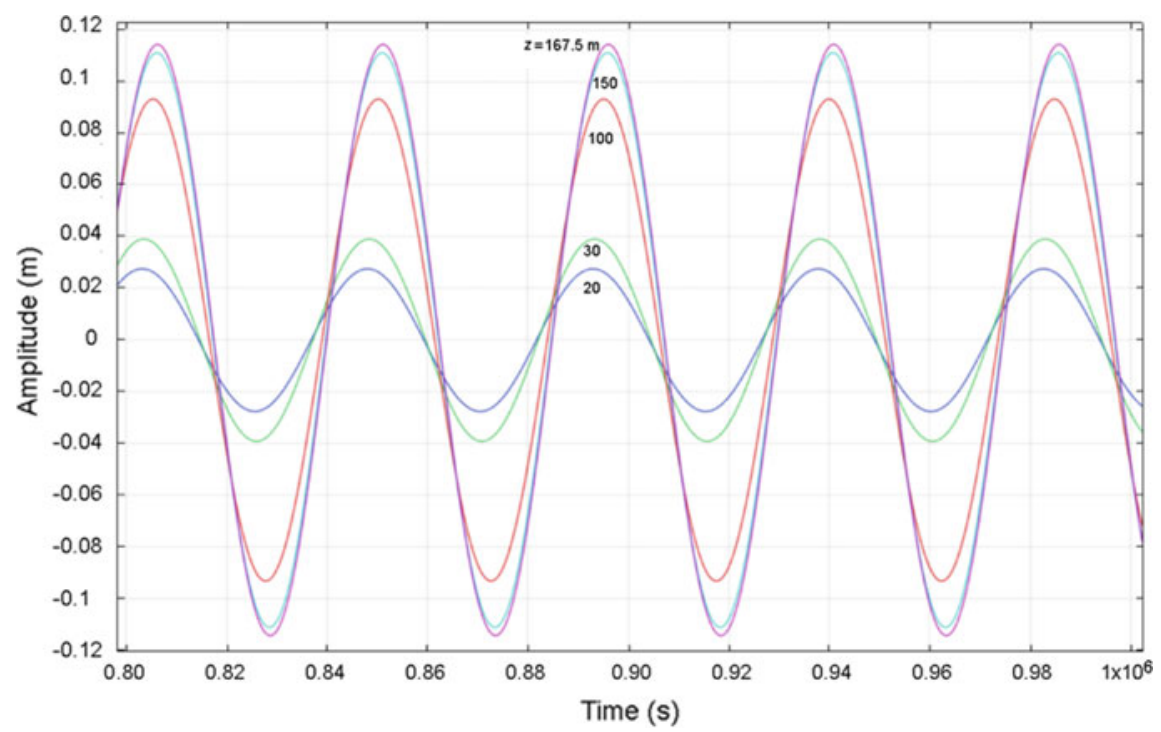

Fig. 5.24 Simulated water level oscillations in a silt aquifer in response to the $\mathrm{M}_{2}$ tide when the average water table depth is $0.5 \mathrm{~m}$. Numbers on the curves mark the depth of the screened interval of the well (from Wang et al. 2019) 
(a) Silt
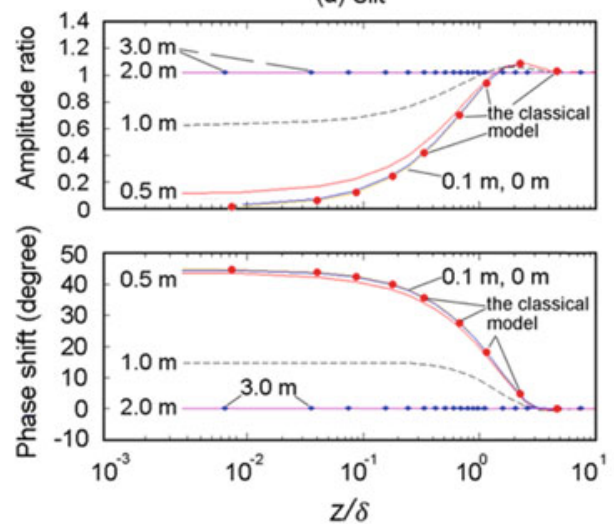

(b) Sand

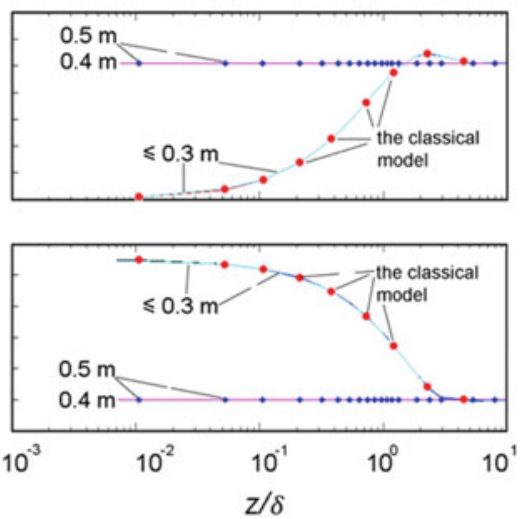

Fig. 5.25 Simulated amplitude ratio and phase shift of the tidal response of pressure head in unconfined aquifers composed of $\mathbf{a}$ silt and $\mathbf{b}$ sand, plotted against the normalized depth of the water table $z / \delta$ (see text for definition of $\delta$ ). Numbers next to each curve show the average watertable depth in the simulation. Red solid circles denote the predicted response for the traditional model of unconfined aquifers (from Wang et al. 2019)

response between a silt aquifer and a sand aquifer may be explained by the different thickness of their capillary fringes (where $k_{r}$ decreases from 1 to $\sim 0$ ) together with their different conductivities, as explained earlier. Figure 5.26 shows the significant difference between the capillary fringe in a silt aquifer and that in a sand aquifer. Furthermore, the high conductivity and thin capillary fringe would lower the effect of the capillary fringe in a sand aquifer on its tidal response (Barry et al. 1996), as discussed earlier.

Based on the capillary model for an unconfined aquifer, Wang et al. (2019) simulated the tidal response with the seasonal change of water level documented in the Lijiang well that opens to a fine-grained carbonate aquifer (Liao and Wang 2018). Results of their simulation (stars in Fig. 5.27) show excellent agreement with observation (dots in Fig. 5.27). Thus, the seasonal change of the tidal response of water level in this well may simply be due to the capillary zone above the water table and its seasonal removal when the water table rises to the surface during rainy seasons. More studies of the capillary effect on the tidal response of groundwater are definitely needed to further demonstrate this effect. 

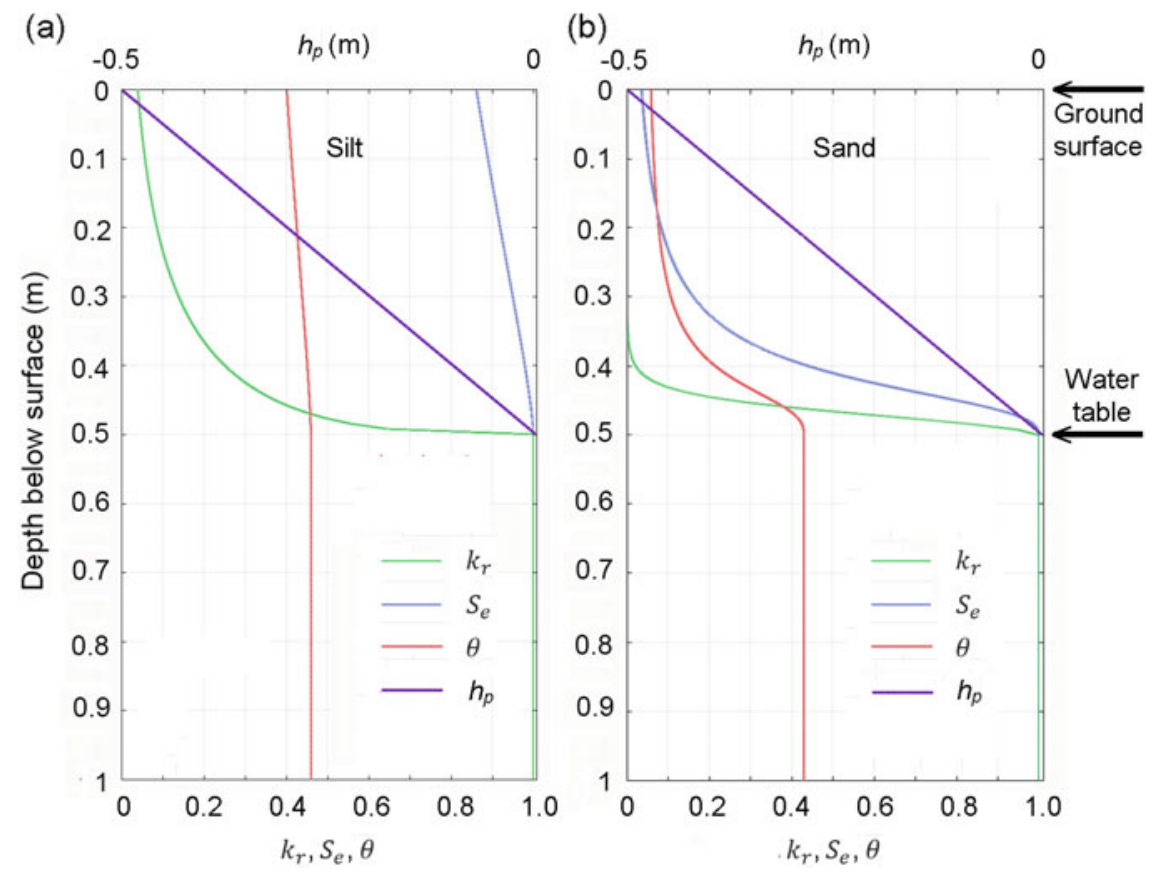

Fig. 5.26 Relative hydraulic conductivity, relative saturation, water content and pressure head in $\mathbf{a}$ a silt aquifer and $\mathbf{b}$ a sand aquifer above and below the water table, with the average water table depth set at $0.5 \mathrm{~m}$ (based on van Gnuechten 1980)

\subsection{Groundwater Response to Barometric Changes}

\subsubsection{Barometric Response of Aquifers and Barometric Efficency}

The barometric pressure on Earth's surface is due to the weight of the atmosphere per unit area. This load is balanced both by the stresses in the solid matrix and by the pressure in the pore water. A change in the barometric pressure causes changes in both the stress in the solid matrix and the pressure in the pore fluid. Thus, in response to an increase of the barometric pressure, the increase of water pressure inside an open well that penetrates a confined aquifer will be greater than the increase of pore pressure in the surrounding formations and will thus force the well water to flow into the aquifer until an equilibrium is reached between the water pressure in the well and the pore pressure in the aquifer. The response of water level in an open well (Fig. 5.28) is thus opposite in sign from that of the barometric change, i.e., water level decreases with increases in the barometric pressure, and vice versa (Fig. 5.29). Jacob (1940) 
(a)
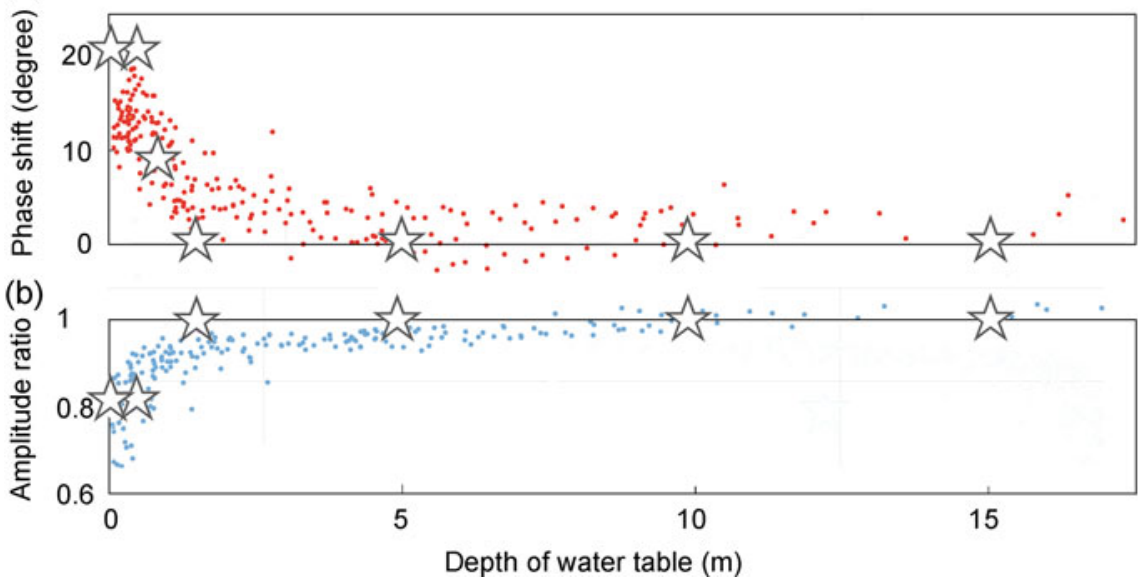

Fig. 5.27 Observed a phase shift (red dots) and $\mathbf{b}$ amplitude ratio (blue dots) of the tidal response to the $\mathrm{M}_{2}$ tide in the Lijiang well plotted against the water table depth (from Liao and Wang 2018). Simulated phase shift and amplitude ratio with the hydraulic parameters listed in the last column of Table 4.3 are plotted as stars. Notice that the phase shift is close to 0 and the amplitude ratio close to 1 when the water level depth is more than $2 \mathrm{~m}$, but phase shift increases while amplitude ratio decreases when the water table becomes shallower than $2 \mathrm{~m}$ below the ground surface (from Wang et al. 2019)

defined the ratio between the water level change in the well and the barometric change (expressed in water height) as the barometric efficiency, BE (Sect. 3.2.5; Eq. 3.87), with typical values between 0.25 and 0.75 (Bear 1972) which is a measure of the aquifer compressibility. The time-delay between the water-level response and the barometric change, as discussed in a later subsection, contains information about the diffusivity of both the aquifer and the aquitard (the semi-confining layer).

Quantitative analysis of the barometric response began with Jacob (1940) and has since been broadly applied to estimate the hydraulic properties of aquifers and aquitards (e.g., Rojstaczer 1988; Evans et al. 1991; Odling et al. 2015). It has also been used to study earthquake effects on groundwater systems (Zhang-Shi et al. 2019a, Zhang-Wang et al. 2019).

\subsubsection{Analytical Solution with a Half-Space Aquitard}

If the aquifer is perfectly confined and has high lateral transmissivity, the response of water level in a well to a change of barometric pressure is nearly instntaneous and linearly proportional to the barometric change. However, most aquifers are not perfectly confined and a confining layer may allow flow across its boundaries. Under such conditions, the barometric efficiency would depend on the frequency of the applied load, and is denoted by $\mathrm{BE}(\omega)$. Analysis of this dependency may reveal how 

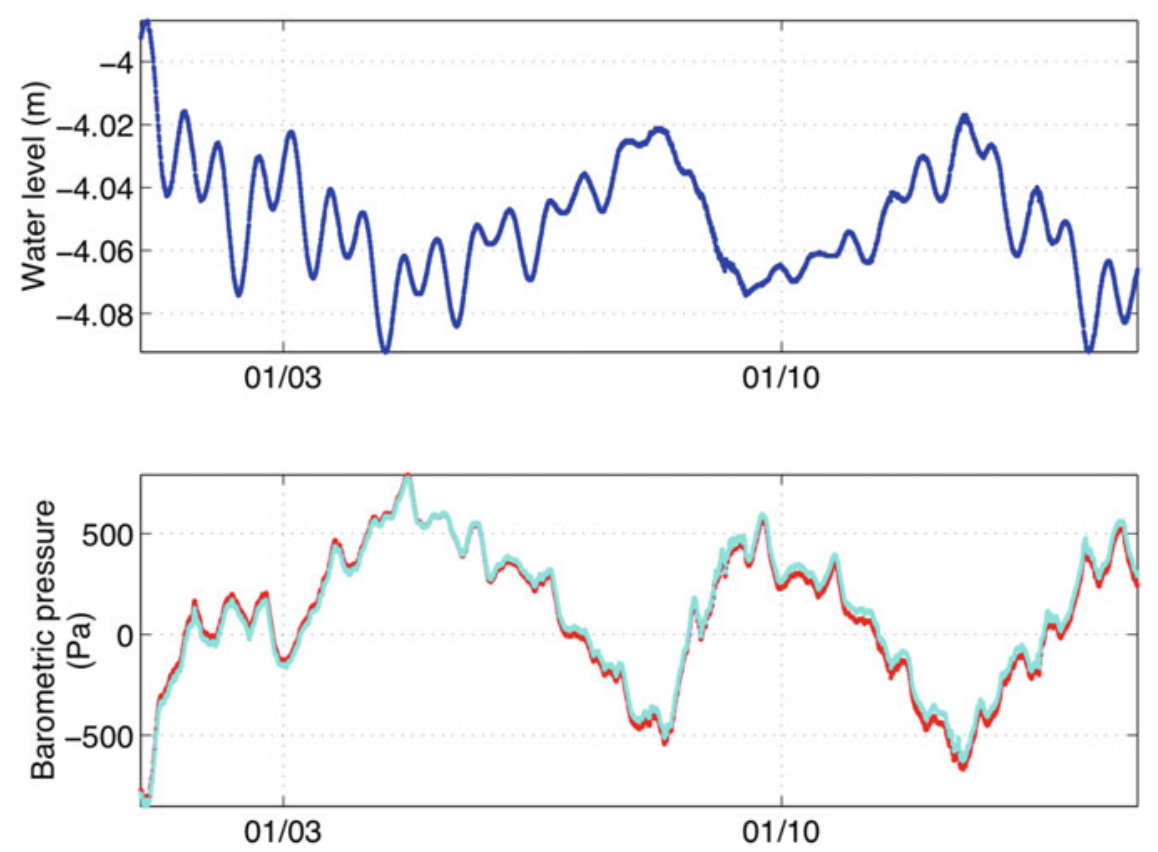

Fig. 5.28 Water level recorded in well CIB of the Pinon Flat Observatory and barometric pressure on site during the first 15 days of 1999 (modified from Doan et al. 2006)

the vertical hydraulic conductivity of the aquitard and the horizontal transmissivity of the aquifer depend on frequency and has been the subject of discussion in several papers (e.g., Rojstaczer 1988; Hussein et al. 2013; Odling et al. 2015). In the following we first review the analytical model of Rojstaczer (1988), which is often cited in barometric studies. We will then review an improved model and some numerical analyses by Olding et al. (2015). These models allow estimates of the pneumatic diffusivity of the unsaturated zone, the vertical hydraulic diffusivity of the semiconfining layer, and the lateral permeability of the aquifer, with errors due to the simplifications of the models. Comparison among the models will be made to provide some understanding of the probable errors in these estimates.

Rojstaczer (1988) derived an analytical model for interpreting the response of a semi-confined aquifer to changes of the barometric pressure. To simplify the analysis, he assumed that the barometric response may be treated by three individual but connected one-dimensional problems - a vertical pneumatic flow in the unsaturated zone of the aquitard (between the surface and the water table), a vertical groundwater flow in the saturated zone of the aquitard (between the water table and the base of the aquitard), and a radial flow between the aquifer and the well, connected by conditions of continuity across their boundaries, as described next (Rojstaczer 1988).

The amplitude of the change in water level in a well is affected by the atmospheric load, the far field pore pressure (in terms of the equivalent water level), and the 


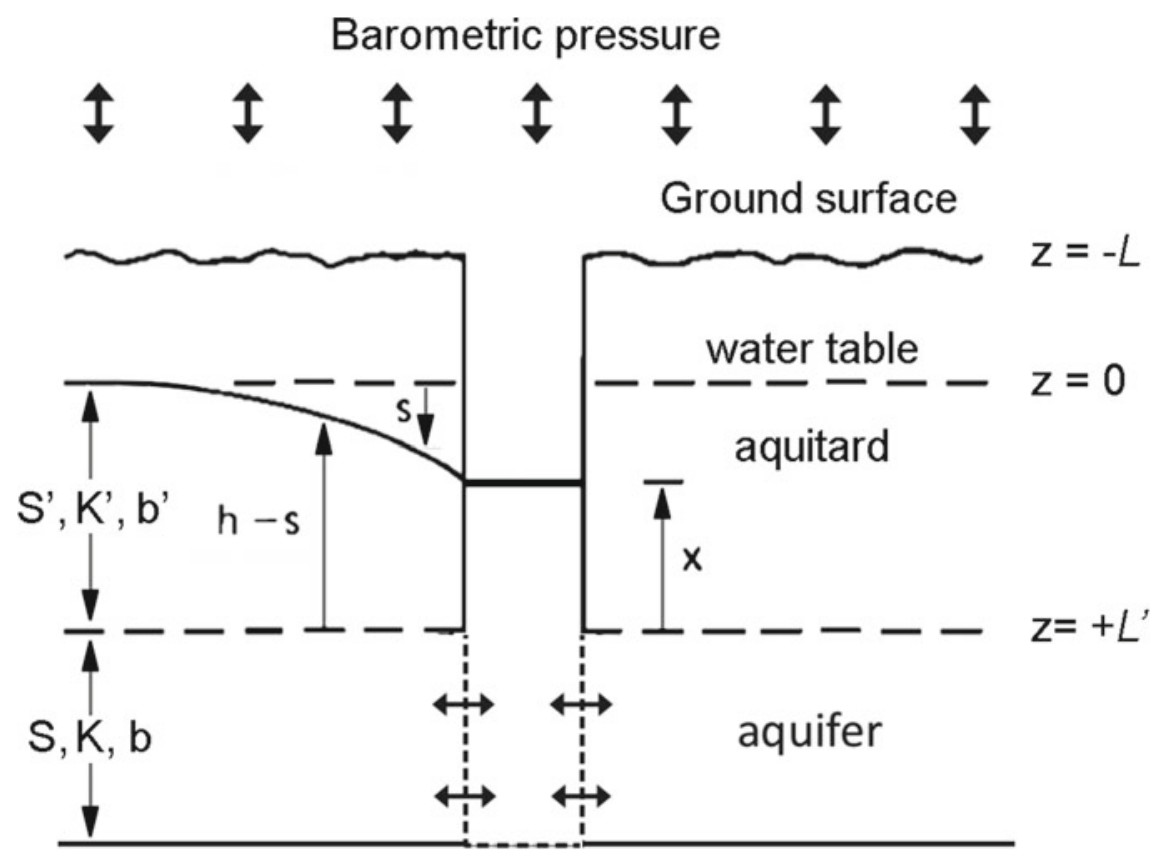

Fig. 5.29 Schematic diagram showing an aquifer and a semi-confining layer (aquitard), borehole and groundwater flow in response to changing baromatric pressure (modified from Odling et al. 2015)

drawdown at the well. Thus the response of the water level in wells may be described in the frequency domain as

$$
x_{o}=-\frac{A}{\rho g}+\frac{P_{o}}{\rho g}-s_{o},
$$

where $A$ is the amplitude of the atmospheric load, $P_{o}$ is the amplitude of the far field pore pressure in the aquifer, and $s_{o}$ is the amplitude of the drawdown at the well. The periodic flow of air in the unsaturated aquitard between the surface and the water table is governed by the differential equation

$$
D_{a} \frac{\partial^{2} P_{a}}{\partial z^{2}}=\frac{\partial P_{a}}{\partial t}
$$

where the the barometric pressure $P_{a}$ is subjected to the following boundary condition

$$
P_{a}( \pm L, t)=A \cos (\omega t) .
$$

$\mathrm{z}=-L$ is taken to be the Earth's surface above the groundwater table $(z=0), A$ is the amplitude of the barometric oscillations at the surface, $D_{a}$ is the pneumatic 
diffusivity in the unsaturated layer, assumed constant, and the condition at $\mathrm{z}=L$ is a design to ensure no flow of air across the groundwater table. The solution for air-pressure at the water table $(z=0)$ is (Rojstaczer 1988)

$$
P_{a}=A(M+i N) \exp (i \omega t)
$$

where

$$
\begin{aligned}
& M=\frac{2 \cosh \left(\sqrt{R_{a}}\right) \cos \left(\sqrt{R_{a}}\right)}{\cosh \left(2 \sqrt{R_{a}}\right)+\cos \left(2 \sqrt{R_{a}}\right)} \\
& N=\frac{2 \sinh \left(\sqrt{R_{a}}\right) \sin \left(\sqrt{R_{a}}\right)}{\cosh \left(2 \sqrt{R_{a}}\right)+\cos \left(2 \sqrt{R_{a}}\right)}
\end{aligned}
$$

and

$$
R_{a}=L^{2} \omega / 2 D_{a}
$$

For the vertical groundwater flow in the saturated aquitard, the controlling differential equation is

$$
D^{\prime} \frac{\partial^{2} P}{\partial z^{2}}=\frac{\partial P}{\partial t}+A \omega \gamma \sin \omega t
$$

where $P$ is the excess pore pressure in the saturated aquitard (above hydrostatic pressure), $D^{\prime}$ is the hydraulic diffusivity of the aquitard, and $\gamma$ is the loading efficiency defined as $1-\mathrm{BE}$. The upper boundary condition is equal to the barometric pressure at the water table (5.56), i.e.,

$$
P(0, t)=P_{a}=A(M+i N) \exp (i \omega t)
$$

Rojstaczer (1988) simplified the problem by assuming that the vertical flow occurs in a half space so that the lower boundary condition becomes

$$
P(\infty, t)=A \gamma \exp (i \omega t)
$$

Under these boundary conditions, the solution of (5.60) at the base of the aquitard $\left(z=L^{\prime}\right)$ is

$$
P\left(z=L^{\prime}, t\right)=A\left[\gamma+(M+i N-\gamma) \exp \left(-(1+i) \sqrt{R^{\prime}}\right)\right] \exp (i \omega t)
$$

where

$$
R^{\prime}=L^{\prime 2} \omega / 2 D^{\prime}
$$


Finally, assuming that the aquifer has negligible loading efficiency, i.e., $\gamma \sim 0$, and that the aquitard has negligible storage, we may express the controlling differential equation for the radial flow between the borehole and the aquifer with a semi-confining aquitard as (Hantush and Jacob 1955)

$$
T\left(\frac{\partial^{2} s}{\partial r^{2}}+\frac{1}{r} \frac{\partial s}{\partial r}\right)-\frac{K^{\prime} s}{L^{\prime}}=S \frac{\partial s}{\partial t},
$$

where the small letter $s$ is the draw down near the well, $T$ and the capital letter $S$ are the transmissivity and storativity of the aquifer, respectively, and $K^{\prime}$ and $L^{\prime}$ are the hydraulic conductivity and the thickness of the semi-confining aquitard, respectively.

The boundary conditions are

$$
s(\infty, t)=0, \text { at } r \rightarrow \infty,
$$

and

$$
\lim _{r \rightarrow 0} \frac{T \partial s}{\partial r}=\frac{\omega r_{w}^{2} x_{o}}{2 r_{c} T} \sin \omega t
$$

where $r_{w}$ is the radius of the cased section of the well where water level is measured, $r_{c}$ is the radius of the screen section of the well, and $x_{o}$ is the amplitude of the water level fluctuation in the well casing produced by the volumetric discharge of the aquifer. Subjected to these conditions, (5.65) may be solved to yield the drawdown in the well (Rojstaczer 1988)

$$
s_{w}=\frac{i}{2} W x_{o} K_{o}\left\{\left[W^{2}\left(S^{2}+q^{-2}\right)\right]^{1 / 4} \exp \left[\frac{i}{2} \tan ^{-1}(q S)\right]\right\} \exp (i \omega t)
$$

where $K_{o}$ is the modified Bessel function of the second kind of order zero, $W$ is a dimensionless frequency defined as

$$
W=\omega r_{w}^{2} / T,
$$

and

$$
q=L^{\prime} \omega / K^{\prime} .
$$

The barometric efficiency and the phase shift of the response are then expressed by

$$
\mathrm{BE}(\omega)=\left|x_{o} \rho g / A\right|,
$$

and 

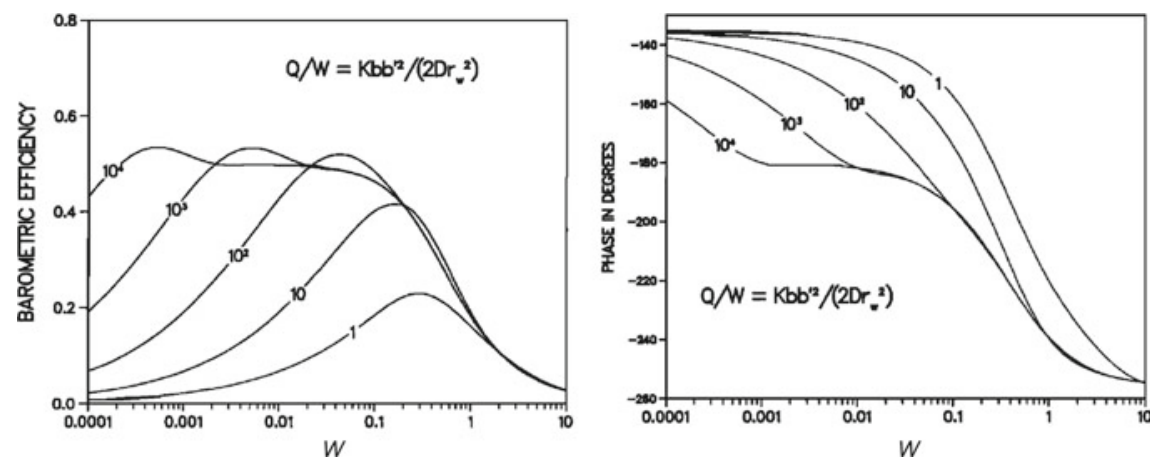

Fig. 5.30 Modeled barometric efficiency (left) and phase (right) of the response of a well to barometric pressure as a function of the dimensionless frequency $W$. Assumed values are $S=$ $S^{\prime}=10^{-4}$ and $\mathrm{BE}=0.5$. Numbers on the curves represent the value of $K b b^{, 2} /\left(2 D r^{2}\right)$, another dimensionless quantity (Rojstaczer 1988)

$$
\eta(\omega)=\arg \left(x_{o} \rho g / A\right)
$$

where $x_{o}$ is evaluated with (5.53), $P_{o}$ from $P\left(z=L^{\prime}\right) \exp (-i \omega t)$ (5.63) and $s_{o}$ from $s_{w} \exp (-i \omega t)$ (5.68). Rojstaczer (1988) evaluated and plotted the barometric efficiency and the phase shift as a function of the diemnsionless frequency $W$ (Fig. 5.30).

\subsubsection{Analytical Solution with a Finite Aquitard}

The model of Rojstaczer (1988) simplifies the solution with that for a half-space aquitard. Odling et al. (2015) presented the solution with an aquitard of finite thickness, which we present in Appendix 5.3. This solution is analogous to that for heat conduction in a solid of two layers with different thermal conductivities, subjected to a periodic surface condition (Carslaw and Jaeger 1959, 3.7). The solution for the pressure at the base of the aquitard (Appendix 5.3) is

$$
P\left(z=L^{\prime}, t\right)=A\left[\gamma+(M+i N-\gamma)\left(E^{\prime}-F^{\prime} \frac{G E^{\prime}+H G^{\prime}}{G F^{\prime}+H H^{\prime}}\right)\right] \exp (i \omega t)
$$

where $M$ and $N$ are defined in (5.57-5.58), and

$$
E^{\prime}=\cosh \left[(1+i) \sqrt{R^{\prime}}\right],
$$




$$
\begin{gathered}
F^{\prime}=\frac{L^{\prime}}{K^{\prime}} \frac{\sinh \left[(1+i) \sqrt{R^{\prime}}\right]}{\left[(1+i) \sqrt{R^{\prime}}\right]}, \\
G^{\prime}=-\frac{K^{\prime}}{L^{\prime}}\left[(1+i) \sqrt{R^{\prime}}\right] \sinh \left[(1+i) \sqrt{R^{\prime}}\right], \\
H^{\prime}=E^{\prime},
\end{gathered}
$$

$L^{\prime}, K^{\prime}$ and $D^{\prime}$ are, respectively, the thickness, hydraulic conductivity and diffusivity of the saturated aquitard. The parameters $E, F, G$ and $H$ for the aquifer are defined similarly but with $L^{\prime}, K^{\prime}, D^{\prime}$ and $R^{\prime}$ replaced by $L, K, D$ and $R$, respectively, and $R$ is given by

$$
R=L^{2} \omega / 2 D
$$

Here we replaced $A, B, C$, and $D$ in Carslaw and Jaeger with $E, F, G$, and $H$ in order to avoid the possible confusion with the parameters $A$ and $D$ defined earlier. We also follow the earlier use of parameters with a prime for the aquitard parameters and those without a prime for the aquifer parameters.

Since the aquifer in the model is one-dimensional and horizontal (5.65), the pressure at the base of the aquitard (5.72) is identical to that in the aquifer. Thus $P_{o}$ in (5.53) is given by

$$
P_{o}=\frac{P\left(z=L^{\prime}, t\right)}{\exp (i \omega t)}=A\left[\gamma+(M+i N-\gamma)\left(E^{\prime}-F^{\prime} \frac{G E^{\prime}+H G^{\prime}}{G F^{\prime}+H H^{\prime}}\right)\right]
$$

The predicted results of the two analytical models, i.e., that for a half-space aquitard (Rojstaczer 1988) and that for a finite aquitard (Odling et al. 2015), based upon identical prarameters (Odling et al. 2015, Table 1), are plotted and compared in Fig. 5.31. It shows that, at low frequencies $(<0.1 \mathrm{cpd})$, the half-space model predicts a phase shift tens of degrees smaller than that predicted by the finite-aquitard model.

\subsubsection{Numerical Solution}

Odling et al. (2015) carried out a suite of numerical simulations of the barometric effect on water level in wells using the software MODFLOW 2000. The model consists of an aquitard of $20 \mathrm{~m}$ in thickness with hydraulic conductivity and specific storage typical of glacial sediments overlying an aquifer of $10 \mathrm{~m}$ in thickness with hydraulic conductivity and specific storage typical of fractured chalk (Table 5.4). Odling et al. (2015) assumed that the unsaturated zone of the aquitard has a minor influence on the barometric response of the aquifer and excluded it in the numerical 

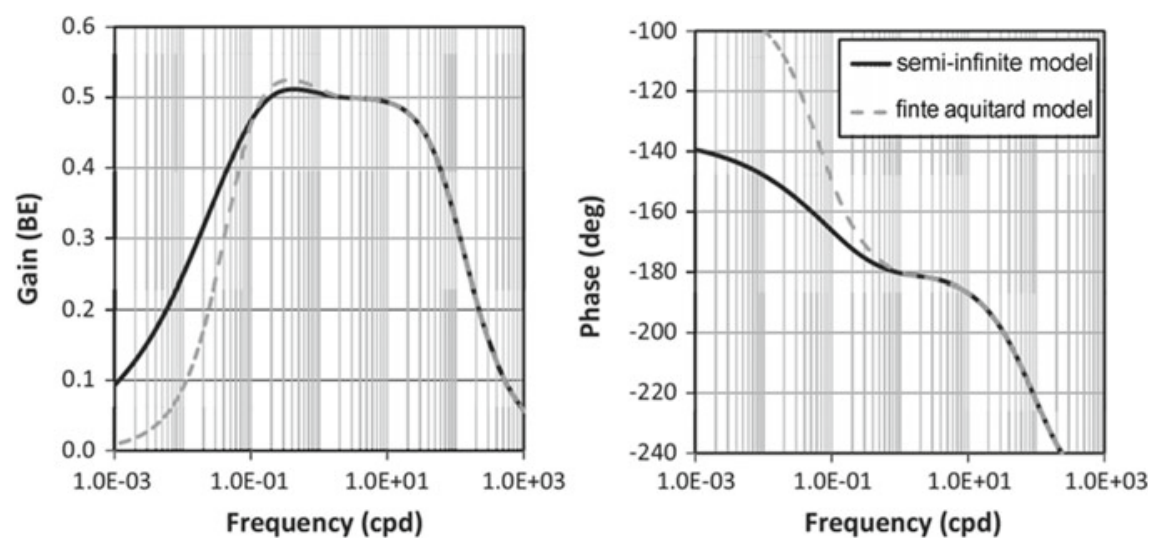

Fig. 5.31 Comparison between the half-space model of (Rojstaczer, 1988) (solid black curve) with the finite-aquitard model (dashed grey curve) (from Odling et al. 2015)

Table 5.4 Layer properties assumed in the numerical simulations

\begin{tabular}{l|l|l|l}
\hline Material & $K(\mathrm{~m} / \mathrm{d})$ & $S_{S}\left(\mathrm{~m}^{-1}\right)$ & $D\left(\mathrm{~m}^{2} / \mathrm{d}\right)$ \\
\hline Confining layer A & $1.57 \times 10^{-3}$ & $1.57 \times 10^{-3}$ & 1 \\
\hline Confining layer B & $9.53 \times 10^{-3}$ & $9.53 \times 10^{-4}$ & 10 \\
\hline Confining layer C & $3.35 \times 10^{-2}$ & $6.71 \times 10^{-4}$ & 50 \\
\hline Aquifer & 1 & $2.76 \times 10^{-6}$ & $3.6 \times 10^{5}$ \\
\hline Heterogeneity & 1 & $1.0 \times 10^{-4}$ & $1.0 \times 10^{4}$
\end{tabular}

simulation. The radius of the boreholes in the numerical simulations is assumed to be infinitely small, i.e., the influence on the barometric response of a finite borehole radius is not modeled, which affects the responses only at relatively high frequencies (Hussein et al. 2013). Finally, the numerical model does not include the influence of the elastic properties of the solid aquifer matrix, so that changes in barometric pressure are transmitted entirely to the pore waters. Thus, the result corresponds to the case of an aquifer with static barometric efficiency (BE) equal to 1, which scales the gain of the barometric response by a factor of $\mathrm{BE}$ but leaves the phase unaffected (Odling et al. 2015).

Figure 5.32 compares the numerical results with that predicted by the finiteaquitard model. The results are in general agreement at aquitard hydraulic diffusivities lower than $100 \mathrm{~m}^{2} / \mathrm{d}$, with the numerical results lying slightly towards higher frequencies. With increasing diffusivity, the peak gains from the numerical results become progressively lower than those predicted by the analytical model and, at diffusivities of $10^{3}$ and $10^{4} \mathrm{~m}^{2} / \mathrm{d}$, all phases from the numerical results lie well towards lower frequencies. This comparison led Odling et al. (2015) to suggest that the finiteaquitard model may provide reasonable predictions for the barometric response if the aquitard (confining layer) hydraulic diffusivity is $100 \mathrm{~m}^{2} / \mathrm{d}$ or below. 

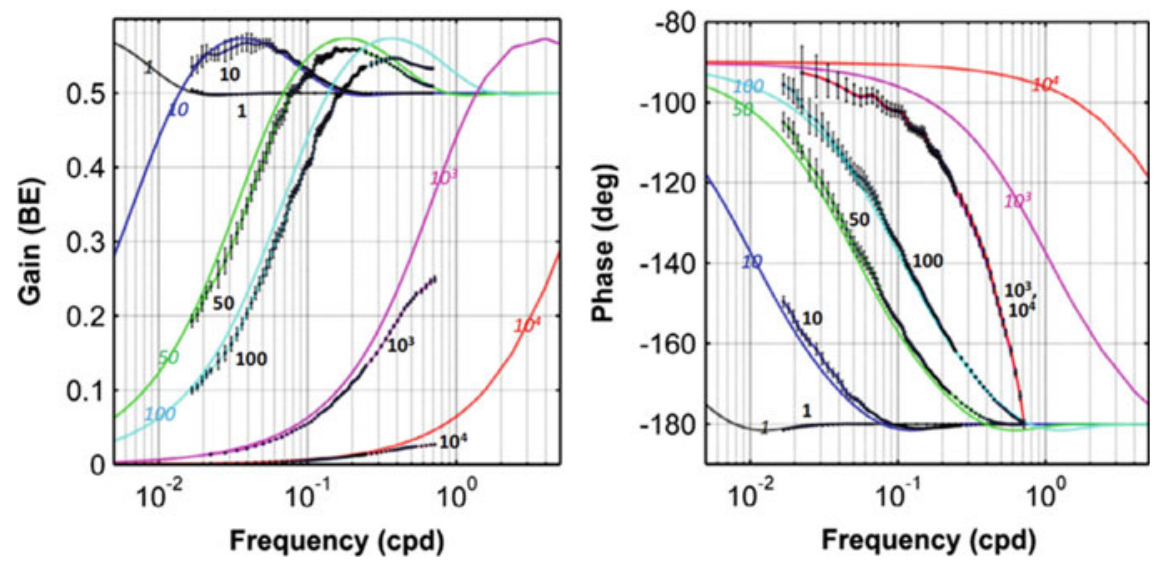

Fig. 5.32 Comparison between the finite-aquitard model (colored solid curves) and numerical simulations (black curves with one standard deviation error bars) as a function of frequency. Curves are labeled with the aquitard hydraulic diffusivity $\left(\mathrm{m}^{2} / \mathrm{d}\right)$ (from Odling et al. 2015)

\subsubsection{Applications}

Odling et al. (2015) applied the numerical simulation to examine the barometric response in three open monitoring boreholes in the semi-confined Chalk Aquifer of East Yorkshire, NE England. It is a semi-confined fractured chalk aquifer of Quaternary age, confined by an aquitard of highly heterogeneous sands, gravels, clay rich till and alluvium. The Chalk Aquifer is the UK's principal aquifer and the Yorkshire area is intensely farmed; thus the aquifer is particularly vulnerable to nitrate contamination from agricultural fertilizers. Time series of borehole water levels and barometric pressure were recorded at $15 \mathrm{~min}$ intervals over periods of 294 to 800 days, and the barometric response of the water level in the three monitoring boreholes was determined over the frequency range 0.015-2 cpd (Fig. 5.33).

The best-fit analytical barometric response curves for the Benningholme borehole yield an estimate of $B E=0.49$ and a confining layer hydraulic diffusivity of $10 \mathrm{~m}^{2} / \mathrm{d}$, typical of clay rich sediments. The estimated BE is similar to the value calculated from the known compressibility and matrix porosity for the Chalk Aquifer matrix in this region, suggesting that the analytical model may provide realistic predictions. On the other hand, the barometric response for the boreholes at Thornholme Moor and Bracey Bridge both show lower gain than that for the Benningholme borehole (Fig. 5.33). The fit of the analytical model to the barometric response for Thornholme Moor yields an estimate of hydraulic diffusivity $\left(310 \mathrm{~m}^{2} / \mathrm{d}\right)$ typical of silt-rich alluvium and $\mathrm{BE}=0.39$, the latter being lower than that estimated for the Benningholme borehole. The fit of the analytical model to the barometric response for the borehole at Bracey Bridge is much poorer and gives a very low estimate of $\mathrm{BE}(0)$ and a very high hydraulic diffusivity $\left(20,000 \mathrm{~m}^{2} / \mathrm{d}\right)$, typical of sands. Odling et al. (2015) interpret the very high value of hydraulic diffusivity and the poor fit by the analytical model 

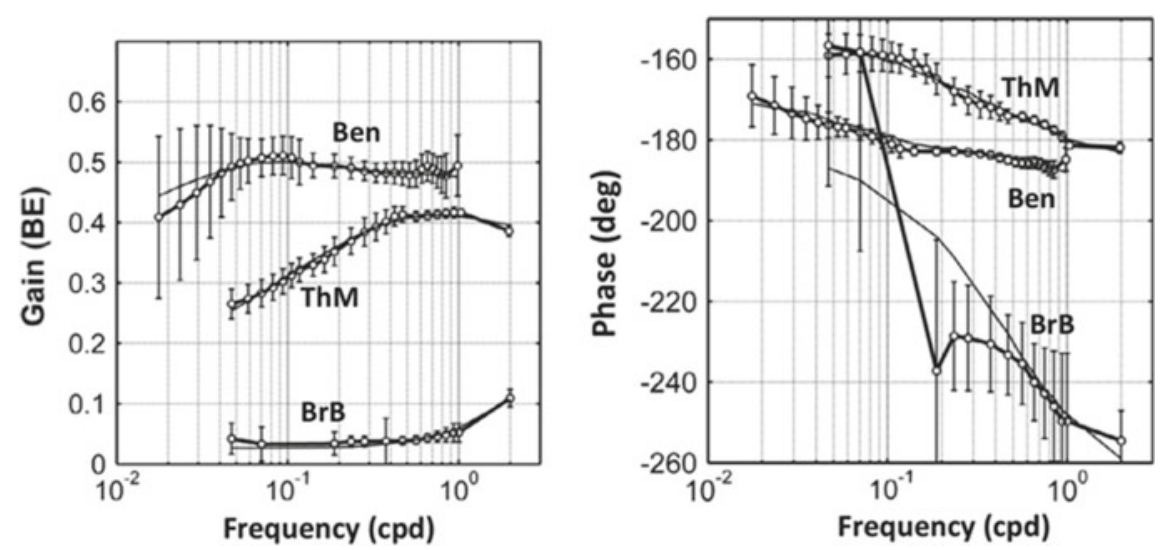

Fig. 5.33 Barometric responses estimated from water-level records in three boreholes in the Chalk Aquifer of East Yorkshire, NE England. The thick curves are the best numerical fit to the data; the thin curves are the best analytical fit to the data (from Odling et al. 2015)

as suggesting that this borehole may lie close to a fully penetrating heterogeneity with high diffusivity.

\subsection{Estimating Hydraulic Property with Tidal and Barometric Methods}

A recent development in earthquake hydrology is the joint analysis of the tidal and barometric responses of water levels in wells to understand earthquake effects on groundwater systems. Since this development is in its initial stage, a comparison between different studies may be useful to reveal the different approaches in such applications.

Two independent studies (Zhang-Shi et al. 2019; Zhang-Wang et al. 2019) analyzed the tidal and the barometric responses of water level in a deep $(2600 \mathrm{~m})$ well, Zuojiazhuang (ZJZ), in northern China (Fig. 5.34), before and after the 2011 Mw9.1 Tohoku earthquake. The well is screened between depths of 2079 and 2600 $\mathrm{m}$ and is open to an aquifer of Late-Precambrian carbonate rocks. The aquifer is overlain by an aquitard consisting of $>2 \mathrm{~km}$ of younger volcanic rocks and breccia, tuff, sandstone and mudstone.

Zhang-Wang et al. (2019) analyzed the tidal response of water level in the well and calculated the barometric efficiency and the phase shift of the water-level response to barometric pressure before and after the 2011 Tohoku earthquake. Figure 5.35 shows that the earthquake caused significant changes in the tidal response by increasing the phase shift from $-40^{\circ}$ to $\sim 0^{\circ}$ and the amplitude ratio from $\sim 0.7$ to 1 . Moreover, these changes stayed nearly constant from 2011 to 2015 until the well was refurbished. 

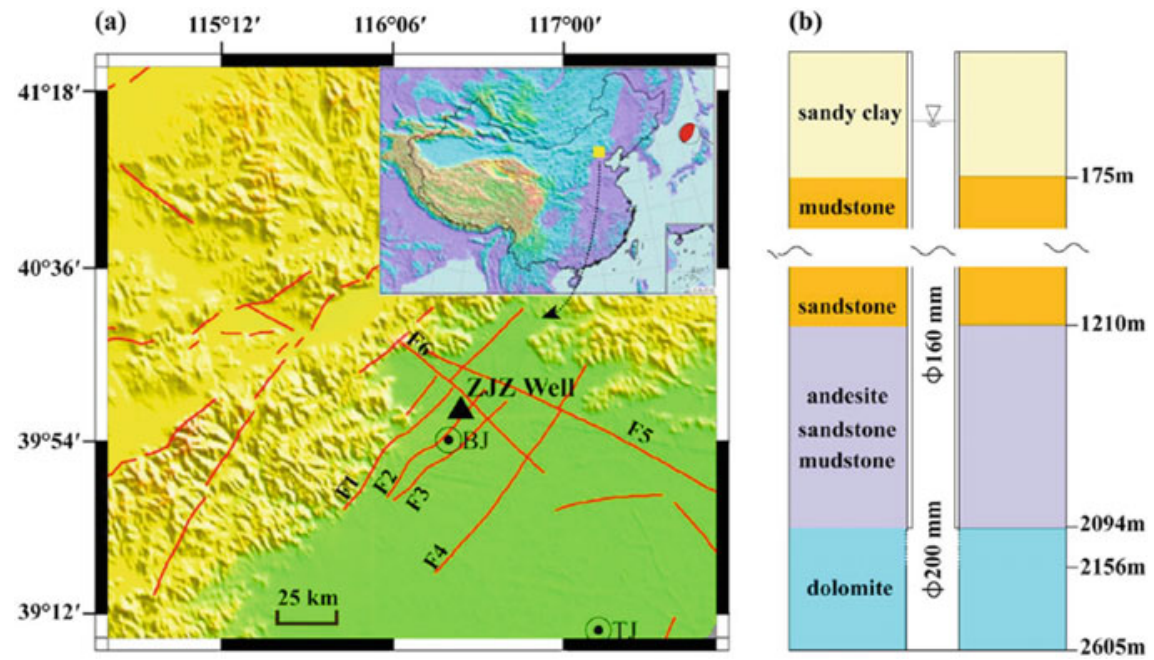

Fig. 5.34 a Location of the Zuojiazhuang Well and the epicenter of the 2011 Tohoku earthquake. b Simplified lithological profile of the borehole. (F1 is the Huangzhuang-Gaoliying fault, F2 is the Shunyi-Qianmen-Liangxiang fault, F3 is the Nanyuan-Tongxian fault, F4 is the Xiandian fault, F5 is the Changping-Fengnan fault, and F6 is the Nankou-Sunhe fault) (from Zhang-Shi et al. 2019)

Some post-seismic phase shifts are slightly above zero, but it is difficult to ascertain their physical significance because the analysis used the theoretical tidal strain as the reference, which may differ appreciably from the actual local strain due to the effects of local topography and subsurface heterogeneities (e.g., Beaumont and Berger 1975).

Zhang-Wang et al. (2019) noted two possible interpretations of the coseismic change of the tidal response; it could either be due to a coseismic increase of the horizontal transmissivity above $10^{-4} \mathrm{~m}^{2} / \mathrm{s}$ or due to an increase of the vertical diffusivity of $\lesssim 0.03 \mathrm{~m}^{2} / \mathrm{s}$. In order to assess which interpretation is correct, they evaluated the barometric efficiency and the phase shift of the water-level response. At frequencies up to $0.8 \mathrm{cpd}$, the barometric efficiency (Fig. 5.36a) and phase shift (Fig. 5.36b) were nearly constant at 0.6 and 0 , respectively, before and after the Tohoku earthquake. At higher frequencies, the results are no longer relaible because the coherence between the two timeseries deteriorated. Zhang-Wang et al. (2019) suggested that these results are evidence that the aquifer was confined both before and after the Tohoku earthquake and thus preferred the interpretation that the coseismic increase of phase shift was due to a large increase in the horizontal permeability during the Tohoku earthquake, rather than due to an increase of the vertical permeability. Using a confined aquifer model (Hsieh et al. 1987) they interpreted the observed tidal response of water level in the ZJZ well to be due to an order of magnitude coseismic increase in the horizontal permeability and a small decrease of the specific storage.

Zhang-Shi et al. (2019) analyzed the tidal response in the same Zuojiazhuang well and also found a coseismic increase of the phase shift of the water level to the $\mathrm{M}_{2}$ 


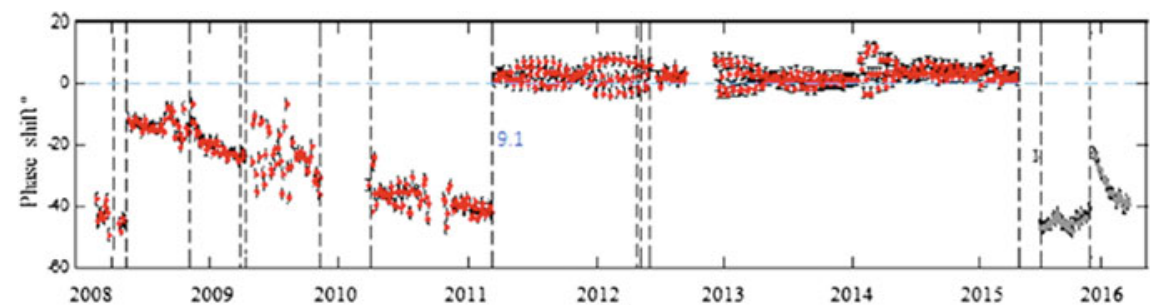

(a)

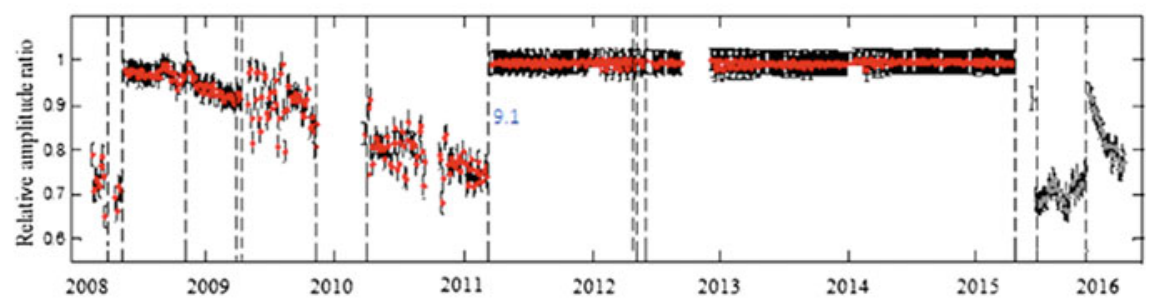

(b)

Fig. 5.35 Phase shift and amplitude ratio of the tidal response to the M2 tide in the ZJZ well. Notice that the amplitude stayed nearly constant following the $2011 \mathrm{Mw} 9.1$ Tohoku earthquake. The discontinuities in the times series in year 2015 were due to well cleaning and renovation; later data were not included in the analysis (from Zhang-Wang et al. 2019)

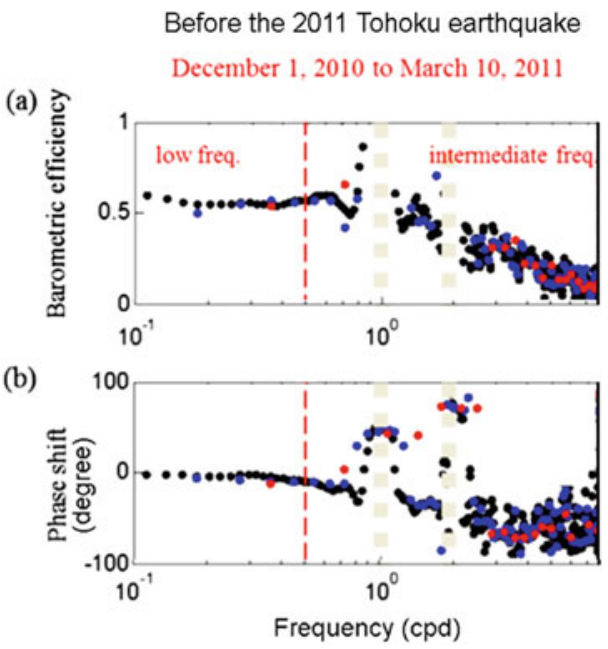

\section{After the 2011 Tohoku earthquake \\ January 1, 2013 to April 11, 2013}
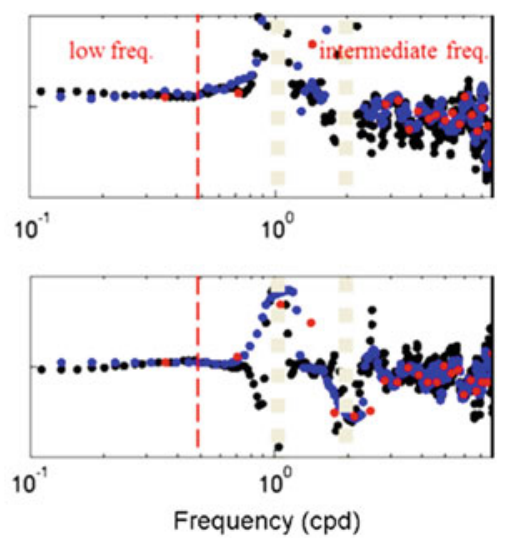

Fig. 5.36 a Barometric efficiency and $\mathbf{b}$ phase shift before (left) and after (right) the Tohoku earthquake, plotted against frequency between 0.1 to $8 \mathrm{cpd}$ in the $\mathrm{ZJZ}$ well. Negative phase shifts indicate that the water-level response lags behind the change of atmospheric pressure. The water level data and the atmospheric pressure data were split into spans of $2 \mathrm{~N}$ samples with $\mathrm{N}=16$ (black dots), 14 (blue dots) and 12 (red dots) (modified from Zhang-Wang et al. 2019) 
tide during the Tohoku earthquake, from a pre-seismic $-40^{\circ}$ to a post-seismic $\sim 2^{\circ}$. They calculated the wavelet power spectra (WPS) for the barometric pressure and water level and the wavelet coherences (WTC) among water level, tidal volumetric strain and the barometric pressure (Fig. 5.37). They showed that the water-level WPS was enhanced after the Tohoku earthquake and the WTC between water level and the barometric pressure expanded in scope.

Zhang-Shi et al. (2019) used data 4 months before and 1 year after the 2011 Tohoku earthquake to calculate the barometric response transfer function. The barometric response, shown as circles with normalized standard errors in Fig. 5.38, shows a nearly constant gain of 0.55 before and after the earthquake over the observed frequency band (Fig. 5.38a) and a phase shift slightly less than $-180^{\circ}$ before the earthquake but slightly greater than $-180^{\circ}$ after the earthquake and (Fig. 5.38b). Fitting the data with Rojstaczer's (1988) barometric response model (5.71) they obtained the best fitting curves before and after the earthquake and estimated a sixfold increase in the horizontal permeability and a two-fold increase in the vertical

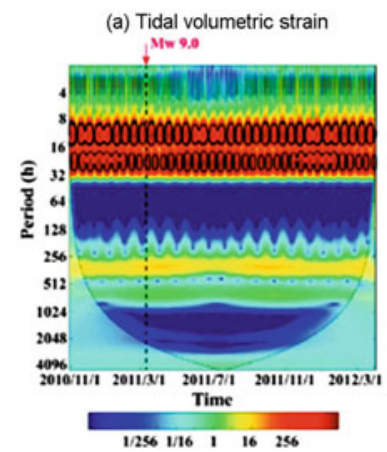

(d) Coherence between (a) and (c)

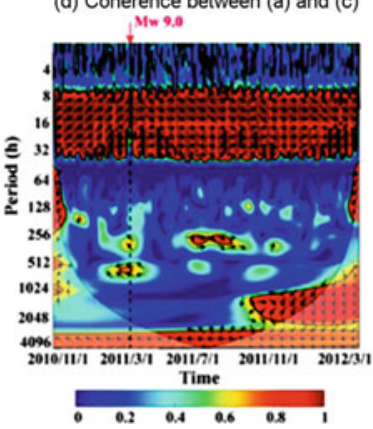

(b) Barometric pressure Mw 9.0

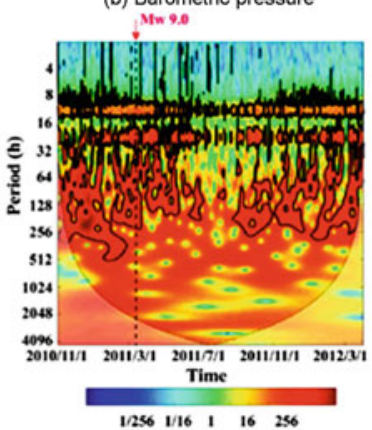

(e) Coherence between (b) and (c) Mw 9.0

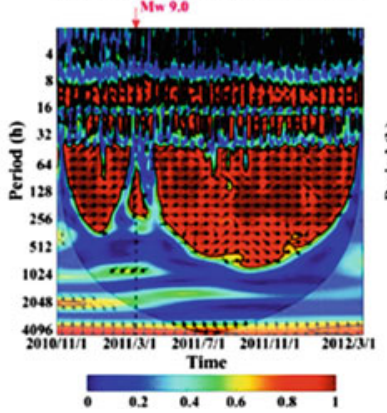

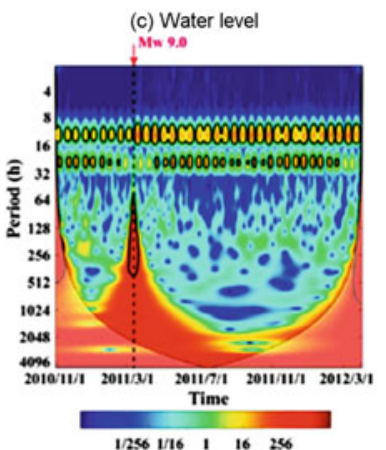

(f) Coherence between (a) and (b) $\mathrm{Mw} 9.0$

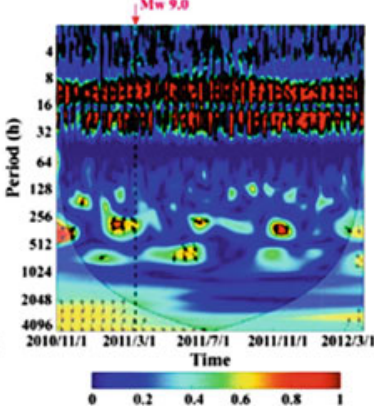

Fig. 5.37 a, b, c, respectively, wavelet power spectra of the tidal volumetric strain, the barometric pressure, and the water level. $\mathbf{d}, \mathbf{e}, \mathbf{f}$, respectively, wavelet coherence between water level and tidal volumetric strain, between water 1 evel and barometric pressure, and between barometric pressure and tidal volumetric strain. The arrows indicate the relative phase relationship: in-phase pointing right, antiphase pointing left, and phase-leading by $90^{\circ}$ pointing straight down (from Zhang-Shi-Shi et al. 2019) 
Fig. 5.38 Barometric response function together with the Rojstaczer (1988) model before and after the earthquake. a Gain response, and $\mathbf{b}$ phase response (from Zhang-Shi et al. 2019)

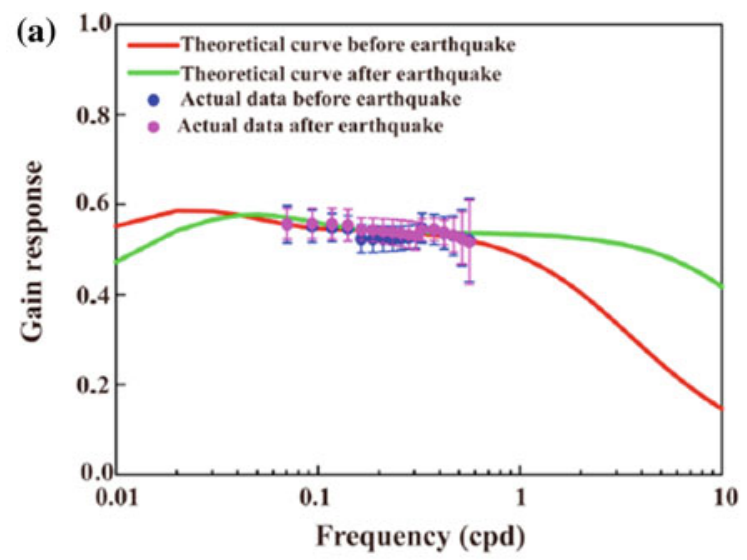

(b)

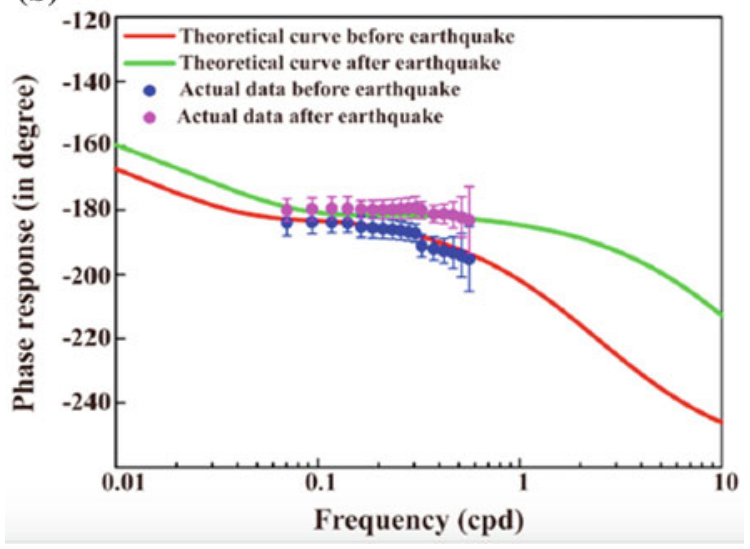

permeability. Finally, they confirm their results for the post-seismic increase of the vertical permeability with a model of the tidal response of a leaky aquifer (Wang et al. 2018), given the aquifer transmissivity and storativity estimated from the barometric response before and after the earthquake.

It is reassuring that the two independent analyses of the tidal and barometric data from the same well have yielded nearly identical responses. The different interpretations between these studies clearly show that despite nearly identical responses there is much room for different interpretations. While Zhang-Wang et al. (2019) interpreted the small post-seismic positive phase shift as the uncertainties introduced in using the theoretical tides in the analysis, Zhang-Shi et al. (2019) interpreted the same positive phase shift as an indication of post-seismic vertical leakage. Obviously, more data and better analysis are required to resolve these ambiguities. 


\subsection{Groundwater Oscillations in Response to Seismic Waves}

Several types of groundwater responses occur during earthquakes. Here we discuss the oscillatory response that is more closely related to the tidal and barometric responses; the other types of responses are discussed in the next chapter. Water level oscillations recorded in wells during earthquakes have long been documented and have been referred to as 'hydroseismogram' (e.g., Byerly and Blanchard 1935). During the 1964 M9.2 Alaska earthquake, water level oscillations with amplitudes as large as $6 \mathrm{~m}$ were recorded in Florida, thousands of kilometers away from the epicenter. Figure 5.39a shows a hydroseismograms in a well in Grants Pass, Oregon, during the 2002 M 7.9 Denali earthquake, Alaska, $3100 \mathrm{~km}$ away (Brodsky et al. 2003). Also shown (Fig. 5.39b) is the vertical component of ground velocity recorded on a broad-band seismometer adjacent to the well. Little change of water level occurred until the Rayleigh waves arrived and the oscillations of the hydroseismogram correlate well with that in the Rayleigh waves. After the seismic vibrations stopped, a 'permanent' change of water level of $12 \mathrm{~cm}$ was revealed.

Another way to show water level responses to different types of seismic waves is by plotting the occurrence time of water level response against the epicentral distance of the responding well, together with the travel time curves of the different types of seismic waves from the source. Figure 5.39c shows such a diagram for the groundwater responses on the Chinese mainland to the Tohoku earthquake (Yan et al. 2014). It clearly shows that the predominant water level responses were triggered by the surface waves rather than the body waves. Water-level oscillations in response to the passage of S-waves and Love waves were also reported (e.g., Wang et al., 2009), but the magnitude of these are much smaller than those responding to Rayleigh waves.

We briefly derive the volumetric strain associated with the Rayleigh waves. Let the $x_{1}$ and $x_{2}$ axes of a Cartesian coordinate system lie in the horizontal plane and orient respectively in the radial and transverse directions of wave propagation. The $x_{3}$ axis is in the vertical direction. The volumetric strain from the Rayleigh waves is related to the radial displacement $\left(u_{1}\right)$ and the vertical displacement $\left(u_{3}\right)$ according to

$$
\theta=\left|\frac{\partial u_{1}}{\partial x_{1}}+\frac{\partial u_{3}}{\partial x_{3}}\right|
$$

The full solutions for $u_{1}$ and $u_{3}$ may be found in standard seismology textbooks (e.g., Aki and Richards 2009; Stein and Wysession 2003). A simplified expression was given by Lay and Wallace (1995) for material with a Poisson's ratio of 0.25 :

$$
\begin{gathered}
u_{1}=-A^{\prime} k \sin \left(\omega t-k x_{1}\right)\left[e^{-0.85 k x_{3}}-0.58 e^{-0.39 k x_{3}}\right], \\
u_{3}=-A^{\prime} k \cos \left(\omega t-k x_{1}\right)\left[0.85 e^{-0.85 k x_{3}}-1.47 e^{-0.39 k x_{3}}\right] .
\end{gathered}
$$


(a)

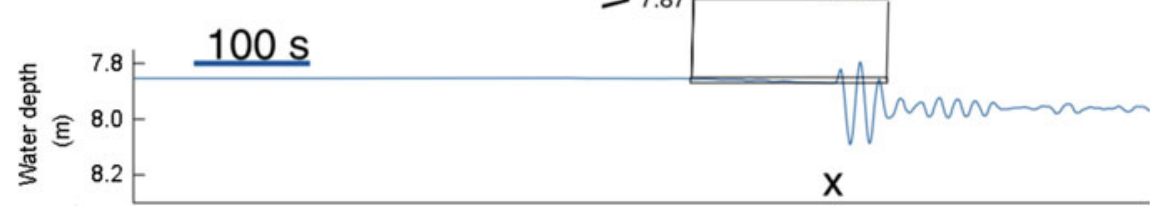

(b)

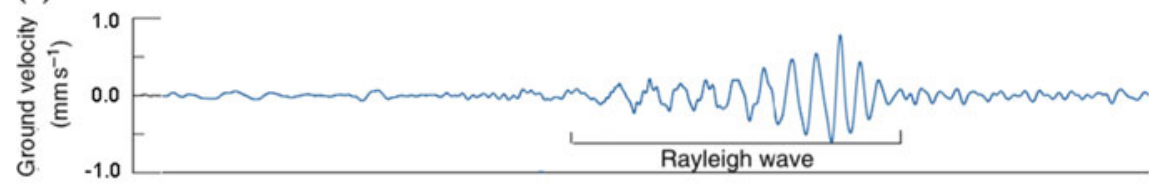

(c)

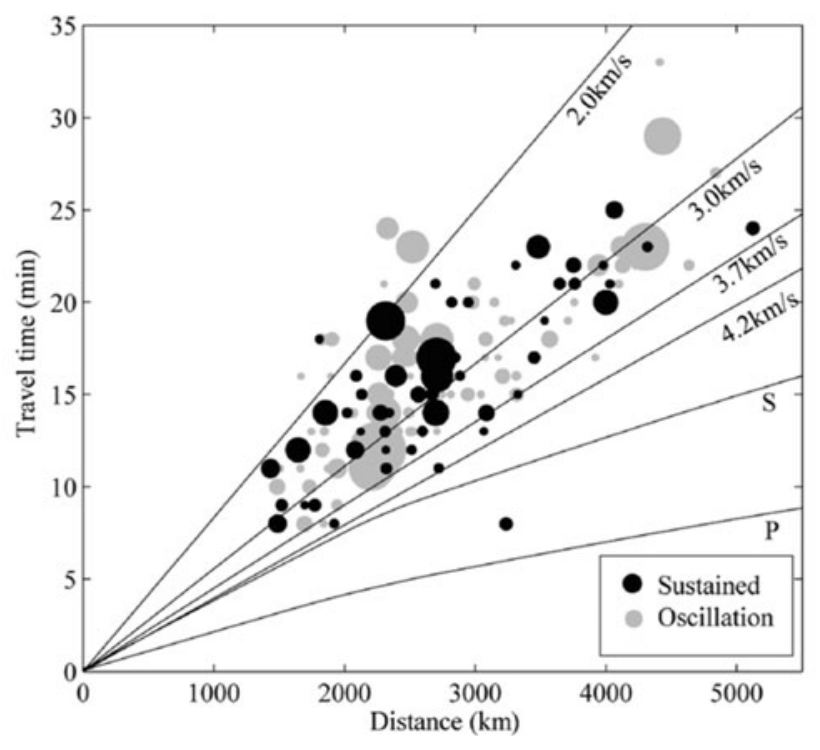

Fig. 5.39 a Water level measured by a float in a well in northern California for the 1999 Mw7.4 Oaxaca earthquake, with tides, barometric effects and linear trend removed. Inset shows magnified view of water level record before the onset of large oscillations. b Vertical ground velocity recorded at a nearby seismic station (YBH) (from Brodsky et al. 2003). c Relationship between travel time (deduced from the beginning of the well response) and well-epicentral distance. The solid lines are travel time curves for P and S body-wave phases (from IASP91 travel times model), as well as for surface waves with velocities of 2.0, 3.0, 3.7 and $4.2 \mathrm{~km} \mathrm{~s}^{-1}$. The size of the circles is proportional to the relative amplitude of the induced water level changes (from Yan et al. 2014) 
where $A^{\prime}$ is the amplitude, $k=\omega / c$ is the wave number, $\omega$ is the angular frequency and $c$ the phase velocity of the Rayleigh waves. Inserting (5.77) and (5.78) into (5.76) we have

$$
\theta=A^{\prime} k^{2} \cos \left(\omega t-k x_{1}\right)\left[-1.72 e^{0.85 k x_{3}}+1.15 e^{0.39 k x_{3}}\right] .
$$

Near the ground surface, $x_{3} \approx 0$ and (5.79) reduces to,

$$
\theta=-0.57 A^{\prime} k^{2} \cos \left(\omega t-k x_{1}\right)
$$

In practice, the volumetric strain may simply be obtained from the vertical displacement of the Rayleigh waves on the seismogram because, near the surface, (5.78) reduces to

$$
u_{3}=0.62 A^{\prime} k \cos \left(\omega t-k x_{1}\right) \text {. }
$$

Combining (5.80) and (5.81), we obtain (Shih 2009)

$$
\theta=-0.92 k u_{3}=\theta_{o} \cos \left(\omega t-k x_{1}\right)
$$

where $\theta_{o}=-0.92 k\left(u_{3}\right)_{o}$ and $\left(u_{3}\right)_{o}$ is the amplitude of the vertical displacement of the Rayleigh waves.

Sun et al. $(2018,2019)$ interpreted the water-level oscillations in response to seismic waves to estimate the aquifer parameters based on Cooper's model (1965) which shows that the amplitude ratio and the phase shift of water-level oscillations response to Rayleigh waves have the following expressions for the amplitude ratio and the phase shift of the response

$$
\begin{gathered}
A=\left|h_{w, o} / h_{\infty, o}\right|=\left\{\left[1-\frac{\pi r_{w}^{2}}{T \tau} \operatorname{Kei}\left(\alpha_{w}\right)-\frac{4 \pi^{2} H_{e}}{\tau^{2} g}\right]^{2}+\left[\frac{\pi r_{w}^{2}}{T \tau} \operatorname{Ker}\left(\alpha_{w}\right)\right]^{2}\right\}_{(5.83)}^{-\frac{1}{2}} \\
\eta=\arg \left[h_{w, o} / h_{\infty, o}\right]=\arg \left[\frac{2 \beta \omega_{w} \omega}{\omega^{2}-\omega_{w}^{2}}\right]
\end{gathered}
$$

where $h_{w, o}$ is the amplitude of the water-level oscillations in the well during an earthquake, $h_{\infty, o}$ is the amplitude of the volumetric strain equivalent water level away from the well, which may be calculated from the vertical component of the Rayleigh waves on the seismogram according to (6.7), and

$$
\alpha_{w}=r_{w}\left(\frac{\omega S}{T}\right)^{\frac{1}{2}},
$$




$$
\begin{gathered}
\beta=\frac{r_{w}^{2} g}{4 \omega_{w} T H_{e}} \operatorname{Ker}\left(\alpha_{w}\right), \\
\omega_{w}=\sqrt{\frac{g}{H_{e}}\left[1-\frac{r_{w}^{2} \omega}{2 T} \operatorname{Kei}\left(\alpha_{w}\right)\right]}, \\
H_{e}=H+3 d / 8,
\end{gathered}
$$

where $r_{w}$ is the radius of the well, $T$ and $S$, respectively, are the transmissivity and storativity of the aquifer, $K_{u}$ is the undrained bulk modulus of the aquifer, $\omega=2 \pi / \tau$ the seismic wave frequency, Kei and Ker, respectively, are the imaginary and real parts of the zeroth-order Kelvin function, $H$ is the height of the water column in the well casing and $d$ is the thickness of the screened aquifer.

Sun et al. (2018) analyzed the water-level response in a well (X10) near Urumqi, Xinjiang, to the 2016 Mw7.8 Solomon Island earthquake. Using the water level data from the well and the seismogram from a nearby seismic station, Sun et al. (2018) calculated the amplification of the water level $A=\left|h_{w, o} / h_{\infty, o}\right|$ as a function of frequency and plotted the results in Fig. 5.40. Fitting their result with Cooper's model they estimated the hydraulic conductivity of the aquifer to be $3.75 \times 10^{-3} \mathrm{~m} / \mathrm{s}$, which is several orders of magnitude greater than that estimated from the interpretation of the tidal response, as discussed below.

Using the same method, Sun et al. (2019) compared the responses of water level in the same well (X10) to another earthquake (Hutubi, Mw6.0, $104 \mathrm{~km}$ from the well) that occurred $\sim 12 \mathrm{~h}$ earlier than the Solomon Island earthquake. The authors found that the permeability increase following the Mw7.8 Solomon Island earthquake was much greater than that induced by the Mw6.0 Hutubi earthquake, even though the

Fig. 5.40 Amplification of water level response in Well X10 in Xingjiang, China, to the Rayleigh waves from the 2016 Mw7.8 Solomon Island earthquake, plotted against wave periods. Circles represent the water level response and solid line represent the model fit with an assumed hydraulic conductivity of $3.75 \times 10^{-3}$ $\mathrm{m} / \mathrm{s}$. Values on top of the graph show other parameters used in the model (from Sun et al. 2018)

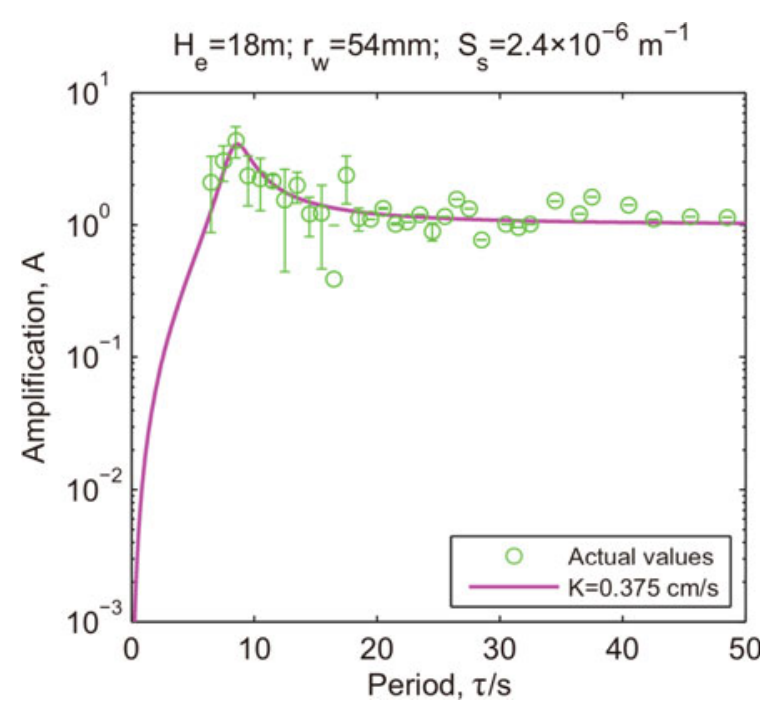


latter had a seismic energy density $\sim 3$ orders of magnitude greater on account of its closer distance. The authors attributed this difference to a stress or strain memory from the first earthquake.

Sun et al. (2020) further compared the periodic responses for four analytical models as functions of the loading frequency (Fig. 5.41). They noticed that the transmissivity estimated from interpreting the response to seismic waves with the model by Cooper et al. (1965) is several orders of magnitude greater than that from interpreting the tidal response with the model by Wang et al. (2018) and that from interpreting the barometric response with the model of Rojstaczer (1988) (Table 5.5). They attributed these differences to factors such as spatial scale effects in the hydraulic parameter estimation, applicability of the estimation models under different conditions, and frequency of the periodic loadings. More research is needed to understand these differences.

Barbour et al. (2019) also analyzed the response of water level in the USGS deep well in Oklahoma to Rayleigh waves from several distant earthquakes. They showed that at periods below 60 to $70 \mathrm{~s}$ there is a frequency-dependent response similar to the theoretical prediction of a confined reservoir (Cooper et al., 1965); at longer periods, however, the response does not converge to the prediction of a confined aquifer model (e.g., Hsieh et al. 1987) but shows amplification and phase advance, which supports the occurrence of vertical flow (leakage).

\subsection{Concluding Remarks}

As noted in the Introduction, the analysis of the response of groundwater level to natural forcing, such as tides and barometric pressure, is an economical and effective means for continuous monitoring of hydraulic properties of aquifers. This approach has gained increasing attention among hydrogeologists, particularly in the community that studies of the groundwater response to earthquakes. The method has also been shown to be particularly effective in detecting the leakage and confinement of aquifers, which has become an important problem for the protection of shallow groundwater resources against possible leakage of hazardous wastewaters that have been increasingly injected into underground aquifers. The new development of using the response of groundwater to Rayleigh waves to estimate aquifer properties has the potential to enhance our understanding on the dependence of aquifer properties on the frequency of the applied forcing and deserves further study.

Finally, we list in Table 5.5 some estimates of permeability from the interpretations of the responses to tidal, barometric pressure and seismic waves. These are to be viewed as examples for comparison, rather than a comprehensive compilation. 

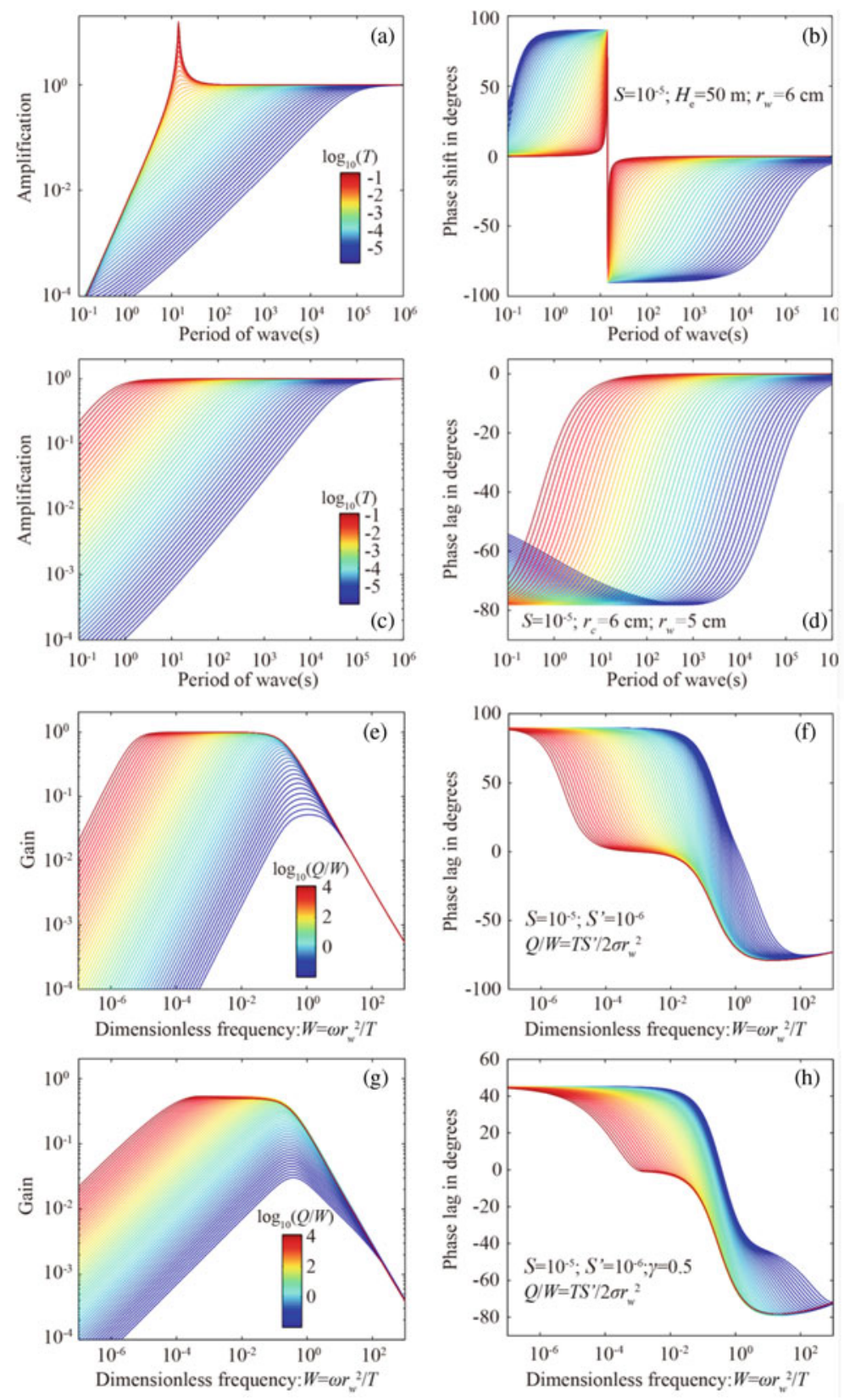

Fig. 5.41 Amplification factor and phase lag of water level response to periodic loading. $K$ and $K^{\prime}$ in the figures are the hydraulic conductivity of the aquifer and aquitard, respectively; $\mathrm{d}$ and $\mathrm{b}$ are the thickness of the aquifer and aquitard, respectively. a, b Cooper's model, c, $\mathbf{d}$ Hsieh's model, e-f Wang's model, where $T=K d$ and $\sigma=K^{\prime} / b^{\prime}$, and $\mathbf{g}$, h Rojstaczer's model 
Table 5.5 Permeability $\left(\mathrm{m}^{2}\right)$ estimated from interpreting water-level responses to tidal, barometric and seismic forcing

\begin{tabular}{|c|c|c|c|c|}
\hline \multicolumn{3}{|l|}{ Methods } & \multirow[t]{2}{*}{ Locations } & \multirow[t]{2}{*}{ References } \\
\hline Tidal & Barometric & Seismic waves & & \\
\hline $\begin{array}{l}8 \times 10^{-15}(S= \\
\left.10^{-4}\right)^{\mathrm{b}} \\
2 \times 10^{-14}(\mathrm{~S}= \\
\left.10^{-6}\right)\end{array}$ & & & Parkfield, CA & $\begin{array}{l}\text { Hsieh et al. } \\
\text { (1987) }\end{array}$ \\
\hline $\begin{array}{l}1 \times 10^{-15} \text { (before) }^{\mathrm{d}} \\
6 \times 10^{-15} \text { (after) }\end{array}$ & & & $\begin{array}{l}\text { Pin õ n Flat Obs., } \\
\text { S. California }\end{array}$ & $\begin{array}{l}\text { Elkhoury et al. } \\
\text { (2006) }\end{array}$ \\
\hline $10^{-16}$ (after) & & & $\begin{array}{l}\text { Wenchuan } \\
\text { rupture zone, } \\
\text { China }\end{array}$ & $\begin{array}{l}\text { Xue et al. } \\
(2013)\end{array}$ \\
\hline $\begin{array}{l}10^{-16} \text { (before) } \\
5 \times 10^{-15} \text { (after) }\end{array}$ & & & E. China & $\begin{array}{l}\text { Yan et al. } \\
\text { (2014) }\end{array}$ \\
\hline $\begin{array}{l}2.4 \times 10^{-15} \\
\text { (before) } \\
7.8 \times 10^{-15} \text { (after) }\end{array}$ & & & $\begin{array}{l}21 \mathrm{~km} \text { from } \\
\text { Wenchuan } \\
\text { rupture, China }\end{array}$ & $\begin{array}{l}\text { Liao et al. } \\
(2015)\end{array}$ \\
\hline $\begin{array}{l}3 \times 10^{-14} \text { to } \\
3 \times 10^{-13}\end{array}$ & & & S. California & $\begin{array}{l}\text { Allègre et al. } \\
\text { (2016) }\end{array}$ \\
\hline $\begin{array}{l}2.3 \times 10^{-14 a} \\
2.2 \times 10^{-15 b}\end{array}$ & & & $\begin{array}{l}31^{\mathrm{a}} \mathrm{m} \text { and } 548^{\mathrm{b}} \\
\mathrm{m} \text { from the San } \\
\text { Andreas fault }\end{array}$ & $\begin{array}{l}\text { Xue et al. } \\
\text { (2016) }\end{array}$ \\
\hline $\begin{array}{l}2 \times 10^{-14} \text { to } \\
1.2 \times 10^{-13}\end{array}$ & & & $\begin{array}{l}\text { Yunan, SW } \\
\text { China }\end{array}$ & $\begin{array}{l}\text { Liao and } \\
\text { Wang (2018) }\end{array}$ \\
\hline $\begin{array}{l}5 \times 10^{-16} \text { (before) } \\
1 \times 10^{-14} \text { (after) }\end{array}$ & & & Beijing, China & $\begin{array}{l}\text { Zhang-Wang } \\
\text { et al. (2019) }\end{array}$ \\
\hline \multirow[t]{3}{*}{$\begin{array}{l}6.9 \times 10^{-16} \\
\text { (before) } \\
1.4 \times 10^{-15} \text { (after) }\end{array}$} & $\begin{array}{l}7.2 \times 10^{-16} \\
\text { (before) } \\
4.0 \times 10^{-15} \\
\text { (after) }\end{array}$ & & Beijing, China & $\begin{array}{l}\text { Zhang-Shi } \\
\text { et al. (2019) }\end{array}$ \\
\hline & $\begin{array}{l}2 \times 10^{-13}\left(S^{\prime}=\right. \\
0)^{\mathrm{c}} \\
7 \times 10^{-12}\left(S^{\prime}=\right. \\
\left.10^{-2}\right)^{\mathrm{c}}\end{array}$ & & $\begin{array}{l}\text { USGS Deep } \\
\text { Oklahoma well }\end{array}$ & $\begin{array}{l}\text { Zhu and Wang } \\
(2020)\end{array}$ \\
\hline & & $\begin{array}{r}3 \text { to } 5 \times 10^{-11} \\
7 \text { to } 25 \times 10^{-11}\end{array}$ & $\begin{array}{l}\text { X10 well, } \\
\text { Urumqi, China }\end{array}$ & $\begin{array}{l}\text { Sun et al. } \\
(2018) \\
\text { Sun et al. } \\
(2019)\end{array}$ \\
\hline 1.6 to $10.5 \times 10^{-9 \mathrm{e}}$ & $6.1 \times 10^{-8 \mathrm{e}}$ & $1.7 \times 10^{-4 \mathrm{e}}$ & $\begin{array}{l}\text { Jingle well, } \\
\text { Shanxi, China }\end{array}$ & $\begin{array}{l}\text { Sun et al. } \\
(2020)\end{array}$ \\
\hline
\end{tabular}

${ }^{\mathrm{a} B}$ Blank space means that no data are available

${ }^{\mathrm{b}} \mathrm{S}$ is the assumed storativity of the aquifer

${ }^{\mathrm{c}} S^{\prime}$ is the assumed storativity of the aquitard

$\mathrm{d}$ (Before) and (after) refer to values estimated before and after a specific earthquake, respectively

${ }^{\mathrm{e}}$ Permeability converted from measured transmissivity and assumed aquifer thickness of $100 \mathrm{~m}$ 


\section{Appendices. Derivation of Equations}

\section{Appendix 5.1 Solution for a Confined Aquifer}

We use complex numbers to facilitate the derivation of a solution. We first derive the response away from the well, $h_{\infty}$, and then consider the effect of the well on aquifer response from wellbore storage. Let the disturbance in water level due to the well be expressed as

$$
\Delta h(r, t)=h(r, t)-h_{\infty}(t)
$$

where $h_{\infty}(t)[\mathrm{m}]$ is the hydraulic head away from the well, which is a function of time only and may be evaluated by replacing $h$ by $h_{\infty}$ in Eq. (5.12):

$$
0=S \frac{\partial h_{\infty}}{\partial t}-\frac{S B K_{u}}{\rho g} \frac{\partial \epsilon}{\partial t} .
$$

Since $h_{\infty}$ and $\epsilon$ are both periodic with the same frequency $\omega$ we have

$$
h_{\infty, o}=\left(\frac{B K_{u} \epsilon_{o}}{\rho g}\right) .
$$

where $h_{\infty, o}$ is the complex amplitude of $h_{\infty}$ and $\epsilon_{o}$ the amplitude of $\epsilon$.

Replacing $h$ by $\Delta h+h_{\infty}$ in Eqs. (5.14)-(5.16) and using Eq. (5.18) we have

$$
T\left[\frac{\partial^{2} \Delta h}{\partial r^{2}}+\frac{1}{r} \frac{\partial \Delta h}{\partial r}\right]=S \frac{\partial \Delta h}{\partial t} .
$$

Since the stationary periodic solution of equation (A5.4) has the form $\Delta h=$ $\Delta h_{o}(r) e^{i \omega t}$, it can be reduced to an ordinary differential equation

$$
T\left[\frac{d^{2} \Delta h_{o}}{d r^{2}}+\frac{1}{r} \frac{\mathrm{d} \Delta h_{o}}{d r}\right]=i \omega S \Delta h_{o},
$$

with the boundary conditions

$$
\begin{gathered}
\Delta h_{o}(r \rightarrow \infty)=0 \\
\Delta h_{o}\left(r=r_{w}\right)=h_{w, o}-h_{\infty, o}=h_{w, o}-\left(\frac{B K_{u} \epsilon_{o}}{\rho g}\right), \\
\left.2 \pi r_{w} T \frac{d \Delta h_{o}}{d r}\right|_{r=r_{w}}=i \omega \pi r_{c}^{2} h_{w, o} .
\end{gathered}
$$


The solution to equation (A5.5) is $\Delta h_{o}=C_{I} I_{0}(\beta r)+C_{K} K_{0}(\beta r)$, where $I_{0}$ and $K_{O}$ are, respectively, the modified Bessel functions of the first and second kind and the zeroth order, and

$$
\beta=\left(\frac{i \omega S}{T}\right)^{1 / 2}
$$

Given that $I_{0}(r)$ goes to infinity at large $r$, the boundary condition (Eq. A6) requires that $C_{I}=0$; thus $\Delta h_{o}=C_{K} K_{o}(\beta r)$. Solving for $C_{K}$ with equation (A5.8) and recalling that $\frac{d K_{o}(r)}{d r}=-K_{1}(r)$, where $K_{1}$ is the modified Bessel function of the second kind and the first order, we have

$$
C_{K}=-\frac{i \omega r_{c}^{2} h_{w, o}}{2 T \beta r_{w} K_{1}(\beta r)}
$$

Thus,

$$
\Delta h_{o}=-\frac{i \omega r_{c}^{2} h_{w, o} K_{o}(\beta r)}{2 T \beta r_{w} K_{1}(\beta r)} .
$$

Inserting equation (A5.11) into equation (A5.7) we obtain the solution,

$$
h_{w, o}=\frac{1}{\xi}\left(\frac{B K_{u} \epsilon_{o}}{\rho g}\right),
$$

where

$$
\xi=1+\left(\frac{r_{c}}{r_{w}}\right)^{2} \frac{i \omega r_{w}}{2 T \beta} \frac{K_{o}\left(\beta r_{w}\right)}{K_{1}\left(\beta r_{w}\right)}
$$

\section{Appendix 5.2 Solution for a Leaky Aquifer}

Replacing $h$ by $\Delta h+h_{\infty}$ in Eqs. (5.28)-(5.31) and using Eq. (5.34) we have

$$
T\left[\frac{\partial^{2} \Delta h}{\partial r^{2}}+\frac{1}{r} \frac{\partial \Delta h}{\partial r}\right]-\frac{K^{\prime}}{b^{\prime}} \Delta h=S \frac{\partial \Delta h}{\partial t}
$$

which may be reduced to an ordinary differential equation

$$
T\left[\frac{d^{2} \Delta h_{o}}{d r^{2}}+\frac{1}{r} \frac{\mathrm{d} \Delta h_{o}}{d r}\right]-\frac{K^{\prime}}{b^{\prime}} \Delta h_{o}=i \omega S \Delta h_{o},
$$


with the boundary conditions

$$
\begin{gathered}
\Delta h_{o}(r \rightarrow \infty)=0, \\
\Delta h_{o}\left(r=r_{w}\right)=h_{w, o}-h_{\infty, o}=h_{w, o}-\frac{i \omega S}{i \omega S+K^{\prime} / b^{\prime}}\left(\frac{B K_{u} \epsilon_{o}}{\rho g}\right), \\
\left.2 \pi r_{w} T \frac{d \Delta h_{o}}{d r}\right|_{r=r_{w}}=i \omega \pi r_{c}^{2} h_{w, o} .
\end{gathered}
$$

The solution to Eq. (A5.18) is $\Delta h_{o}=C_{I} I_{o}\left(\beta^{\prime} r\right)+C_{K} K_{o}\left(\beta^{\prime} r\right)$, where

$$
\beta^{\prime}=\left(\frac{K^{\prime}}{T b^{\prime}}+\frac{i \omega S}{T}\right)^{1 / 2}
$$

The boundary condition (Eq. A5.19) requires that $C_{I}=0$ and the boundary condition (A5.17) leads to

$$
C_{K}=-\frac{i \omega r_{c}^{2} h_{w, o}}{2 T \beta r_{w} K_{1}\left(\beta^{\prime} r\right)}
$$

and

$$
\Delta h_{o}=-\frac{i \omega r_{c}^{2} h_{w, o} K_{o}\left(\beta^{\prime} r\right)}{2 T \beta r_{w} K_{1}\left(\beta^{\prime} r\right)} .
$$

Inserting equation (A5.21) into equation (A5.17) we obtain the solution as

$$
h_{w, o}=\frac{i \omega S}{\left(i \omega S+K^{\prime} / b^{\prime}\right) \xi^{\prime}}\left(\frac{B K_{u} \epsilon_{o}}{\rho g}\right)=\frac{1}{\xi^{\prime}} h_{\infty, o}^{\prime},
$$

where

$$
\xi^{\prime}=1+\left(\frac{r_{c}}{r_{w}}\right)^{2} \frac{i \omega r_{w}}{2 T \beta^{\prime}} \frac{K_{o}\left(\beta^{\prime} r_{w}\right)}{K_{1}\left(\beta^{\prime} r_{w}\right)}
$$

\section{Appendix 5.3 Barometric Response with Finite Aquitard}

In order to apply the existing solution in Carlslaw and Jaeger $(1959,3.7)$ to the present study of vertical flow of groundwater in an aquitard of finite thickness, we need to substitute $P$ in $(5.60)$ by 


$$
P^{*} \equiv P-A \gamma \cos \omega t
$$

and re-express Eq. (5.60) as

$$
D^{\prime} \frac{\partial^{2} P^{*}}{\partial z^{2}}=\frac{\partial P^{*}}{\partial t} .
$$

Following Carlslaw and Jaeger (1959), the time factor exp $(i \omega t)$ is omitted from the derivation, but is included at the end. We replace $A, B, C$, and $D$ in Carslaw and Jaeger by $E, F, G$, and $H$ to avoid the possible confusion with the parameters $A$ for the amplitude of barometric oscillations and $D$ for diffusion, as defined earlier. In using this solution, there is also a need to employ the subscripts $t$ and $b$ to denote the top and bottom of each layer and a prime to denote the aquitard pressure to distinguish it from the aquifer pressure without a prime. Since $P_{t}^{*}=P_{b}^{*^{\prime}}$ and $q_{t}^{*}=q_{b}^{*^{\prime}}$, we have

$$
\begin{gathered}
\left(\begin{array}{c}
P_{b}^{*} \\
q_{b}^{*}
\end{array}\right)=\left(\begin{array}{cc}
E & F \\
G & H
\end{array}\right)\left(\begin{array}{c}
P_{t}^{*} \\
q_{t}^{*}
\end{array}\right)=\left(\begin{array}{cc}
E & F \\
G & H
\end{array}\right)\left(\begin{array}{c}
P_{b}^{*^{\prime}} \\
q_{b}^{*^{\prime}}
\end{array}\right) \\
=\left(\begin{array}{cc}
E & F \\
G & H
\end{array}\right) \cdot\left(\begin{array}{cc}
E^{\prime} & F^{\prime} \\
G^{\prime} & H^{\prime}
\end{array}\right) \cdot\left(\begin{array}{c}
P_{t}^{*^{\prime}} \\
q_{t}^{*^{\prime}}
\end{array}\right) \\
=\left(\begin{array}{c}
E E^{\prime}+F G^{\prime} E F^{\prime}+F H^{\prime} \\
G E^{\prime}+H G^{\prime} G F^{\prime}+H H^{\prime}
\end{array}\right) \cdot\left(\begin{array}{c}
P_{t}^{*^{\prime}} \\
q_{t}^{*^{\prime}}
\end{array}\right),
\end{gathered}
$$

where

$$
\begin{gathered}
E=\cosh [(1+i) \sqrt{R}], \\
F=\frac{L}{K} \frac{\sinh [(1+i) \sqrt{R}]}{[(1+i) \sqrt{R}]}, \\
G=-\frac{K}{L}[(1+i) \sqrt{R}] \sinh [(1+i) \sqrt{R}], \\
H=E, \\
R=L^{2} \omega / 2 D,
\end{gathered}
$$

and $L, K$ and $D$ are, respectively, the thickness, hydraulic conductivity and diffusivity of the aquifer. The parameters $E^{\prime}, F^{\prime}, G^{\prime}$ and $H^{\prime}$ for the aquitard are defined similarly but with $L, K, D$ and $R$ replaced by $L^{\prime}, K^{\prime}, D^{\prime}$ and $R^{\prime}$, respectively.

A no-flow condition is assumed at the base of the aquifer, hence 


$$
q_{b}=0=\left[\left(G E^{\prime}+H G^{\prime}\right) P_{t}^{*^{\prime}}+\left(G F^{\prime}+H H^{\prime}\right) q_{t}^{*^{\prime}}\right] .
$$

Thus

$$
q_{t}^{*^{\prime}}=-\frac{G E^{\prime}+H G^{\prime}}{G F^{\prime}+H H^{\prime}} P_{t}^{*^{\prime}}
$$

From (A5.26) and (A5.34) we have

$$
\begin{aligned}
P_{b}^{*^{\prime}} & =E^{\prime} P_{t}^{*^{\prime}}+F^{\prime} q_{t}^{*^{\prime}} \\
& =\left(E^{\prime}-F^{\prime} \frac{G E^{\prime}+H G^{\prime}}{G F^{\prime}+H H^{\prime}}\right) P_{t}^{*^{\prime}}
\end{aligned}
$$

By virtue of (A5.24) we replace $P_{b}^{*^{\prime}}$ by $P_{b}^{\prime}-A \gamma \exp (i \omega t)$ and $P_{t}^{*^{\prime}}$ by $P_{t}^{\prime}-$ $A \gamma \exp (i \omega t)$ in (A5.34) and obtain

$$
P_{b}^{\prime}-A \gamma \exp (i \omega t)=\left(E^{\prime}-F^{\prime} \frac{G E^{\prime}+H G^{\prime}}{G F^{\prime}+H H^{\prime}}\right)\left[P_{t}^{\prime}-A \gamma \exp (i \omega t)\right]
$$

Since $P_{b}^{\prime}=P$ (aquifer pressure) and

$$
P_{t}^{\prime}=P_{a}=A(M+i N) \exp (i \omega t)
$$

we have the pressure in the aquifer

$$
P=A\left[\gamma+(M+i N-\gamma)\left(E^{\prime}-F^{\prime} \frac{G E^{\prime}+H G^{\prime}}{G F^{\prime}+H H^{\prime}}\right)\right] \exp (i \omega t)
$$

\section{Appendix 5.4 Effect of Fractures on Groundwater Response}

The tidal and barometric response of groundwater in fractures has not received adequate attention. Existing models (Hanson and Owen 1982; Bower 1983) consider only the tidal response of groundwater in a single highly conductive, planar fracture, that intersects the well. The models are constructed for the purpose of finding the orientation of the conductive fractures from the tidal response of water level in wells. Both Hanson and Owen (1982) and Bower (1982) develop mathematical solutions for the problem. The results of Hanson and Owen (1983), as summarized by Barbour et al. (2019), are given below.

Consider a saturated planar fracture with a normal denoted by $\hat{n}=(\cos \alpha 1, \cos \alpha 2$, $\cos \alpha 3$ ), where $\alpha 1, \alpha 2$, and $\alpha 3$ are the angles between $\hat{n}$ and the east, north, and up directions, respectively. The response of the pressure in the fracture to a time-varying 
tidal strain tensor $\mathbf{e}(t)$ is

$$
p(t)=-C \hat{n} \mathbf{e}(t) \hat{n}^{T},
$$

where $C$ is a proportional constant that depends on the compliances of the fracture, wall rock, and fluid. The pressure response to a constituent of the tidal strain of frequency $\omega_{k}$ may be expressed in the frequency domain as

$$
\tilde{p}\left(\omega_{k}\right) \exp (i \omega t)=-C \hat{n} \tilde{\mathbf{e}}\left(\omega_{k}\right) \hat{n}^{T} \exp (i \omega t) .
$$

Expressing the tidal strain tensor in its geographical components

$$
\tilde{\mathbf{e}}\left(\omega_{k}\right)=\left[\begin{array}{ccc}
\tilde{e}_{\lambda \lambda}\left(\omega_{k}\right) & \frac{1}{2} \tilde{e}_{\lambda \theta}\left(\omega_{k}\right) & 0 \\
\frac{1}{2} \tilde{e}_{\lambda \theta}\left(\omega_{k}\right) & \tilde{e}_{\theta \theta}\left(\omega_{k}\right) & 0 \\
0 & 0 & \tilde{e}_{z z}\left(\omega_{k}\right)
\end{array}\right],
$$

where $\lambda$ is longitude (positive east), $\theta$ is latitude (positive north) and $z$ is vertical, and inserting Eq. (5.91) into Eq. (5.90), we relate the tidal response of pressure in fracture to the fracture orientation, the compliance constant $C$, and the tidal strain

$$
\begin{aligned}
\tilde{p}\left(\omega_{k}\right)= & \frac{C}{1-v} v\left[\tilde{e}_{\lambda \lambda}\left(\omega_{k}\right)+\tilde{e}_{\theta \theta}\left(\omega_{k}\right)\right] \\
& -\frac{C}{1-v}\left[\tilde{e}_{\lambda \lambda}\left(\omega_{k}\right)+v \tilde{e}_{\theta \theta}\left(\omega_{k}\right)\right] \cos ^{2} \alpha_{1} \\
& -\frac{C}{1-v}\left[\tilde{e}_{\theta \theta}\left(\omega_{k}\right)+v \tilde{e}_{\lambda \lambda}\left(\omega_{k}\right)\right] \cos ^{2} \alpha_{2} \\
& -C \tilde{e}_{\lambda \theta}\left(\omega_{k}\right) \cos \alpha_{1} \cos \alpha_{2}
\end{aligned}
$$

where we have used the following relationships to simply the expression:

$$
\cos ^{2} \alpha_{1}+\cos ^{2} \alpha_{2}+\cos ^{2} \alpha_{3}=1 \text {, }
$$

where $\tilde{e}_{z z}=-v\left(\tilde{e}_{\lambda \lambda}+\tilde{e}_{\theta \theta}\right) /(1-v)$, and is valid near the Earth's surface.

Neglecting the effect of ocean tides, $\tilde{e}_{\lambda \lambda}\left(\omega_{k}\right)$ and $\tilde{e}_{\theta \theta}\left(\omega_{k}\right)$ are in phase with the tidal potential and $\tilde{e}_{\lambda \theta}\left(\omega_{k}\right)$ leads (diurnal constituents) or lags (semidiurnal constituents) the tidal potential by $90^{\circ}$. Denoting the phase of the tidal potential as $\phi_{k}$, we have

$$
\begin{gathered}
\arg \left[\tilde{e}_{\theta \theta}\left(\omega_{k}\right)\right]=\arg \left[\tilde{e}_{\lambda \lambda}\left(\omega_{k}\right)\right]=\phi_{k}, \\
\phi_{k}-\arg \left[\tilde{e}_{\lambda \theta}\left(\omega_{k}\right)\right]=\mp \pi / 2 .
\end{gathered}
$$

Equation (A5.42) becomes 


$$
\begin{aligned}
\tilde{p}\left(\omega_{k}\right)= & \frac{C}{1-v} v\left[\left|\tilde{e}_{\lambda \lambda}\left(\omega_{k}\right)\right|+\left|\tilde{e}_{\theta \theta}\left(\omega_{k}\right)\right|\right] \exp \left(i \phi_{k}\right) \\
& -\frac{C}{1-v}\left[\left|\tilde{e}_{\lambda \lambda}\left(\omega_{k}\right)\right|+v\left|\tilde{e}_{\theta \theta}\left(\omega_{k}\right)\right|\right] \exp \left(i \phi_{k}\right) \cos ^{2} \alpha_{1} \\
& -\frac{C}{1-v}\left[\left|\tilde{e}_{\theta \theta}\left(\omega_{k}\right)\right|+v\left|\tilde{e}_{\lambda \lambda}\left(\omega_{k}\right)\right|\right] \exp \left(i \phi_{k}\right) \cos ^{2} \alpha_{2} \\
& \mp i C\left|\tilde{e}_{\lambda \theta}\left(\omega_{k}\right)\right| \exp \left(i \phi_{k}\right) \cos \alpha_{1} \cos \alpha_{2}
\end{aligned}
$$

where the - sign is for diurnal tides and the + sign is for semidiurnal tides.

The first three terms on the right side of Eq. (A5.43) are real, while the last term is imaginary. If the measured pressure response is now referenced to the tidal potential, we have

$$
\begin{aligned}
\operatorname{Re}\left[\tilde{p}\left(\omega_{k}\right) \exp \left(-i \phi_{k}\right)\right]= & \frac{C}{1-v} v\left[\left|\tilde{e}_{\lambda \lambda}\left(\omega_{k}\right)\right|+\left|\tilde{e}_{\theta \theta}\left(\omega_{k}\right)\right|\right] \\
& -\frac{C}{1-v}\left[\left|\tilde{e}_{\lambda \lambda}\left(\omega_{k}\right)\right|+v\left|\tilde{e}_{\theta \theta}\left(\omega_{k}\right)\right|\right] \cos ^{2} \alpha_{1} \\
& -\frac{C}{1-v}\left[\left|\tilde{e}_{\theta \theta}\left(\omega_{k}\right)\right|+v\left|\tilde{e}_{\lambda \lambda}\left(\omega_{k}\right)\right|\right] \cos ^{2} \alpha_{2}
\end{aligned}
$$

and

$$
\operatorname{Im}\left[\tilde{p}\left(\omega_{k}\right) \exp \left(-i \phi_{k}\right)\right]=\mp i C\left|\tilde{e}_{\lambda \theta}\left(\omega_{k}\right)\right| \cos \alpha_{1} \cos \alpha_{2}
$$

Hanson and Owen (1982) inferred fracture orientation from three parameters of the fluid level tidal response: the phases of a diurnal tide and a semidiurnal tide, and the ratio of the amplitudes of these two constituents. The dependence on fracture compliance is avoided by using the ratio of the amplitudes of the $\mathrm{M}_{2}$ and $\mathrm{O}_{1}$ tides. The phase of the pressure change relative to the tidal potential is given by

$$
\begin{aligned}
& \arg \left[\tilde{p}\left(\omega_{k}\right) \exp \left(-i \phi_{k}\right)\right]=\tan ^{-1} \\
& \quad \times\left(\frac{\mp(1-v)\left|\tilde{e}_{\lambda \theta}\left(\omega_{k}\right)\right| \cos \alpha_{1} \cos \alpha_{2}}{v\left[\left|\tilde{e}_{\lambda \lambda}\left(\omega_{k}\right)\right|+\left|\tilde{e}_{\theta \theta}\left(\omega_{k}\right)\right|\right]-\left[\left|\tilde{e}_{\lambda \lambda}\left(\omega_{k}\right)\right|+v\left|\tilde{e}_{\theta \theta}\left(\omega_{k}\right)\right|\right] \cos ^{2} \alpha_{1}-\left[\left|\tilde{e}_{\theta \theta}\left(\omega_{k}\right)\right|+v\left|\tilde{e}_{\lambda \lambda}\left(\omega_{k}\right)\right|\right] \cos ^{2} \alpha_{2}}\right)
\end{aligned}
$$

where the - is used for diurnal tides and the + is used for semidiurnal tides, and the ratio of the amplitudes of the $\mathrm{M}_{2}$ and $\mathrm{O}_{1}$ tides is given by

$$
\frac{\left|\tilde{p}\left(\omega_{k}\right)\right|}{\left|\tilde{p}\left(\omega_{j}\right)\right|}=\left[\frac{\operatorname{Re}\left[\tilde{p}\left(\omega_{k}\right)\right]^{2}+\operatorname{Im}\left[\tilde{p}\left(\omega_{k}\right)\right]^{2}}{\operatorname{Re}\left[\tilde{p}\left(\omega_{j}\right)\right]^{2}+\operatorname{Im}\left[\tilde{p}\left(\omega_{j}\right)\right]^{2}}\right]^{\frac{1}{2}} .
$$

Hanson and Owen (1982) noted that, according to Eq. (5.95), a fracture with NW strike $\left(\cos \alpha_{1} \cos \alpha_{2}>0\right)$ and a fracture with NE strike $\left(\cos \alpha_{1} \cos \alpha_{2}<0\right)$ exhibit phase shifts of opposite sign with respect to the potential for a given tide. For a given 
fracture, the diurnal and semidiurnal tides exhibit phase shifts of opposite sign with respect to the tidal potential.

Barbour et al. (2019) applied the same approach to show that the fracture model may not explain the tidal response of water level in the Arbuckle aquifer, as determined from the water level documented in the USGS Deep Well in Oklahoma.

\section{References}

Agnew DC (2007) Earth tides. In Treatise on geophysics 3:163-195

Aki K, Richards PG (2009) Quantitative seismology, 2nd edn. University Science Books, Mill Valley

Allègre V, Brodsky EE, Xue L et al (2016) Using earth-tide induced water pressure changes to measure in situ permeability: a comparison with long-term pumping tests. Water Resour Res 52:3113-3126. https://doi.org/10.1002/2015WR017346

Ansari E, Bidgoli TS, Hollenbach A (2019) Accelerated fill-up of the Arbuckle Group aquifer and links to U.S. midcontinent seismicity. J Geophys Res Solid Earth 124:2670-2683. https://doi. org/10.1029/2018JB016926

Barbour AJ, Norbeck JH, Rubinstein JL (2017) The effects of varying injection rates in Osage County, Oklahoma, on the 2016 Mw 5.8 Pawnee earthquake. Seismol Res Lett 88:1040-1053. https://doi.org/10.1785/0220170003

Barbour AJ, Xue L, Roeloffs E et al (2019) Leakage and increasing fluid pressure detected in Oklahoma's wastewater disposal reservoir. J Geophys Res Solid Earth 124:2896-2919. https:// doi.org/10.1029/2019JB017327

Barry DA, Barry SJ, Parlange J-Y (1996) Capillarity correction to periodic solutions of shallow flow approximation. Coast Estuar Stud 50:495-510

Beaumont C, Berger J (1975) An analysis of tidal strain observations from the United States of America: I. The laterally homogeneous tide. Bull Seismol Soc Am 65(6):1613-1629

Bear J (1972) Dynamics of fluids in porous media. Dover, New York

Bostock J (1855) The natural history. Pliny the Elder, Taylor and Francis, Red Lion Court, Fleet Street, London

Bower DR (1983) Bedrock fracture parameters from the interpretation of well tides. J Geophys Res 88:5025-5035

Brodsky EE, Roeloffs E, Woodcock D et al (2003) A mechanism for sustained groundwater pressure changes induced by distant earthquakes. J Geophys Res 108:2390. https://doi.org/10.1029/200 2JB002321

Byerly P, Blanchard FG (1935) Well gauges as seismographs. Nature 135:303-304

Carslaw HS, Jaeger JC (1959) Conduction of heat in solids, 2nd edn. Clarendon Press, Oxford, UK

Cooper HH, Bredehoeft JD, Papadopoulos IS et al (1965) The response of well-aquifer system to seismic waves. J Geophys Res 70(16):3915-3926

Detournay E, Cheng AHD (1993) Fundamentals of poroelasticity, Vol. II of comprehensive rock engineering: principles, practice \& projects, pp 113-171. Pergamon Press

Doan ML, Brodsky EE, Prioul R et al (2006) Tidal analysis of borehole pressure: a tutorial, Schlumberger-Doll Research Report, Cambridge, Mass

Elkhoury JE, Brodsky EE, Agnew DC (2006) Seismic waves increase permeability. Nature 441(7097):1135-1138

Ellsworth WL (2013) Injection-induced earthquakes. Science 341(6142). https://doi.org/10.1126/ science. 1225942

Evans K, Beavan J, Simpson D (1991) Estimating aquifer parameters from analysis of forced fluctuations in well level: An example from the Nubian formation near Aswan, Egypt 1. Hydrogeological background and large-scale permeability estimates. J Geophys Res 96:12127-12137 
Feng Q, Zhan H (2015) On the aquitard-aquifer interface flow and the drawdown sensitivity with a partially penetrating pumping well in an anisotropic leaky confined aquifer. J Hydrol 521:74-83

Fetter CW (1999) Contaminant hydrogeology. Prentice Hall, Upper Saddle River, NJ

Gillham RW (1984) The capillary fringe and its effect on water-table response. J Hydrol 67(14):307-324. https://doi.org/10.1016/0022-1694(84)90248-8

Hanson JM, Owen LB (1982) Fracture orientation analysis by the solid Earth tidal strain method. Society Petroleum Engineers AIME Paper, SPE11070. https://doi.org/10.2118/11070-MS

Hantush MS, Jacob CE (1955) Non-steady Green's functions for an infinite strip of leaky aquifers. Trans Am Geophys Union 36(1):101-112. https://doi.org/10.1029/TR036i001p00101

Harrison JC (1974) Cavity and topography effects on the measurement of tilt and strain, EOS. Trans Am Geophys Union 56:1151

Hsieh P, Bredehoeft J, Farr J (1987) Determination of aquifer permeability from earthtide analysis. Water Resour Res 23:1824-1832

Hsieh PA, Cooley RL (1995) Comment on'Horizontal aquifer movement in a Theis-Thiem confined system' by Donald C. Helm. Water Resour Res 31(12):3107-3111

Hussein ME, Odling NE, Clark RA (2013) Borehole water level response to barometric pressure as an indicator of aquifer vulnerability. Water Resour Res 49(10):7102-7119

Ingebritsen SE, Manga M (2019) Earthquake hydrogeology. Water Resour Res 55:5212-5216. https://doi.org/10.1029/2019wr025341

Jacob CE (1940) The flow of water in an elastic artesian aquifer. EOS Trans AGU 21:574-586

Langenbruch C, Zoback MD (2016) How will induced seismicity in Oklahoma respond to decreased saltwater injection rates? Sci Adv 2(11):e1601542. https://doi.org/10.1126/sciadv.1601542

Langenbruch C, Weingarten M, Zoback MD (2018) Physics-based forecasting of man-made earthquake hazards in Oklahoma and Kansas. Nat Commun 9:2946. https://doi.org/10.1038/s41467018-06167-4

Lay and Wallace (1995) Modern Global Seismology, San Diego: Academic Press, 521

Liao X, Wang CY, Liu CP (2015) Disruption of groundwater systems by earthquakes. Geophys Res Lett 42(22):9758-9763

Liao X Wang CY (2018) Seasonal permeability change of the shallow crust inferred from deep well monitoring. Geophys Res Lett 45:11130-11136. https://doi.org/10.1029/2018g1080161

Love AEH (1911) Some problems of geodynamics. Cambridge University Press, Cambridge

Meyboom P (1967) Groundwater studies in the Assiniboine River drainage basin, Part II. Hydrologic characteristics of phreatophytic vegetation in south-central Saskatchewan. Bull Geol Surv Canada 139:18-23

Morgan BC, Murray KE (2015) Characterizing small-scale permeability of the Arbuckle Group, Oklahoma. Open File Report OF2-2015, 1-12. National Archives and Records Administration, 1989

Mualem Y (1976) A new model for predicting the hydraulic conductivity of unsaturated porous media. Water Resour Res 12:513-522

Neuman SP, Witherspoon PA (1969) Applicability of current theories of flow in leaky aquifers. Water Resour Res 5(4):817-829

Odling NE, Serrano RP, Hussein MEA et al (2015) Detecting the vulnerability of groundwater in semi-confined aquifers using barometric response functions. J Hydrol 520:143-156

Rahi K, Halihan T (2009) Estimating selected hydraulic parameters of the Arbuckle-Simpson aquifer from the analysis of naturally-induced stresses, Report, Oklahoma Water Resource Board 31

Roeloffs EA (1996) Poroelastic techniques in the study of earthquake-related hydrologic phenomena. Adv Geophys 37:135-195

Rojstaczer S (1988) Determination of fluid flow properties from the response of water levels in wells to atmospheric loading. Water Resour Res 24(11):1927-1938. https://doi.org/10.1029/WR024i $011 \mathrm{p} 01927$

Schoenball M, Ellsworth WL (2017) Waveform-relocated earthquake catalog for Oklahoma and southern Kansas illuminates the Regional Fault Network. Seismol Res Lett 88(5):1252-1258. https://doi.org/10.1785/0220170083 
Shi Z, Hu X, Wang CY (2020) Hydro-mechanical coupling in the shallow crust-Insight from groundwater level and satellite radar imagery in a mining area, J Hydro, https://doi.org/10.1016/ j.jhydrol.2020.125649

Shih DCF (2009) Storage in confined aquifer: spectral analysis of ground-water responses to seismic Rayleigh waves. J Hydrol 374:83-91

Stein S, Wysession M (2003) An introduction to seismology, earthquakes, and earth structure. Blackwell, New York

Sun X, Xiang Y, Shi Z (2018) Estimating the hydraulic parameters of a confined aquifer based on the response of groundwater levels to seismic Rayleigh waves. Geophys J Int 213:919-930

Sun X, Xiang Y, Shi Z (2019) Changes in permeability caused by two consecutive earthquakesinsights from the responses of a well-aquifer system to seismic waves. Geophys Res Lett 46:10367-10374. https://doi.org/10.1029/2019GL084704

Sun X, Shi Z, Xiang Y (2020) Frequency dependence of in-situ transmissivity estimation of wellaquifer systems from periodic loadings, Water Resources Research (in press)

Turner IL, Nielsen P (1997) Rapid water table fluctuations within the beach face: Implications for swash zone sediment mobility? Coast Eng 32(1):45-59. https://doi.org/10.1016/S0378-383 9(97)00015-X

Van Genuchten MT (1980) A closed-form equation for predicting the hydraulic conductivity of unsaturated soils 1. Soil Sci Soc Am J 44:892-898

Wang CY, Chia Y, Wang PL et al (2009) Role of S waves and Love waves in coseismic permeability enhancement. Geophys Res Lett 36: https://doi.org/10.1029/2009GL037330

Wang CY, Doan ML, Xue L et al (2018) Tidal response of groundwater in a leaky aquiferApplication to Oklahoma. Water Resour Res 54:8019-8033. https://doi.org/10.1029/2018WR 022793

Wang CY, Zhu AY, Liao X et al (2019) Capillary effects on groundwater response to Earth tides. Water Resour Res 55:6886-6895. https://doi.org/10.1029/2019WR025166

Wang HF (2000) Theory of linear poroelasticity with applications to geomechanics and hydrogeology. Princeton University Press, New Jersey

Witherspoon PA, Freeze RA (1972) The role of aquitards in multiple aquifer systems. Geotimes 17(4):22-24

Xue L, Li HB, Brodsky EE et al (2013) Continuous permeability measurements record healing inside the Wenchuan earthquake fault zone. Science 340:1555-1559

Xue L, Brodsky EE, Erskine J et al (2016) A permeability and compliance contrast measured hydrogeologically on the San Andreas Fault. Geochem Geophys Geosyst 17:858-871. https:// doi.org/10.1002/2015GC006167

Yan R, Woith H, Wang R (2014) Groundwater level changes induced by the 2011 Tohoku earthquake in China mainland. Geophys J Int 199:533-548. https://doi.org/10.1093/gji/ggu196

Zhang Y, Wang CY, Fu LY et al (2019a) Unexpected far-field hydrological response to a great earthquake. Earth Planetary Sci Lett 519:202-212. https://doi.org/10.1016/j.eps1.2019.05.007

Zhang H, Shi Z, Wang G et al (2019b) Large earthquake reshapes the groundwater flow system: insight from the water-level response to Earth tides and atmospheric pressure in a deep well. Water Resour Res 55:4207-4219. https://doi.org/10.1029/2018WR024608

Zhu AY, Wang CY (2020) Response of leaky aquifers to earth tides-interpreted with numerical simulation. J Hydrol 581:124458. https://doi.org/10.1016/j.jhydrol.2019.124458 
Open Access This chapter is licensed under the terms of the Creative Commons Attribution 4.0 International License (http://creativecommons.org/licenses/by/4.0/), which permits use, sharing, adaptation, distribution and reproduction in any medium or format, as long as you give appropriate credit to the original author(s) and the source, provide a link to the Creative Commons license and indicate if changes were made.

The images or other third party material in this chapter are included in the chapter's Creative Commons license, unless indicated otherwise in a credit line to the material. If material is not included in the chapter's Creative Commons license and your intended use is not permitted by statutory regulation or exceeds the permitted use, you will need to obtain permission directly from the copyright holder.

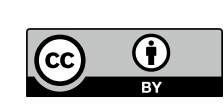

